Florida International University FIU Digital Commons

3-11-2011

\title{
Women and Development in Senegal: Microcredit and Household Well Being
}

Safietou Kane

Florida International University, safietoukane@hotmail.com

DOI: $10.25148 /$ etd.FI1 1041504

Follow this and additional works at: https://digitalcommons.fiu.edu/etd

\section{Recommended Citation}

Kane, Safietou, "Women and Development in Senegal: Microcredit and Household Well Being" (2011). FIU Electronic Theses and Dissertations. 345.

https://digitalcommons.fiu.edu/etd/345 


\section{FLORIDA INTERNATIONAL UNIVERSITY}

Miami, Florida

\section{WOMEN AND DEVELOPMENT IN SENEGAL: MICROCREDIT AND}

HOUSEHOLD WELL BEING

A dissertation submitted in partial fulfillment of the

requirements for the degree of

DOCTOR OF PHILOSOPHY

in

COMPARATIVE SOCIOLOGY

by

Safiétou Kane

2011 


\section{To: Dean Kenneth Furton}

College of Arts and Sciences

This dissertation, written by Safiétou Kane, and entitled Women and Development in Senegal: Microcredit and Household Well Being, having been approved in respect to style and intellectual content, is referred to you for judgment.

We have read this dissertation and recommend that it be approved.

$\begin{array}{r}\hline \text { Guillermo Grenier } \\ \hline \text { Vrushali Patil } \\ \hline \text { John Clark } \\ \hline \text { Liliana Goldin, Major Professor }\end{array}$

Date of Defense: March 11, 2011

The dissertation of Safiétou Kane is approved.

\begin{tabular}{r}
\hline $\begin{array}{c}\text { Dean Kenneth Furton } \\
\text { College of Arts and Sciences }\end{array}$ \\
\hline Interim Dean Kevin O'Shea \\
University Graduate School
\end{tabular}

Florida International University, 2011 


\section{DEDICATION}

I dedicate this dissertation to my mom, my dad, my sister, my brothers, and all Senegalese women. My family's love, understanding, support, and belief in me have been a great asset during this dissertation process. 


\section{ACKNOWLEDGMENTS}

I wish to thank the members of my committee for their support, help, guidance, and belief in me. Their willingness to work with me and confidence in my abilities has been much appreciated. In particular, I would like to thank my advisor Dr Liliana Goldin for her direction throughout this dissertation process.

I would also like to thank everybody who has contributed to my dissertation fieldresearch. I especially thank my research participants in Grand-Yoff for welcoming me into their homes and their lives.

Finally, I would like to thank the Compton Foundation and FIU Graduate School for their generous fellowships which have financially sustained my dissertation research and writing. 


\title{
ABSTRACT OF THE DISSERTATION \\ WOMEN AND DEVELOPMENT IN SENEGAL: MICROCREDIT AND HOUSEHOLD WELL BEING
}

\author{
by \\ Safiétou Kane \\ Florida International University, 2011 \\ Miami, Florida \\ Professor Liliana Goldin, Major Professor
}

The challenging living conditions of many Senegalese families, and the absence of a providing spouse, have led women to covet new economic opportunities, such as microcredit loans. These loans offer Senegalese women the possibility to financially support their households and become active participants in their economies by starting or sustaining their micro businesses. The study takes place in Grand-Yoff, an overpopulated peri-urban area of the Senegalese capital city Dakar, where most people face daily survival issues. This research examines the impact of microcredit activities in the household of Senegalese female loan recipients in Grand-Yoff by examining socioeconomic indicators, in particular outcomes of health, education and nutrition.

The research total sample is constituted of 166 female participants who engage in microcredit activities. The research combines both qualitative and quantitative methods. Data for the study were gathered through interviews, surveys, participant observation, focus-groups with the study participants and some of their household members, and document analysis. 
While some women in the study make steady profits from their business activities, others struggle to make ends meet from their businesses' meager or unreliable profits. Some study participants who are impoverished have no choice but to invest their loans directly into their households' dire needs, hence missing their business prerogative. Many women in the study end up in a vicious cycle of debt by defaulting on their loans or making late payments because they do not have the required household and socioeconomic conditions to take advantage of these loans. Therefore, microcredit does not make a significant impact in the households of the poorest female participants. The study finds that microcredit improves the household well-being - especially nutrition, health and education - of the participants who have acquired significant social capital such as a providing spouse, formal education, training, business experience, and belonging to business or social networks.

The study finds that microcredit's household impact is intimately tied to the female borrowers' household conditions and social capital. It is recommended that microcredit services and programs offer their female clients assistance and additional basic services, financial guidance, lower interest rates, and flexible repayment schedules. 


\section{TABLE OF CONTENTS}

CHAPTER $\quad$ PAGE

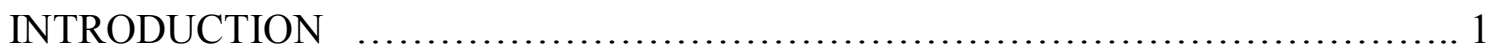

I. THE CONTEXT ................................................................ 5

The Debates around Microcredit: the Pros and Cons of Microfinance ............... 6

Senegalese Women and Credit: From Tradition to

Current Commercial Enterprises ….......................................... 13

Senegal: Political Economy and Society .................................... 23

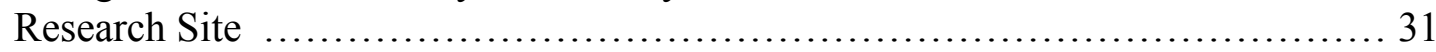

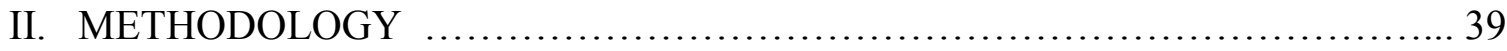

Research Site and Context ….................................................... 39

Research Participants ........................................................... 41

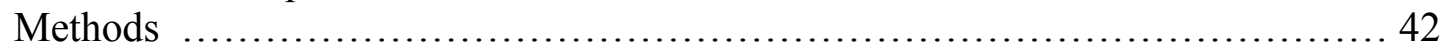

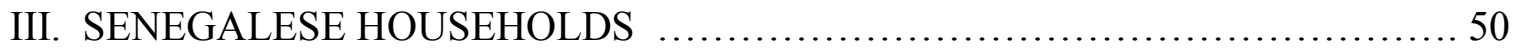

Characteristics of Senegalese Households …................................50

The Economic Realities of Senegalese Households ….......................... 56

The Changing Face of Senegalese Households: More Women

Are Becoming their Families/Households Breadwinners ........................63

IV. SENEGALESE WOMEN, MICROCREDIT AND

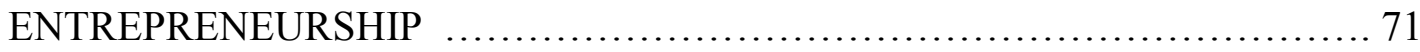

Typology of Microcredit Institutions …................................. 72

Senegalese Women and Microcredit: Typology of Female Borrowers ............ 81

Microcredit and Prospects for Female Entrepreneurship In Senegal ............... 91

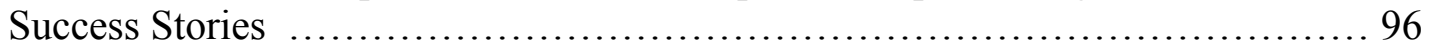

V. THE IMPACT OF MICROCREDIT ACTIVITIES IN

THE HOUSEHOLD .................................................... 101

The Significant Impact of Microcredit on the Well-being of Female

Recipients and their Household Members .................................. 102

Loans Directly Invested in the Household rather than Businesses ................109

When Microcredit Fails to make a Significant Impact in the Household .......... 113

Cases of Women who Primarily Invest their Credit into their

Businesses: a Financial Ripple Effect for the Household ....................... 115

VI. MICROCREDIT AND SOCIAL CAPITAL …............................ 118

Social Capital in Microfinance Models ....................................... 119

At the Household Level ................................................... 122 
Social, Credit and Business Networks …................................. 126

Formal Education, Training, Skills and Business Experience ..................... 131

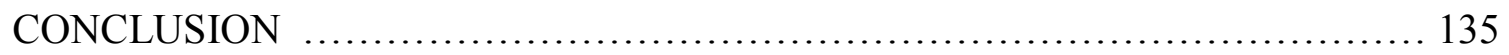

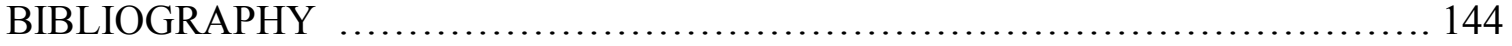

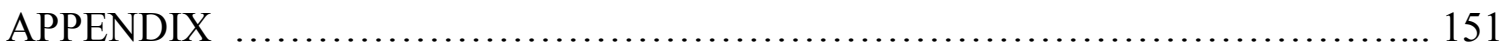

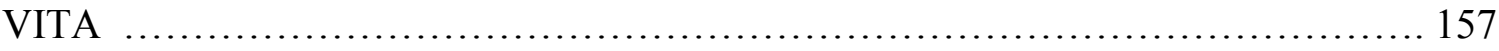





\section{Introduction}

"Since I got the loan and built my oven, I feel like I am really doing business," says a Senegalese business woman who sells smoked fish. Like many women in Senegal, she has been a beneficiary of microcredit loans to start her own business. For the past two decades, international aid has turned its attention to helping women in poor countries. Many development projects geared toward women in developing countries have focused on reproductive health, literacy for girls, and the AIDS epidemic, especially on the African continent. However, in recent years there has been an interesting shift in aiding women in the area of microcredit or microenterprise, whereby loans are given to women to aid them in starting their own small businesses.

In most African countries women tend to account for an average $51 \%$ of the population, and make up about $65 \%$ of the rural labor force (UNDP 2009). In addition, women tend to shoulder the greater burden of child and family welfare, social and community obligations, engaging in more than one economic activity as well as undertaking domestic chores. Therefore, in connection with the growing emphasis on poverty reduction, microcredit has been recognized as the most necessary and the 'missing ingredient' in poverty alleviation (Pitamber 2003). This optimism was best illustrated at the Microcredit Summit in Washington D.C. in 1997 when 20 billion dollars were devoted to microfinance programs worldwide, demonstrating that the self reliance of the poor is an attractive approach for development agencies and donors alike.

In 2004, the Group of Eight (G8) confirmed the importance of microfinance as a development tool against poverty, putting it at the forefront of the strategies described in the G8 action plan. Moreover, 2005 was declared "the year of microfinance" as a tool of 
poverty reduction by former UN Secretary General Koffi Annan. Since that time there has been a multitude of microcredit services around the world targeting women to help them start microenterprises. In addition, Mohammad Yunus' Grameen Bank has further popularized the concept of lending to poor women. This trend has accelerated the creation of many women's savings and credit cooperatives and microcredit programs in Senegal.

Senegalese women, like many West African women, have traditionally been engaged in commercial activities. However, a lack of substantial resources or access to credit has prevented most of them from entering the formal sector or starting their businesses. Many micro-enterprise projects have begun in Senegal and are funded by local and international aid organizations, the Senegalese government, microfinance institutions, banks, and cooperatives. There has been a proliferation of microcredit institutions and services in the capital city of Dakar, the Senegalese urban epicenter. In 2004, there were 805 financial structures geared towards micro-lending in Senegal, and 68 women savings and credit cooperatives have been functioning as of 2006. Savings and credit banks have increased from 60 in 1992 to 800 in 2004 (ANSD 2009).

Senegal has a female adult literacy rate of $29 \%$ compared to a $51 \%$ adult literacy rate for males (UNDP, 2009), with great challenges in reproductive health, prenatal care, and child health (ranking Senegal in the low Human Development index of the UNDP). With 56\% living below the poverty line of $\$ 2$ a day (UNDP 2009), the majority of Senegalese families are confronted with daily survival issues. Therefore, economic strategies such as microcredit ones may also improve other areas of women and their children's lives such as health and education. The promotion of microcredit strategies and 
projects has provided a means for African women to access credit in order to improve their economic condition. In addition, it gives them tools to compete in their economies. However, the long enthusiasm about microcredit and poverty alleviation for women does not come without challenges. Third-world and African women entrepreneurs and microcredit borrowers tend to face greater constraints than men, such as socio-cultural barriers, legal and structural constraints, higher rates of illiteracy, inadequate experience in credit management, and lack of collateral. Therefore, microcredit faces structural and contextual challenges when targeting African women.

This research examines the impact of microcredit activities in the household of Senegalese female loan recipients by examining socio-economic indicators, in particular outcomes of health, education and nutrition. The women in the study reside in GrandYoff, an overpopulated peri-urban area of the capital city Dakar where most inhabitants are faced with dire survival needs. More specifically, the study considers whether and how microfinance activities impact these women and their households toward greater economic freedom, and their implications for overall well being.

After conducting preliminary research during the summer of 2008, I returned to Dakar, the capital city of Senegal to continue my field-research for eight months in 2009. I chose Dakar's peri-urban area of Grand-Yoff as my research site because peri-urban areas of the capital represent a bridge between the city and the village. Many residents in these neighborhoods are migrants from rural parts of the country and levels of poverty in these areas are exacerbated by their overpopulation. Grand-Yoff is known for its popular neighborhood's women savings and credit cooperative (Mutuelle d'Epargne et de Crédit des Femmes de Grand Yoff), which is the pioneer neighborhood women's savings and 
credit institution in Dakar. The area is also characterized by a plethora of microcredit institutions, making it an ideal place to conduct the study.

I conducted interviews, surveys, participant observation and focus-groups with a total sample of 166 female participants who are microcredit recipients, and some of their household members. The study's findings show that while some participants are successful at their microcredit ventures and are able to take care of their household needs, microcredit negatively impacts the well-being of other participants and their households.

This study contributes to the development literature by evaluating the ways in which micro-lending strategies may impact household dynamics in a broad and integrated way, including the health, education and nutrition of women microcredit recipients and their households. Furthermore, this research does not assume, but actually tests conventional knowledge that microcredit is a key to women's financial autonomy, and an effective tool for poverty alleviation. Lessons learned from Senegalese women will be valuable by adding to the already existing literature on Third-World (and poor) women and microcredit, especially in urban areas. This research will also add to the already existing literature on livelihood strategies, as they relate to gender and the African context. 


\section{Chapter I. The Context}

\section{Introduction}

Traditionally, Senegalese men have financially been in charge of their families while women took care of the household. However, nowadays many men are unemployed or cannot take full or partial financial care of their families. Therefore, most Senegalese women can no longer afford to remain unemployed. As most husbands in Senegal may no longer be the support of their families, most women turn to microcredit institutions to get loans that allow them to start or sustain their commercial activities, and consequently earn a living to feed their families. Many women in the informal sector cannot obtain credit through the formal banking system for lack of formal education, jobs, or collateral. But with the advent and boom of microcredit services, women now have access to small loans to start their micro-businesses. Many microfinance services and strategies seek to alleviate poverty and fill the vacuum left by the welfare.

In this chapter, I introduce the context of the study. I first explore the debates around microcredit by underlining the positive and negative aspects of microcredit. Secondly, I offer a discussion on Senegalese women and credit, from traditional times to recent years. Thirdly, I provide an overview of Senegal's political economy and society. Finally, I render a description of the Senegalese capital city Dakar and its peri-urban area Grand-Yoff where I conducted my research. 


\section{The Debates around Microcredit: the Pros and Cons of Microfinance}

\section{a. The Grameen Bank's Model}

Providing credit to women in developing countries has made a difference in their household economic subsistence. Because of illiteracy and lack of collateral, many women from poor countries have little access to formal credit. Mohammad Yunus has popularized the concept of microcredit through the Grameen Bank. The rationale behind the Grameen Bank is that access to microcredit will foster the growth of microentreprises among the poor and women in particular, encouraging their economic self-reliance. The origin of Grameen Bank (Grameen means "rural" or "village" in Bangali language) can be traced back to 1976, when Professor Muhammad Yunus, head of the Rural Economics Program at the University of Chittagong, launched an action research project to examine the possibility of designing a credit delivery system to provide banking services targeted at the rural poor.

Grameen Bank targets the poorest of the poor, with a particular emphasis on women, who receive 95 percent of the bank's loans. The emphasis on women comes from the rationale that they are worthier of credit because they reinvest in the household, but most importantly, face structural conditions that make them socially and economically more vulnerable than men. Women represent a suitable clientele because given that they have less alternatives, such as traditional credit lines and salaries - they are more likely to be credit constrained and they have an inequitable share of power in the household decision making (Mainsah et al. 2004). Lending to women also generates considerable secondary effects, including the empowerment of a marginalized segment of 
society; women represented less than 1 percent of borrowers from commercial banks (Yunus and Jolis 1998). However, the Grameen model does not come without its critics; for research has already shown its negative effects, especially when credit has been provided to poor women who lack the structural and basic means to strive.

Many criticize the Grameen model of lending to the poor for its lack of accountability and neglect of social welfare, especially women's welfare. Rather than job creation, education, or training, the Yunus solution focuses on jump-starting selfemployment, providing the capital for poor women to use their innate "survival skills" to pull themselves out of poverty (Neff 1996). A question to ask is how can poor women who lack basic resources really have access, or adequately take advantage of microcredit. Furthermore, how well could they sustain any business if their very basic survival needs are merely met? Goetz and Gupta (1996) have found many downsides to the Grameen model that they deem a collection agency, more preoccupied with collecting repayment than empowering women. Furthermore, they find that male relatives are the ones who really take advantage of women's loans. Therefore, one must not overlook the structural impediments of many poor women, especially in the household where they may not have much, if no bargaining power.

Scholars and critics have raised important question about microfinance's potential for poverty reduction in the developing world, given all the structural challenges women face in their households and communities. Mayoux (2001) explains that there are three underlying paradigms in the debate on microenterprise and gender empowerment: a financial self-sustainability paradigm, a poverty alleviation paradigm, and a feminist empowerment paradigm. According to Mayoux, the latter paradigm is an entry point to 
negotiation and change in other broader issues of gender equality and women's rights, bringing about perceived change in gender relations and women's empowerment. However, we must argue that this paradigm is the hardest to achieve. The first two paradigms of financial and poverty reduction for women fall into the realm of most microfinance and microcredit services. Therefore, the empowerment of third-world women through microfinance does not go without challenges that can seriously impede their long term goals.

\section{b. Gender and Feminist Ideologies}

The literature and theorizing on "gender and development," stemming mostly from feminist discourses, have been proponents of microcredit. Feminist engagement with development has, since the 1970's, sought to challenge the myths created and sustained by pervasive male bias. Women's empowerment in the development process has been viewed as the achievement of women's overall well-being. According to Mahmud (2003: 578): “Improvements in women's well-being were closely connected to women's capabilities as agents of change and, subsequently, that these capabilities of women must also strongly influence the well-being of other family members, particularly of children but also of the elderly and of adult men." Therefore, the issue of "agency" is critical in gender or feminist theorizing because it not only emphasizes women's wellbeing, but must consider their power to achieve such goals.

There has been a shift in the gender and development discourse to incorporate notions of women's agency in the attainment of greater well-being for all, and women in particular. It is important to distinguish this shift in emphasis as one from passive 
acceptance of well-being enhancing assistance to one of active participation in the attainment of those well-being objectives (Mahmud 2003). It is therefore important to recognize women's "agency" as important development goals in themselves, and not just as a means to achieving other development objectives. However, agency is very different from autonomy and can be controlled or influenced by the latter. Thus taking into account the structural conditions of women is crucial to their overall well-being. More and more women are assuming the role of head of household, yet they continue to face difficulties in obtaining employment. The only option self-employment is equally challenging because women's access to property and land remains limited (Guérin 2006). The impetus to conceptualize women's agency in development programs is reflected in the current interest on micro-enterprise or micro-lending in recent years, for such programs allow women power of choice and decision making.

Critiques of feminist ideologies, as they pertain to development issues, challenge main ideas of solidarity, autonomy, or empowerment within the gender and development discourse. Indeed, the socio-cultural context and structures of many third-world and firstworld women, do not necessary easily grant their autonomy. For many women, lack of basic resources is tied to factors beyond economics, such as patrilineal systems, religious institutions, or household demands. Andrea Cornwall (2007: 150) notes: "Amidst the feminist critique of orthodoxies, exposure of prejudices and assumptions, and efforts to put right the 'gender blindness' of development, reside potent gender myths in which idealized representations of women, and of their relationships with men and with each other, gain a life of their own." Here, Cornwall underlines the problematic nature of feminist concepts of "solidarity," "autonomy" and "empowerment," claiming that gender 
myths associated with these ideals may have outlived their usefulness. For instance, empowerment, as a concept, is highly contextual and changes from one environment to another, whereas the microcredit delivery process is applied in almost the same way in most countries. However, the overarching goals of transforming unequal and inequitable gender relations have not lost their salience. Therefore, while the plight for women's well-being and autonomy has much value and resonance, we must be attuned to women's everyday demands and constraints.

Many feminists and gender theorists must also pay close attention to third-world women's household structures and their resource allocation before attempting to deconstruct them. O’Laughlin (2007), in her study of African rural households and resource allocation, argues that for most feminists the theoretical dismantling of the unitary household model is now superfluous outside of rational choice theory and neoclassical microeconomics. She suggests that trying to assure poor women a "larger piece of the small pie" will lead to a significant reduction in poverty, misrepresents the political processes needed to efface the gaps between rich and poor and to achieve gender justice. Hence, feminist theorizing on gender and development might not necessarily reflect the realities of many women in the third-world, and have especially become mythical. The revision of third-world womens' resource allocation must be relevant to the benefit and access these women might get from it, or else it will be disconnected from its goals.

\section{c. Integrated Development Approaches to Microcredit}

Many microcredit programs are providing additional services and resources that women in developing countries lack to ensure their success. Many programs 
acknowledge the problems which gender relations pose for women's control of loans. They offer integrated programs designed to enhance women's institution-building at the grassroots level, provide technology and training support for women's investments, and some programs, particularly those managed by women's NGOs, work to raise women's consciousness about gender and class relations (Goetz and Gupta 1996). The demand for microcredit extends well beyond the need for just microenterprise credit. Furthermore, poor households seek loans for a multitude of uses besides business investment: to cope with emergencies, acquire household assets, pay schooling and health fees, and, in general, to better manage complicated lives (Collins et al 2009). Thus, the household needs of loan recipients have great potential to cripple their abilities to invest their credit into their businesses.

The redeeming feature of microcredit is that, even without a significant increase in women's access to resources whose allocation is structurally determined, it is possible to increase access to other choice-expanding but less restricted resources and to enhance the exercise of women's agency, both of which can eventually be effective in transforming structures that restrict women's access to resources (Mahmud 2007). The argument supports integrated development approaches that enhance many aspects of women's lives through the provision of needed social services so that they can take full advantage of microcredit. Therefore third-world women's households and resource allocation need to be well understood and contextualized by development experts in their plight to ensure these women access to more resources.

As stated before, third-world and African women tend to face greater financial or economic constraints than men. Women in developing countries face socio-cultural 
barriers, legal and structural constraints, higher rates of illiteracy, inadequate experience in credit management, and lack of collateral. Therefore, economic development programs, such as microcredit, have to address structural and contextual challenges when targeting African women. As empowerment is highly contextual and changes from one environment to another, the microcredit delivery process must not be applied in the same way everywhere. Hence, there is a need for more integrated approaches that combine women's access to health, education and other basic services with economic projects.

A study in Mali (West Africa) of an integrated approach of microenterprises in agriculture, animal husbandry and manufacturing activities, combined with health, sanitation and training activities for rural women, argues that these non-economic activities have been important assets that reinforce the success of women's microenterprises (Creevey 2006). These broader development approaches have the benefit of addressing the needs of women, but also their children and households. This, in turn, maximizes women's economic participation. Therefore, Economic development programs are not to be discarded, but rather improved through the incorporation of social services for women in developing countries.

If economical or financial independence is key to the survival of women in developing countries and their children, access to health, education, transportation and other social services are vital for the achievement of their economic potential. Household income and survival are central elements in poverty alleviation. Hence, microcredit services must not be disconnected from the household structures of their targeted female populations. For instance, in understanding the situation of the urban poor, much emphasis has shifted to analysis of their household income and subsistence. Furthermore, 
economic programs that stress women and children's education and health have greater chances of yielding desired results (Rakodi 1991).

A study of women and microcredit in Bangladesh found that improvement in women's material resource base as a result of participation in microcredit programs is small because increase in women's resource access was limited to resources that do not expand women's choices a great deal (Mahmud 2003). Therefore, women need adequate or sufficient access to resources before they can benefit from microcredit. Furthermore, the poorest and most disadvantaged women from developing countries could easily be excluded from access to microlending. Guérin (2006) argues in her study of microcredit among Senegalese women, that the short-comings of informal finance are not only a technical matter, but a social issue reflecting the gender biases in finance. In order to genuinely improve the well-being of women, one must go beyond microfinance services. Consequentially, the poorest of women might never be able to benefit from microcredit or any other economic venture for lack of basic resources that other women, usually entrepreneurs, already have at their disposal.

In Senegal, there is a multitude of microcredit services and projects that respond to the great demand for microcredit loans, mostly from women. But, microfinance is not a new phenomenon among Senegalese women.

\section{Senegalese Women and Credit: From Tradition to Current Commercial Enterprises}

\section{a. Women's Entrepreneurship and Cultural Norms: Income and Ideology}


Despite the difficult employment situation faced by many Senegalese men today, males continue to dominate women in regards to employment. The overall economic activity rate for females represents $69 \%$ of that of males (UNDP 2008). Therefore, many aid projects have targeted women to boost their economic participation, especially in the area of microcredit. One USAID project funding women in the Southern region reports that the female entrepreneurs make sure all loans are repaid, and that they have to be prudent because there is simply too much at stake (USAID 2007). Many Senegalese try their best to repay loans because they need their business ventures to survive. However, many women microcredit recipients end up defaulting because of too many household and economic hurdles. Cassar et al. (2007) note that social homogeneity appears to facilitate confidence that other members will indeed repay, augmenting the belief that the group is likely to receive subsequent loans in the future and that those who do repay in early rounds will not get burned by those who default on their payments.

There is a great deal of variety in the enterprises of Senegalese women. Some basic assumptions on the solidarity among the poor or women who form credit or funding chains often mask the diversity in businesses, business approaches, and life circumstances. The dissertation's research shows that women are engaged in different activities with great diversity in their business practices. Lo (2007) argues in her study of women's microenterprises in Senegal and Mali that most definitions of women's enterprises convey a fixed and invariant perception and characterization of women's microenterprises based on level of capitalization, size and labor. What is lost in these definitions is the heterogeneity of needs, aspirations, capabilities and self-concepts of women's microenterprises. Hence, an understanding of women's socio-economic context 
allows us to appreciate the varied meanings of their enterprises. A closer look at women's individual or collective businesses often unveils differences in their approaches to trade and marketing, and many socio-cultural influences to their business operations.

A proper understanding of the economic situation of Senegalese women requires an understanding of their household realities. Women's subordinate position with regard to control over resources and decision-making in the household is often ignored in development theorizing and programs. Gender relationships seen as natural - especially in the unitary household model that assumes that households are nuclear units - can be easily reinforced by development or state programs and policies. The unitary or nuclear household model appears inconsistent with field observations in Africa as, African households have been characterized by their multiple economic spheres, incomplete pooling of resources, and conflict among household members over the distribution of resources (Fisher 2000). This brings to light the fact that many members in Senegalese households are indeed part of extended families, adding to the financial burdens of breadwinners. It becomes more complex in many cases where there are different household members who contribute to the household funds. Hence, an understanding of intra-household relationships and women's constraints and needs is important to enhance the welfare of all family members in Senegal and other poor countries.

For Senegalese women, venturing in entrepreneurship does not come without bending social rules. Patriarchy still remains a dominant influence in their daily lives. As Perry (2005) argues on her work in rural Senegal, structural limits for Wolof (the dominant ethnic group) women are a highly polarized division of labor and patriarchal customs that prevent them from owning and controlling land, livestock and agricultural 
equipment. As informal labor is still very gendered in Senegal, most women entrepreneurs seem to follow comparative advantage lines, whereby they do what they have traditionally been doing. Prevailing gender norms related to the division of labor between women and men in Senegal, combined with market-based impediments, determine largely the economic opportunities to which women entrepreneurs have access. That trend confirms the pattern of confinement of women's microenterprises to less lucrative, precarious occupations, and marginal sub-sectors (Lo 2007). Microenterprise projects encourage women to break these barriers by making substantial revenues. However, women still remain in the informal sector.

\section{b. The Informal Economy: a Niche for Senegalese Women}

The informal sector in Senegal, as in most developing countries, is diverse and stratified. The informal market in many African counties has disproportionately large numbers of women who are known to be at the center of food production, processing and distribution on the continent. As most women find themselves in the informal sector, their demand for credit varies accordingly. The informal sector in Senegal includes various types of economic activities and employs people in agriculture, the industrial sector, trade and diverse services. As Versluysen (1999:30) argues: “The informal sector is far from homogenous, and microenterprises come in many shapes and sizes. In countries where self-employment and microfinance are already firmly anchored, the informal sector is highly stratified." Therefore, poor women resort to cooperatives formed along neighborhood or labor lines. This allows them to draw credit from a common capital and save their money in the same fund. However, these women's micro- 
businesses are very diverse and stratified. In Senegal, major areas of business for women are sewing and tailoring, selling goods and staples, fabric, accessories, jewelry, and natural local juices.

The informal sector is very attractive to many in developing countries because they get away from paying taxes by not having fixed and/or formal businesses. Most business owners have unidentified or mobile activities, where they do not have fixed selling locations or go door to door. According to the Senegalese National Statistics Agency, in 2003 there were 281,600 informal units of production in Dakar that employed 434,200 people in non-agricultural services. Furthermore, each household in Dakar was financially supported by at least one person operating in the informal economy (ANSD 2004). That shows the primordial role the informal sector has in the Senegalese economy. In Senegal, almost no informal workers pay taxes, and the majority is not even aware of the legislations in that regard.

Many informal workers in Dakar have been increasingly struggling with productivity in the past decade because there is a lot of competition and most people end up selling the same goods, especially imported items. This is a particular problem for women micro-entrepreneurs who often import the same goods for sale (fabric, clothing, jewelry, accessories etc.), which leads to extreme competition and dropped prices. Many participants in the study were not able to make profits because of that reason. Those who sold local goods, especially staples, and those who were more creative, did fare better. Trade is a very tough business in Senegal and remains the niche for most female entrepreneurs because it remains of their major areas of expertise. Therefore, the 
microenterprises of most female Senegalese entrepreneurs suffer from gendered labor division.

\section{c. The Credit System in Senegal}

The proliferation of microcredit institutions in Senegal resulted in 800 funds and 68 savings and credit cooperatives providing microfinance services by 2004 (ANSD 2008). Senegal alone comprises $21 \%$ of all microfinance institutions services in Francophone West Africa (BCEAO 2005). Microcredit services and projects have put a particular emphasis on lending to women with the goals of boosting their microenterprises. These services are provided or supported by major microcredit institutions such as Crédit Mutuel du Sénégal, PAMECAS, ACEP and Microcred, international aid organizations like the USAID, local and international non-governmental organizations, banks, savings and credit cooperatives, and the Senegalese government.

The government's microcredit strategies and services offer some flexibility and accommodate women's small and medium enterprises through two organs: 1) the Ministry of the Economy and Finance and 2) the Ministry of Small and Medium Enterprises, Female Entrepreneurship, and Microfinance. The creation of the latter ministry speaks to the magnitude of microcredit services that target women, with two projects that provide microcredit to women entrepreneurs at different stages (small and medium enterprises).

The credit system in Senegal can be divided in three tiers: 1) a bottom tier, where small credit is provided, accommodating women of very modest means who are concerned with survival strategies, 2) a middle tier, where women more or less have basic 
needs addressed, and 3) a top tier, where we find solid women entrepreneurs. Most women's savings and credit institutions or cooperatives belong to the bottom and middle tiers and cater to low-income and poor women, such as those residing in Grand-Yoff. These women's cooperatives have to compete with other major microcredit institutions that also heavily target women.

Microfinance loans allow urban and rural women to realize their business aspirations and become active participants in the Senegalese economy. Most of these women have skills, but lack capital to put them to work. Though these women remain in the informal economy, access to credit allows them to initiate, solidify, and/or sustain their economic activities. Most women I interviewed in the poor peri-urban area of Grand-Yoff belong to the neighborhood's savings and credit institution (Mutuelle d'Epargne et de Crédit des Femmes de Grand-Yoff). The participants show diversity in their borrowing because they get loans from different microcredit institutions (MFIs) in the area. However, microcredit is not a new phenomenon among Senegalese women, for they have traditionally been engaged in informal microfinance.

\section{d. Tontines: Gendered Traditional Microfinance Schemes}

As many of their counterparts around the world, Senegalese women, have traditionally participated in informal savings and credit networks, known as tontines. The term tontine derives from France where a banker by the name of Tonti proposed to Louis $\mathrm{XV}$ the idea to borrow money each year without reimbursing the amount, but only the interest every year until the last borrower dies. The term is used in most French speaking 
West-African countries to refer to informal microfinance networks. Tontines are also called Naat or Mbotaay, their indegenous appellations in Senegal.

Tontines are traditional savings and microfinance pools that are self-selected mostly and are found all over Africa, in Latin America, the Caribbean, and Asia. There are also similar forms of savings such as Rotating Savings and Credit Associations (ROSCAs) and Accumulating Savings and Credit associations (ASCRAs). Tontines have a deep rooted tradition in Senegal and signify a prominent participation of women, as compared to men. Tontines denote thereby, a very gendered form of savings and money handling, and explain why Senegalese women - and West-African women in general find microcredit to be favorable to them.

In the tontine model, members contribute a fixed amount of cash or in kind to a common fund or pooled resources at regular intervals (weekly or monthly). The total amount is then allotted to each member in turn until all members are served. Women use these savings to fund their small business ventures, ceremonies, or necessary household items. Tontines denote patterns of reciprocity, sociability, and solidarity among Senegalese women, for the pools are self-selected, and are often arranged among relatives and friends. According to Kane (2001: 297), to understand the dynamism that characterizes tontines in contemporary African communities, one must explore their roots in reciprocity and sociability practices built on familial and neighborhood ties. Here, trust plays a big role in financial pool formations whereby Senegalese women establish tacit trust that leads them to belonging to the same tontines. As Cassar et al. (2007) argue, group lending is likely to be more successful when a borrower faces a pool of potential borrowing partners that contains a large number of people whom she personally trusts. 
Moreover, to the extent that borrowers have a choice within this pool, it supports the notion that informal social capital in the process of group self-selection and screening is likely to matter in group lending. Therefore, while many studies show that solidarity among women can be a myth, Senegalese women, though not homogeneous, understand solidarity in microfinance as a necessity for success. However, we must not confuse solidarity among Senegalese women with homogeneity because women who engage in tontines or microcredit activities have different business, personal aspirations or goals. Most importantly, these Senegalese women also belong to different socio-economic classes.

Senegalese women see microfinance as a necessary means of savings allowing them to achieve their economic ventures. The concept of lending mixed with savings, as illustrated in tontines, favors the acceptance and expansion of microcredit services. Guérin (2006) argues that the permanent savings-credit tontine (a form of microlending derived from the traditional tontine structure) aims to stabilize income-generating activities through regular cash injections, and Senegalese women belong to both forms of tontine. Many of the research participants are indeed members of both tontines and microcredit institutions. The tension between the "individual" and the "collective" is more pronounced for women than men because of their domestic obligations and limited access to individual economic rights, namely property, formal credit, and lucrative income-generating activities (Guérin 2006). Therefore, to cope with these demands Senegalese women practice multiple methods of savings - borrowing from MFI's and belonging to tontines simultaneously - that permit them to meet their obligations. 


\section{e. Limitations of Microcredit in Senegal}

Microcredit services and strategies in Senegal do not come without limitations. Many of the participants commonly complained about high interest rates, the repayment schedules and collateral in order to acquire loans. Microfinance institutions ask for house or car deeds, jewelry and proof of employment as collateral in the credit application process. Standard practice for most credit institutions is also to send their credit agents to applicants' homes. Once there, the agents evaluate the assets of applicants to decide the amount of credit that they can receive. Those who have houses, cars or gold jewelry to their names or their spouses' fare much better because that collateral will guarantee them a higher line of credit. Most MFIs also ask for a deposit from the credit recipient to be held until the loan is paid back.

Microcredit interest rates are usually too high for most people in Senegal, whether poor or not. Therefore, the study participants have a very hard time repaying their loans and constantly complain about the high interest rates. The repayment time line is too short for most of them to be able to pay their loans without backlash. The short repayment time line, along with high interest rates and the deposit most credit institutions ask for in order to give credit, make it tremendously trying for most credit recipients. Penalties are also tough on clients who fail to pay their loans back; they range from confiscating clients' assets to suing them for non-payment, which can result in imprisonment. One MFI goes as far as posting the pictures of clients who have defaulted on their loans. This is very humiliating in communities where most people know or recognize one another. 
Many participants in the study leave one credit institution to join another one, only to find that credit conditionality in the new institution is still harsh for them. Many MFIs lure their potential clients in with very appealing televisions ads or posters, but once they become members, clients uncover a totally different reality than what was promised. Therefore, many MFIs disguise their credit operations and fail to keep the promises made to their clients. Furthermore, the difficult financial climate force many MFIs, cooperatives and banks in Senegal to change the terms of their credit delivery and services in order to minimize their losses, especially as more people are unable to keep up with their repayments. Hence, many women in Senegal belong to different microfinance institutions and tontines in order to juggle their financial responsibilities. That is no different from the realities and payments habits of many Americans who resort to paying one credit card with another. Thus, many microcredit recipients experience this very vicious repayment cycle. Many participants in the study argue they have no choice but to resort to such tactics as they cannot afford to default on their loans or cease to receive credit for their household survival and commercial activities.

\section{Senegal: Political Economy and Society}

\section{a. Political Economy}

Senegal was colonized by France from 1887 to 1960 and is located on the extreme West coast of the African continent. The country covers an area of 196,712 per square kilometer (slightly smaller than South Dakota). Senegal's total population is estimated at $13,711,597$ and is ethnically diverse. The country's boundaries as drawn by France feature the Moors to the North, the Sudanic people to the East and a variety of ethnic 
groups to the South. Ethnic groups found in the country are: Wolof (43.3\%), Pular (23.8\%), Serer (14.7\%), Jola (3.7\%), Mandinka (3\%), Soninke (1.1\%), European and Lebanese (1\%), and other (9.4\%). The main ethnic groups (Wolof, Pular and Serer) are related in language and social customs, and have maintained close social, political and religious ties (Johnson 1971). Senegal has not experienced the tribal conflicts that have plagued most African nations, and has a sense of unity few African countries possess. The overwhelming majority of Senegalese people is Muslim (94\%), while Christians (mostly Roman Catholic) constitute 5\%, and people with indigenous beliefs represent 1\% of the population. The country's official language is French and the most widely spoken local language is Wolof (that of the dominant ethnic group). Senegal comprises fourteen administrative divisions called regions, including the capital city Dakar.

The majority of Senegal's labor force is involved in agriculture. During French colonization peanut production was at the center of the country's economy. After achieving independence in 1960, peanut production and trade still dominated the agricultural sector and export market. Peanut production occupied $49 \%$ of the total cropped area and contributed about $87 \%$ of the country's export earnings. With $70 \%$ of the labor force actively involved in agriculture, which accounts for more than $20 \%$ of the total GDP, Senegal still remains an important producer of peanut (Tshibaka 2003). However, government policy did not support the farming population. The development priority supported by France, and continued by the post-independence government, was to maintain a relatively high level of consumption, in particular for urban people. Senegal's independence in 1960 did not end or reduce the old political and economic relationship of the region with France. France remained the major trading partner of 
Senegal, and the export market of Senegal therefore depended on the whims and caprices of France (Mbodji 1991).

The country did not experience economic growth during the early years of independence, between 1960 and 1980. In fact between 1970 and 1980, GDP growth was lower than population growth by 25 percent (Mbodji 1991). Growth in agricultural production was actually declining because of environmental factors (soil degradation and drought) and the exodus of farmers from rural areas because of progressive decreases in their income. Furthermore, while the peanut sector accounted for $80 \%$ of jobs and $20 \%$ of the industrial turnover, by the end of the 1960's, the price of peanuts fell. From 1970 to 1981, the state proceeded to become entrepreneurial by participating in the companies' capitalization, controlling banks, directing investments and administering tax profits. The farmers, who had formed cooperative groups, were compelled to deal with the state. In spite of this, the economic performance of the entrepreneurial state was not successful. Senegal's gradual decline in agricultural production was essentially due to unfavorable environmental conditions caused by the decreasing farmable area, population growth, the country's specialization in peanuts and the decline of its prices in the world market (Berthelemy, Seck and Vourch, 1996: 42). That was made even worse by structural adjustment policies implemented in the 1980's by the Senegalese government under heavy pressure from the U.S., France, the World Bank and the International Monetary Fund (IMF). Senegal started instituting a Structural Adjustment Program (SAP) in 1984. This move was intended to remedy the economic crisis that began in the late 1970's. The industrial, agricultural and educational sectors were targeted by the new 
policies without success, severely hurting those sectors most directly involved in shaping the Senegalese economy.

The textile industry emerged as the fastest growing, most diversified, and best integrated sub-sector of import-substitution manufacturing. In the early 1970's, the World Bank considered the industrial sector as Senegal's most dynamic branch of importsubstitution manufacturing. Manufacturers' heavy reliance on government-enforced market control generated profits for the former, while weakening the economic structure of the industry (World Bank 1979). Indeed, there was an absence of local market competition and the government's import controls allowed local firms to inflate the selling prices of locally manufactured goods beyond the reach of the people. The results were low sales, and profit decline.

The system of import control became increasingly ineffective, and the government had to relax its import restriction policy leading the textile industry to face devastating competition from foreign textiles. Layoffs, production cutbacks and textile firm bankruptcies followed. This caused increased tensions between domestic political expediency and external demands for economic reform to increase (Berthelemy et al 1996). After renegotiations with the IMF and the World Bank, Senegal's textile industry was restructured in the 1980 's. The government compressed private demand, restricted domestic credit, and cut its own expenditures on social services, especially education, health, and subsidies for agricultural and industrial sectors.

A high fertility accentuates levels of poverty in Senegal, making living conditions very harsh and leaving most families to be faced with daily survival needs. The country's population in 2009 estimated at 13,711,597 inhabitants represents a doubling in numbers 
every 25 years and a rate of increase of $2.7 \%$ every year (ANSD 2009). According to the UNDP (2009) $60.3 \%$ of the Senegalese population was living under $\$ 2$ a day between the years 2000 and 2007, and between 2000 and 2006, 33.4\% of the population was living below the national poverty line. People struggle very hard to put food on the table before even attending to health care and education needs. The cost of living has increased by $5.8 \%$ in 2008 with school expenditures costing $6.6 \%$ more, while rent, water and electricity have increased by $1.5 \%$ (ANSD 2009), and health care still remains very expensive. These statistics illustrate the difficult economic conditions most Senegalese people are coping with.

\section{a. Health in Senegal and Implications for Women and the Family}

Women in Senegal suffer from lack of adequate health care, particularly in regards to reproductive health services and maternal and infant care. The Senegalese government's public and private expenditures on health are $6.7 \%$ of its total expenditure (UNDP 2009). That explains the lack in health resources that plagues Senegalese citizens. Health and literacy are major areas where women from developing countries face serious challenges. In term of health infrastructures, equipment and personnel, Senegal has still not reached the norms established by the World Health Organization (WHO). In 2008, the country counted 986 health clinics, 95 health centers and 22 hospitals. Many areas in Senegal, generally rural ones, are more disadvantaged than others in terms of access to health infrastructures. Efforts have been made by the Senegalese government in health care, such as the implementation of the expanded vaccination program (Program Elargi de Vaccination) targeting nine diseases, where $77 \%$ of children have been vaccinated in 
2008 (ANSD 2009). However, the Senegalese government needs to make considerable efforts to reach the United Nations Millennium Development Goals (UNDP 2009).

When it comes to women, Senegal faces serious challenges regarding maternal health, reproductive health or family planning, and infant mortality. The contraceptive prevalence rate of married women ages 15 to 49 in Senegal was 12\% from 1997 to 2005 (UNDP 2005), highlighting a serious need for support and resources in reproductive health. In the 1990's, the Senegalese government implemented a series of policy changes for the provision of family planning services through the public sector, a strategy to provide high quality services through reference centers (Sonago 2003). An evaluation of those programs revealed that women who received good care were 1.3 times more likely to be using a contraceptive method than others. Furthermore, women die frequently from childbirth because of lack of health care. Even in urban areas, where there are more resources than in rural ones, poverty greatly affects populations, especially women and children who are the most vulnerable segment. The research site, which is a peri-urban area of Dakar, displays a population living under very poor conditions who can hardly afford medical care.

The reduction of fertility rates in Senegal is very slow besides many efforts produced in modern contraceptive methods. In 2008 demographic statistics recorded 5 children per one woman in Senegal. Life expectancy at birth is 55.4 years and maternal mortality has been estimated at 401 deaths for every 100,000 births for the period of 1998 to 2005 (UNDP 2009). Probability of death varies considerably according to the area of residence. According to the Senegalese National Statistics Agency, the risk of dying before 5 years of age is much higher in rural areas $(82.85 \%)$ than urban ones $(52.41 \%)$. 
Hence, populations in other regions of Senegal besides Dakar, especially villages, are discriminated against when it comes to human development, notably access to health.

Maternal mortality remains high because of many factors including mothers' low literacy rates, early or late maternity and the low level of contraceptive use. The literacy level of mothers plays a huge role in the health and well being of their children. Records show that the risk of dying before 5 years of age is much higher among children whose mothers are illiterate or only have a primary education, compared to children whose mothers have a high school or university education (ANSD 2009). Therefore, children whose mothers have the greatest access to education and their children, have higher chances of survival.

\section{b. The State of Education in Senegal}

After independence, the primary aim of the Senegalese government was to train a local elite who could replace the departing French administrators. By the 1980's, there was a high demand for education in towns and in the rural regions (Mbodji 1991). Under the pressure of foreign donors and lenders (especially the World Bank and the IMF), budget reallocations for increased access to primary schooling (especially in rural areas) and for a less elitist education, began. According to the 1991 Senegalese Ministry of Finance report on stabilization and structural adjustment, these educational reforms were difficult to carry out under the tight budget constraints of the IMF's structural adjustment policies and the continuing growth of the school-age population. Hence, resources were drastically reduced in the educational sector: infrastructures were not equally distributed 
and the populations had the burden of building schools and purchasing schooling materials themselves (Fall 2003).

The IMF's policy prescriptions have had a major impact in shaping the Senegalese economy by significantly influencing the provision of social services, and hurting in particular the health and educational sectors. The government could not enforce the educational reforms of the World Bank and the IMF while its budget was significantly cut back in other areas (Barthelemy, Seck and Vourch, 1996). This has negatively affected formal schooling in Senegal, resulting in low literacy rates. The adult literacy rate in Senegal is $41.9 \%$, featuring a gap between the sexes in favor of men, with a female literacy rate of $33 \%$ and a male literacy rate of 52.3 (UNDP 2009).

Access to primary education at the national level has improved between 2006 and 2008 with disparities between boys' and girls' enrollment (ANSD 2009). There are also regional disparities when it comes to primary school enrollment. The capital city Dakar has a privileged position with $123.6 \%$ in enrollment because there are more schools for children to attend, while other towns and rural areas are neglected. At the national level, girls' enrollment is much lower than boys' enrollment in middle school. Many efforts need to be made to increase the enrollment of girls at the middle school level in order to bridge the gap between sexes.

The retention of girls in middle and high school is a major issue in Senegal. During the last five years, high school enrollment has doubled with boys outnumbering girls (ANSD 2009). That can be explained by the fact that when girls grow up they do a lot of chores in the house and help their mothers, and often find it difficult to keep up with school. Furthermore, pupils do not find help with their homework and struggle to get 
good results in school when they live in houses crowded with people. Another detriment to the schooling of these children is the fact that their parents are illiterate and cannot help them with work. Poor populations cannot afford to enroll their children in private schools, where they can get a better education. In rural areas, girls drop out of school more frequently than boys because they have to help at home and might be prone to early marriage.

Though enrollment numbers are high at the university level, students are struggling with lack of space for classes and irregularity in their curriculum and exams. The number of university students has been increasing regularly in the past decade (ANSD 2009). The major public university at Dakar is admitting more students that it can serve, which still leaves behind many high school graduates who do not make the cut. Furthermore, professors and students often go on strike because their demands are not met by the government, which renders many school years invalid. Consequently, there is a proliferation of private universities attended by middle and upper class students.

\section{Research Site}

\section{a. Dakar}

Dakar is the capital city of Senegal. It is overpopulated because people, usually from rural areas, have been migrating there since independence in search of economic opportunities. In 2008, the population of Dakar was estimated at 2,482,294 inhabitants. This represents one quarter of the entire population of Senegal living in an area of only $0.3 \%$ of the country (ANSD 2009). The population in Dakar is young, with $68 \%$ under 30 years of age (ANSD 2009). But living conditions in Dakar, while difficult, are far better 
than in other parts of the country. The chance for survival of children living in Dakar is much higher than that of children in other areas. For every 1,000 children born in Dakar, there are 79 who die before reaching 5 years of age, compared to a probability of 200 out of 1,000 dying in other regions of Senegal (ANSD 2009).

Dakar's privileged position comes from the fact that it overwhelmingly outnumbers other regions in economic opportunities and infrastructures. The majority of infrastructures in Senegal - especially businesses, hospitals, clinics and schools - are found in the capital. Dakar's process of urbanization finds its roots first in the fact that it was the capital of francophone West Africa during colonization, and hence privileged by the French. The development of the industrial and business sectors, along with the expansion of the informal sector have attracted people from other regions in Senegal, especially the young. Therefore, Dakar has been continuously expanding into many periurban areas as a result of the high fertility of its population and the ongoing migration of populations from other regions of the country. This continued rural exodus has impeded the urbanization of the capital city, increasingly adding rural populations to the existing amount of people in Dakar (ANSD 2009). Urbanization is one of the major traits that mark the demographic and socio-economic evolution of West-Africa. From 1960 to 1990, the West-African population has doubled, and the urban population has increased from 13 million to 78 million (Fall et al. 2002).

The Senegalese capital of Dakar is also characterized by high levels unemployment, especially in its peri-urban areas. According to the Senegalese National Statistics Agency (Agence Nationale de la Statistique et de la Démographie), 51.4\% of the unemployed are men and $48.6 \%$ are women, with $83 \%$ of all workers in the informal 
sector (ANSD 2009). The Senegalese capital of Dakar is also characterized by high levels of unemployment, especially in its peri-urban areas. Furthermore, newcomers to Dakar increase the unemployment numbers of the capital city. According to 2008 statistics, $35.8 \%$ of all unemployed in Dakar have been unemployed in the past year (ANSD 2009). Hence, in spite of high unemployment in Dakar, living conditions in other regions of Senegal are harsher and that people continue to migrate to the capital city.

Because of the ongoing rural exodus since independence years, people are constantly leaving the interior of the country, especially rural parts, in quest of a better life and employment in Dakar. Many recent internal migrants reside in Dakar (35.5\% of its population), showing that Dakar plays a preponderant role in the redistribution of migrants (ANSD 2009). These peri-urban neighborhoods are peripheral socially, geographically, and economically. The majority of their residents are poor, having migrated from other regions in quest of more favorable living conditions. These areas located in the outskirts of Dakar are densely populated. Many families live in very crowded and insanitary conditions. Living conditions are worse than those in the center or other parts of Dakar because of a lack of access to basic services such as health, education, and transportation. These services are either far removed from the residents or too expensive for them to afford.

External migration has been increasing in Senegal, and many international migrants come from West-African countries and half of them reside in Dakar. The study's research site which is the peri-urban area of Grand-Yoff is very much home to many international migrants who usually come from English speaking countries. Many of these migrants, especially those from Nigeria and Ghana have the reputation of 
conducting illegal activities and are often viewed with great suspicion by Senegalese people. These migrants have not traditionally moved to Senegal in great numbers, but lately they have become very visible. Other international migrants come from neighboring countries, such as Guinée or the Ivory Coast, and have been settling in Senegal for generations now.

\section{b. Grand-Yoff}

Grand-Yoff was created in 1950 by peasants, with only two families living there in the beginning. My field research took place in the two neighborhoods of Dakar's periurban area of Grand Yoff: Cité Millionnaire and Arafat. These two neighborhoods are next to each other and are the most populated in Grand-Yoff. Grand-Yoff is a poor and working class peri-urban area where people struggle with survival needs, especially food security. Municipal workers that I spoke to at the Grand-Yoff's city hall estimate the population of these two neighborhoods to approximate 200,000 people, which represents half of their estimation of Grand-Yoff's population. These numbers are far above those estimated by the Senegalese National Statistics Agency (Agence Nationale de la Statistique et de la Démographie) and the city of Dakar for 2009: about 200,000 people for all of Grand Yoff. These discrepancies can be explained by the fact that people are constantly coming and going from peri-urban areas because many people are seasonal or they just migrated to the city.

Grand-Yoff is one of the 19 communes or districts found near the capital city of Dakar. The area is an ethnic mosaic because all ethnic groups in Senegal are represented. The continuous rural exodus to Dakar explains why all ethnic groups live there because 
they find suitable (cheap) housing in peri-urban areas compared to the center or other parts of Dakar that are expensive for them. Many residents of Grand-Yoff, especially women, form associations according to kin or occupation. Many of the study's participants belong to associations formed along ethnic lines; this allows them to have a support system. The area is home to one of the major markets in Dakar (Marché GrandYoff), which offers many residents informal employment.

The neighborhoods of Cité Millionnaire and Arafat are filled with buildings where people rent rooms. Families share one or two rooms and live in very tight spaces with only a couple of bathrooms on every floor. This explains why children stay outside to play or chat with others once they are old enough. Most women in the study rent one or two rooms. Husbands and young adults are often absent from home, as they are dayworkers and return home late. Hence, Grand-Yoff appears to be a dormitory because its population seems to double at night, though it still remains heavily populated during the day. In addition, housing in Grand-Yoff does not follow construction norms. That marks a striking difference with middle and upper class neighborhoods in Dakar. Besides major roads, streets and yards are not paved or cemented. This is very common in many periurban areas in Dakar. The streets are unsanitary and they contain sewage, which is a factor in many diseases, and it generates bad odors.

Many habits or ways of living found in rural areas get imported in Grand-Yoff by migrants, making the area a "bridge between the village and the city." That is illustrated by the fact that cattle are kept in front of houses because people do not have space in their homes, which creates more unsanitary conditions for residents. The habit of keeping cattle in front of houses is not very popular in middle and upper-class neighborhoods of 
Dakar, where residents see themselves as more "modernized." Many workers in GrandYoff transport goods on horse-carts, which is a means of transportation in villages.

Women in Grand-Yoff usually sell goods at the market, in front of their houses, by the corner of the street, or door to door. Some also sell goods outside of the neighborhood, usually downtown, while others are house maids in other neighborhoods. Therefore, in the working class neighborhoods of Cite Millionnaire and Arafat, where the women in my sample live, women are usually very busy. Their lives are fast paced and they are constantly looking to earn a living so that they can feed their families. Almost all women in the sample were taking financial care of themselves and their children. Most men in Grand-Yoff also have activities at the market where they sell goods or offer their services. As many men and women migrate from rural areas to the city to find jobs, they often leave their partners or families in the village because they cannot afford to take care of them.

Access to health care is not easy for Grand-Yoff residents. Besides the Hospital of Grand-Yoff and a few other clinics or health centers, there are no health facilities in the two neighborhoods where the study took place. Some of the clinics operate at a cheaper cost, but medication remains very expensive in Senegal. The hospital only admits patients for hospitalization if they have insurance or after they have paid all or a big portion of their bill. Most patients come to the hospital of Grand-Yoff from other areas of Dakar and Senegal to get treatment, be tested, or be hospitalized. Often times, the population living in the area cannot afford to go to the hospital for lack of financial means. Many of the participants told me how expensive or impossible it is for them and their families to go to the hospital. Unless they have serious illnesses or experience a bone fracture, they prefer 
to go to the clinics or health centers in the area that are cheaper. The two neighborhoods of Cité Millionnaire and Arafat do not have health clinics, and the population has to go to health facilities around the area. This lack of health facilities is a common trait of most peri-urban areas of Dakar.

The whole commune of Grand-Yoff comprises 11 elementary schools and one junior high school. None of these schools are in the two neighborhoods where I conducted my research. These two neighborhoods are the most populated and represent half of the populations of Grand-Yoff. There are some private elementary schools that are set up to serve the residents of these neighborhoods. There is a private Catholic high school in the outskirts of the area, but as is the case with the hospital, most residents of Grand-Yoff can barely afford to send their children there. So, most students at the private high school come from middle and upper-class neighborhoods. Many of my participants struggle financially to keep their children in school and find it more challenging when their children become teenagers and reach high school. A few of the participants' children in the study have dropped out of high school or have an irregular attendance because they are faced with financial burdens. Their home conditions are generally not favorable for success at school.

There is a lack of security in Grand-Yoff that most people and some of the participants blame on the new and rapidly increasing immigrant population from Anglophone countries, especially Nigeria and Ghana. According to a municipal advisor, these populations are involved in many illegal activities, notably drug trafficking, prostitution, and rape. This can be explained by the fact there is no order or policing in the area. Furthermore, residents who are not from Dakar may engage in activities they 
would not conduct in their home communities. Therefore, the city hall is working towards setting up a police station in Grand-Yoff to bring more order.

\section{Summary}

A demographic analysis of Senegal reveals a population characterized by its youth and rapid increase in size as a result of a high fecundity rate. Senegal is a relatively urbanized country that is still characterized by a very important rural exodus despite many rural development programs. That explains the overpopulation of peri-urban areas in Dakar, for they offer rural migrants better living conditions. High levels of poverty are related to the lack of access to health care and education that characterizes many segments of the Senegalese population. Many Senegalese families struggle for daily survival, leading many women to covet new economic opportunities, such as microcredit loans. Microcredit loans offer Senegalese women an opportunity to become active participants in their economies by starting or sustaining their micro businesses. These loans allow them to take care of many households needs, especially the nutritional, health and educational needs of their children. But, microcredit also presents much inconveniency, making it challenging for poor women in Senegal to extract profits from it. 


\section{Chapter II. Methodology}

\section{Introduction}

I started my doctoral field-work with preliminary research in the summer of 2008 . I returned to Senegal in 2009 for eight months of research in the capital city of Dakar. My interest was to find out about poor women's involvement with microcredit in peri-urban areas of Dakar. After careful review of the literature on women, development and microcredit in poor countries, Africa and Senegal, I identified Dakar's peri-urban area of Grand-Yoff as an appropriate site to conduct the study. Peri-urban areas represent a bridge between the city and the village because many residents in these neighborhoods have migrated from the interior of Senegal, especially rural parts. Levels of poverty in these areas are exacerbated by their overpopulation as they become crossroads for the many ills of the country, and Dakar in particular. Furthermore, the study provides insights into the ways and reasons why women organize collectively as they do in Dakar's periurban area of Grand-Yoff.

This chapter explains the methods used in carrying out the study. I will first provide a description of the research site and the context where the study was conducted. Then, I will introduce the research participants. I will also elaborate on the instruments used to collect data for this study. Finally, I will explain the data analysis process.

\section{Research Site and Context}

Grand-Yoff is known for its popular neighborhood's women savings and credit cooperative (Mutuelle d'Epargne et de Crédit des Femmes de Grand Yoff).This is the pioneer neighborhood women's savings and credit institution in Dakar, bearing all the 
useful elements of a cooperative. Today these women's savings and credit cooperatives are all over the capital city and other regions of Senegal. I spent three months of preliminary research studying how the cooperative functions through its personnel, committees and members. The women's savings and credit cooperative of Grand-Yoff functions as other banks and cooperatives because it has a personnel on site, and kiosks with tellers around the neighborhood, mainly the market of Grand-Yoff. There are many Microcredit institutions in the area, creating great competition for the neighborhood's cooperative. I found that the cooperative functions on solidarity, reciprocity, and trust because its members share commonalities. This is parallel to traditional savings groups in Senegal: tontines, Nat or Mbotay.

The commune or district of Grand-Yoff was created in 1950 by peasants, with only two families living there in the beginning. My field research took place in two neighborhoods of Dakar's peri-urban area of Grand Yoff: Cité Millionnaire and Arafat. These two neighborhoods are next to each other and are the most populated in GrandYoff. Grand-Yoff is a poor and working class peri-urban area where people struggle with survival needs, especially food security. The Senegalese National Statistics Agency (Agence Nationale de la Statistique et de la Démographie) and the City of Dakar estimated the total population of Grand Yoff at 129,466 in 2008. However, municipal workers that I interviewed estimate the total population of Grand-Yoff to be around 400,000 inhabitants, adding that the study's research site - the two neighborhoods of Cité Millionnaire and Arafat - hosts half of the population of Grand-Yoff. These discrepancies when it comes to the estimation of the population of Grand-Yoff can be 
explained by the fact that the populations of Dakar's peri-urban areas are very mobile, either seasonal or just having migrated to the city.

\section{Research Participants}

While I interacted with most household members, this study is primarily focused on women microcredit recipients and their children. I interviewed 166 women. Most of them have children. The mean of children for the total sample of participants is 5.654. Sixty nine percent of the participants are married. I interacted with all participants at different levels. However, there are 23 cases of women whom I regularly and intensively followed and visited at home during my months of research. The average of children for these 23 cases of women is 5.391. Seventy four percent of them are married. These cases allowed me to assess in depth and for a long period of time the impact of microcredit on these women and their households.

Most men in Grand-Yoff also have activities at the market or downtown where they sell goods or offer their services. As many men and women migrate from rural areas to find jobs, they often leave their partners or families in the village because they cannot afford to take care of them. Most husbands leave early in the morning to look for labor, usually at marketplaces or downtown, and often return late at night. Some participants were widowed or divorced. Also absent most of the time, were adolescents, especially boys who do not usually take care of household chores (cook, clean, look after young siblings or babies). Most women in my sample rent one or two rooms, so there is not enough space for everybody in the family. Even small children are found playing outside or by the stairs. 


\section{Methods}

Conducting this study in Dakar's peri-urban area of Grand-Yoff was not an easy task, however one that was very interesting and informative. The study's research combines both qualitative and quantitative methods. The methods used in gathering the data allowed for triangulation. The complementarity of methods facilitated the study and contributed to enhance the quality of results.

Data for this study were gathered through interviews, surveys participant observation, focus groups and document analysis. I developed surveys/questionnaires that I administered to participants during interviews that were intended to be open-ended. A sample questionnaire can be found in the Appendix. Participants were asked questions pertaining to their financial agency, household structure and leadership, their credit situation and activities, household's nutrition, health and education status. I spoke Wolof with all my participants regardless of their literacy level.

The women's savings and credit cooperative of Grand-Yoff was my opening to the community. During this preliminary phase I was able to build rapport with many female members of the neighborhood cooperative, and other women who sold staples and goods at the market. The first sample of female participants was thus drawn in the summer of 2008 from the cooperative's female members who were microcredit recipients. This preparatory research phase outlined some socio-economic implications of microcredit as it refers to Senegalese women living in urban and semi-urban areas of Dakar, thus allowing me to pilot my study. 


\section{a. Interviews and Surveys}

During the summer of 2008, I conducted open-ended interviews with the personnel of the cooperative, and many female members who are microcredit recipients. I administered surveys to many women members of the cooperative to learn about their personal lives, business activities, savings, reasons for requesting credit, and whether or not microcredit was working for them. The reasons for getting credit were diverse. That allowed me to get insights into the necessity of microcredit and/or microenterprises for women in Senegal as a tool to fight poverty. This prepared me for the eight-month field research the following year. Surveys administered during this time allowed me to make sure my questions were sound and addressed the constructs I intended. I also conducted interviews with some academics and workers in microfinance and development.

I conducted open-ended semi-structured and unstructured interviews for the study because it allowed me to move the conversation in any direction of interest. I would conduct semi-structured interviews with participants during my first meetings with them, but as time progressed and particularly if I would visit them regularly, I conducted unstructured ones. However, the unstructured interviews were sometimes more difficult to control than the open-ended ones because of their lack of predictability. The use of random and snowball sampling allowed me to construct my sample.

I hired an assistant to help me recruit participants and organize focus groups. I chose someone who lived in the neighborhood. She is a university student, which was beneficial to the study because she was able to understand the research and methodology with ease. 
My assistant helped me conduct a random sampling of women in the two neighborhoods of Cité Millionnaire and Arafat. This was done two months after I started research in 2009. After carefully mapping the area, I selected every third building or house (they were few houses compared to buildings) for the purpose of this random sampling. We approached 219 women in every third building or house to find out whether they were microcredit recipients. Out of the total 219 women, 131 were not microcredit recipients, and 88 women were receiving microcredit. We administered short surveys to screen each of the 88 women. I selected women who had at least three children; 14 women had those characteristics and agreed to be part of the study. These 14 participants will become part of the 23 cases of women that I regularly visited and followed. The methods used provided a diverse representative sample of the population.

Many of the female participants would introduce me to their friends, relatives or neighbors. Hence, the use of snowball sample is a great advantage to this study. I had already met some of the participants in 2008, and contacted them when I returned in May 2009. I usually met these women at the neighborhood women's savings and credit institution or would approach them at the neighborhood market, which is a major one in the capital. Participants would continually refer me other women. The assistant was able to refer me to many women. That was a great way of recruiting participants because I was recommended to them, which made them more trustful to engage in my study.

\section{b. Participant Observation}

When I attended the cooperative's yearly general assembly in 2008 and 2009, I was able to understand how women members conduct their financial activities and the many meanings microcredit has for many of them. I uncovered the differences between this 
cooperative and other microcredit institutions or banks. I conducted participant observation with participants in the form of regular visits to their homes (almost all rent rooms), which gave me the opportunity to also meet and talk to their household members (usually children as most husbands are rarely home). I would also visit the participants at work. Almost all participants sell staples or goods at the neighborhood market or at home.

In addition to home and work place visits, I attended many meetings and gatherings of women associations in the neighborhoods. Women in Grand-Yoff are very active and the municipality counts 30 official women associations or organizations in the area. Many women in my sample are part of interest groups where they share the same activity. Others belong to associations that are socio-cultural or kinship based.

\section{c. Focus Groups}

I conducted two focus-groups, one exclusively with women credit recipients and another at the neighborhood's credit cooperative with both male and female members. These focus-groups were very helpful in outlining the major issues women (and their husbands or household members) had in regards to microcredit. They allowed me to make revisions by rewording or adding to my interview and survey questions. The mixed focus group with both men and women was very informative. It was interactive and displayed the tensions between men and women, and husbands and wives, when it comes to women's sudden financial power through microcredit. The second focus group - that only comprised women - was very insightful because women were able to fully elaborate on the meaning or importance of financial power and limitations in regards to spousal or gender relations. 


\section{d. Methodological Issues}

As a Senegalese woman, I tried to often detach myself from many preconceived ideas in order to better grasp the context and issues I was dealing with. This was a constant effort on my part because I was accepted as a natural part of the culture. Furthermore, participants often assumed that I would guess what they meant or hinted at, while I needed to actually understand and process it.

It was very interesting to note the absence of husbands in most women's households. Therefore, I mostly spoke and spent time with women, their young children, teenage girls and other relatives or friends who would be around. I had to reschedule many visits because of the participants' busy lives. However, because all participants live close to one another, I was able to make many "rounds" or visits once I arrived on site. In addition, I would constantly meet or come across many participants and their household members around the neighborhood.

As husbands traditionally take financial care of their families in Senegal, some participants did not feel comfortable at first to answer questions regarding financial power in their marriages. Once I gained the trust of many participants, they would elaborate on the fact that they are their households' financial breadwinners. In spite of this, they would not question their husbands' symbolic power in the household.

\section{e. Documents}

I collected many documents during my field-work. I gathered documents and reports from the government's microcredit programs, the Grand-Yoff women's credit and savings cooperative and other microfinance institutions, research databases and institutions, universities, development agencies such as the USAID, and Non- 
governmental organizations. These documents provided me with additional information on the operations, results and statistics of many microcredit programs in Senegal, and what particular margins of the population are engaged in microfinance. The information provided insights into the benefits of microfinance for MFIs and their clients, and the hurdles these institutions and their members face in particular regarding defaults in repayment.

\section{Data Analysis}

As mentioned earlier, I gathered data for this study through interviews, surveys, participant observation, focus groups, and documents. Born and raised in Senegal, I speak French, the official language and Wolof, the most spoken local language and lingua franca of Senegal. I translated most collected data from French to English. I also transcribed taped notes. I summarized the data through many procedures.

\section{a. Coding}

I coded collected data into categories that were informed by my research. I identified themes or patterns and organized them into coherent categories. I started with preset categories, where I identified the themes before categorizing the data and searched for data that match the themes. Then, I progressed to emergent categories, where I found the themes or issues that occur in the data after reading through it. For example, I coded "positive factors to women's entrepreneurship," "challenges to women's entrepreneurship" and "training of female microcredit recipients" under the theme of female entrepreneurship. I also developed sub-categories when necessary to refine the 
codes even further when necessary. This process of coding allowed me to tally the coded responses and interpret the data.

\section{b. Descriptive Statistics}

I constructed tables to display all pertinent information on the participants, their households and activities. See Appendix. The tables display the following information on the participants:

- $\quad$ Age

- $\quad$ Marital status

- Number of children

- Level of education

- Which microcredit institution they belong to

- $\quad$ Length of time they have been receiving credit

- If they invest their credit or revenues into the household

- Activity

- If they repay their credit easily or with difficulty

I considered three groups out of my total sample: 1) the random sample, 2) the sample of 23 women who were intensively studied, and 3) the total sample which is composed of all women studied. I calculated the mean, modes and medians for each of these groups, which allowed for comparison. For example, the three groups reported similar results in the mean number of children, thus providing additional confidence in the data. The means for the total sample, the random sample and the sample of 23 cases 
are respectively $5.654,5.390$ and 5.391 . The percentage of married women for these three samples is respectively $69 \%, 70 \%$ and $74 \%$.

With the use of statistical software SPSS, I produced histograms and bar charts to display pertinent data for the study population. 


\section{Chapter III. Senegalese Households}

\section{Introduction}

Senegalese households feature very complex structures that can include nuclear, extended and polygamous families. Globalization has already created many changes that affect the economy and households of developing countries. The country's difficult economic situation and current global financial crisis have negatively impacted the survival and livelihoods of many families, especially in the areas of nutrition, health and education. Senegalese households are also characterized by an increasing numbers of female household breadwinners because of women's economic emancipation - especially promoted by the recent boom in microcredit opportunities - and many husbands decreased financial power.

This chapter provides a discussion of Senegalese households by first exploring their composition, size and the central position women have in them. Secondly, I discuss of the challenging economic realities of households such as high levels of unemployment, and their impact on the nutrition, health, education, and housing of families. Finally, I explore the increasing trend of female household breadwinners who have become, in many cases, their households' sole financial support.

\section{Characteristics of Senegalese Households}

\section{a. Structure of Households in Senegal}

In Senegalese households, husbands are usually the heads of households. Nuclear households remain the minority. Many households that are not nuclear are composed of more than one family or unit. Most households include extended family members, and/or 
are polygamous. Extended families include parents, uncle, aunts, nieces and nephews. In contrast to the general idea of the extended family or a universal tendency towards the nuclear family, recent research in Africa shows that there is not one, but rather we observe many family models according to social classes, and despite modernization (Fall and Sy 2002).

As Senegal's population is $95 \%$ Muslim, polygamy is widespread; about one third of men have two or more wives. Co-wives sometimes live in the same house. In rural areas, polygamy is more prevalent as men marry more than one wife for the purpose of having many off springs who will help with labor and chores. Polygamous households are far more problematic in urban housing environments, where living space is finite and expensive, than in rural ones, where compounds can be extended relatively easily. In fact, rural households are almost twice as likely to be polygamous than urban ones (Ross 2008).

The household as a co-resident domestic group (as opposed to the family as a network of kins) can be a residential unit (people sharing the same budget or eating together), a reproduction unit (husband, wife, and children), or a consumption unit (people sharing the same budget).

The 1988 census of Senegal defines three levels of aggregation: "the compound" (concession) is a group of buildings that may or may not be surrounded by a wall or a fence of some type; in some instances it may consist of a single building including a series of separate dwelling units and is often under the authority of a compound head. "The household" (ménage) is a group of people, related or not, living in the same concession, taking their daily meals together, under the authority of one person called the household head." Finally, "the family nucleus" (noyau familial) consists of one or both parents and their direct descendants 
provided those are themselves 'unaccompanied', i.e., they do not have a spouse or children or other dependents living with them in the household." This family nucleus is also said to have a head (Van de Walle 2006: 4).

There is great diversity in the structure and composition of Senegalese households, which depends on many factors such as geographical area (rural against urban), social class, ethnicity, or whether they are monogamous or polygamous. Among the Sereer, Senegal's second largest ethnic group, there are fundamentally different systems of polygamous residence, whereby in the first, a man lives in a large compound with several wives who pool resources at mealtime and assume the care of children jointly. In the second system, women and their own children live separately, sometimes quite far apart, and have distinct budgets (Van de Walle 2006).

The following types of household structures can usually be found among the Senegalese:

- Nuclear: biological parents

- Vertical: three generation families, either married adults host their own parents, or an older patriarch or matriarch rules over married adults

- Horizontal: siblings (brothers and sisters) living together

- Oblique: uncles and aunts with nephews or nieces, either when married adults host their uncles and nieces, or older persons host their nephews and nieces, most of whom are in maternal uncle/uterine nephew relationships

Large compounds and households result primarily from the juxtaposition of nuclear units, organized into vertical, horizontal and oblique structures. Nuclear households are more common in the city, especially the capital Dakar. 
As people move to the city, usually for economic reasons, they are likely to stay with family members, further altering their host families' household composition and dynamics. Culturally, Senegalese people are non-individualistic and never close their doors to their relatives and friends in need of shelter, whether temporarily or permanently. Therefore, households in Senegal are constantly shifting entities. Many migrants that arrive in Dakar live with relatives or people in their social network. In urban settings, this creates a financial strain on families who have to provide them room and board.

During my visits, I would often find relatives at the homes of the study participants. There would be no clear indication as to why or how long they would be staying; they just blend in with the family in extremely congested spaces. Some of the participants who are co-wives do not cohabitate with the other wives for lack of space as they are renting rooms in Grand-Yoff. Many participants' co-wives remained in the village or lived in other areas of Dakar. Their husbands are not always at home as they need to alternate between wives according to Islam. Therefore, co-wives usually have more spare time than wives in monogamous marriages because they can free themselves when their husbands stay at the other wife/wives home. When co-wives cohabitate, they take turn to cook and do chores in the household, thus sharing responsibilities.

\section{b. The Significant Size of Households}

Senegalese families are both large and extended. The average Senegalese household has between 9 and 10 members, while on average every Senegalese woman will have four or five children in her lifetime (Ross 2008). The size of Senegalese households has 
tremendously increased, especially in the city where most people migrate and often live with relatives. Despite tough living conditions in the city, and the capital Dakar in particular, the number of household members increases because of a high fertility rate among women (with a low use of contraceptive methods) and harsh economic realities in other parts of the country. That is the case for the study's participants who often live with extended family members. The mean size of children for the women in the study is 5.7 . Once parents and extended family are included it can easily average 10 household members.

Households' size in Senegal appears particularly high even by African standards. For instance, in the 1988 national census, the average size of households was 9.0 with only minor variations by regions. Senegal has also constructed surveys that provide independent estimates of households' size with 9.3 people in 1997. Senegal appears as an exception in Sub-Saharan Africa, with an extremely high mean size of households, stable over time for at least the past forty years (Van de Walle 2006). This large size of families and households is very problematic in a context where most of the population struggles for their families' survival.

\section{c. The Central Role of Women and Mothers in Households}

Mothers play an essential role in Senegalese families. Besides having to take care of their children, husbands and sometimes extended families, they often struggle to earn money for the survival of their selves and children. In Senegal, women take care of household chores as opposed to men. While the obligation to honor one's parents and family is incumbent on all, it weighs especially heavily on women. The role of women in 
contemporary Senegal reflects the complex interface of African, Islamic, and modern Western traditions. The behavior of wives, daughters, and sisters is seen as a barometer of the order reigning in the household (Ross 2008). Therefore, women and mothers play an essential role in Senegalese households. This role is even more complicated when women need to feed their families, a responsibility that has traditionally been that of men and husbands.

Senegalese women nowadays have to uphold their African and Muslim traditions and values in a modern society. That translates into earning money because of economic tough times and yet having to fulfill their traditional roles as mothers and caretakers in their households. Though a patriarchal society, women have always had a very prominent role in the economy and public sphere in Senegal. Therefore, women's economic participation needs to be balanced with their potent traditional values and responsibilities. For instance, many of the study's participants who were their families' breadwinners would not challenge the authority of their husbands in the household. They understand that their economic independence has conferred upon them more status, however that does not come in opposition to their husbands authority in the public and even private sphere.

Analyzing women's economic emancipation without seriously scrutinizing its context can be misleading. The symbolic power that husbands have in their homes often remains unquestioned by their wives and families because Senegalese women and mothers in particular, safeguard society's traditions and values. This contradicts some of the feminist literature (especially in gender and development) that argues women's economic independence or emancipation must lead to an attainment of equal status in their marital 
relationships, or that grossly idealizes their consequential empowerment. Cornwall (2007) argues that myths of gender and development interventions may not relate to the lived experiences of the women they seek to empower, adding that mainstream development interventions aimed at empowering women are often derived from generalizations about women and men. Furthermore, besides having to conform to traditional values, Senegalese women have very extended family and social networks that fulfill their lives in many ways. This gives them a locus of control outside of their marriages and households. Hence, Senegalese women's economic emancipation presents challenges to their power of decision in the household, but on the other hand it does not interfere with their cultural and households' harmony.

\section{The Economic Realities of Senegalese Households}

The cost of living and household expenses is very high in Senegal. There is a lack of access to basic resources for many families. Parents struggle to provide meals for their families. In addition, many Senegalese households cannot afford health and schooling expenses. Housing is also very expensive. As a result of the global financial crisis, 2008 has been a difficult year for Senegalese populations, resulting in very high prices for household commodities, especially food (rice, cooking oil etc.). This situation created food insecurity and frequent shortages of cooking gas and electricity (ANSD 2009).

Households had to reduce the number of meals and consume food at a lower cost. Families also had to reduce their spending on health, hygiene, clothing and ceremonies, and turn towards getting credit to fund their expenses. More than half of urban households declared getting credit for purposes of household food consumption (ANSD 
2009). Furthermore, there is great inequality when it comes to the purchasing power of Senegalese households. The majority of households come from the weakest consuming segments of the population, while a small minority of $5 \%$ spends more than 7 million CFA $(\$ 13,000)$ a year (ANSD 2005). The three most significant areas of consumption are: (1) food and drinks, (2) rent, water, electricity and cooking gas, and (3) transportation.

\section{a. Unemployment}

The high unemployment rates explain the increasing poverty levels in Senegal. The job market in African countries remains depressed because of the stagnation of the economy's formal sector, in spite of the continuous rise of the informal sector. The agricultural sector does not improve because of its lack of diversification, the limitations of its productivity and its dependence on climatic hazards (Fall et al. 2002). In rural areas lack of agricultural productivity is the cause of most unemployment and results in the exodus towards cities. Therefore, rural populations migrate to the city to seek jobs. In 2008 , the unemployment rate in Senegal was $20.8 \%$ for women and $9.5 \%$ for men, being more pronounced for people between 15 and 29 years of age (ANSD 2009).

Unemployment numbers are very high and most of the population works in the informal sector. Most people always do "gor gorlou" (meaning to hustle in Wolof). Most unemployed people struggle on a daily basis to earn a few cents or rely on potential business ventures. The lack of employment plagues Senegalese families, especially men and husbands who often find it impossible to provide for their families as they wish and 
are expected culturally. Most of the participants' husbands are unemployed (or day workers), which propels their wives to get credit in order to earn money.

\section{b. Nutrition and Food Security}

Good nutrition and food security are pivotal to the survival of families, and remain a major challenge for many Senegalese households. The International Fund for Agricultural Development (IFAD) defines "household food security" as "the capacity of a household to procure a stable and sustainable basket of adequate food." Therefore, access to enough quality food is central to a good nutrition. Many Senegalese families nowadays find it hard to eat three meals a day, or do not cook enough for their daily meals. Households in Senegal and Dakar spend $50 \%$ and $40.1 \%$ of their expenses respectively on food consumption (Fall et al. 2002). That represents a big portion of households spending power and cannot guarantee good nutrition and food security because of the big sizes of many families and the poor quality of nutritional intake.

Most Senegalese households do not have enough income to provide sufficient and nutritionally balanced meals every day. According to the UNDP (20009), 60.3\% of the Senegalese population still lives on less than \$2 a day. Many of the study’s participants cook lunch and put some amount aside for dinner, thus only making one meal a day, in addition to breakfast. Though lunch and dinner are usually cooked separately due to trying times, many poor families split their lunch meal to save some for dinner. Some participants were not able to cook enough for their families, and could only buy ingredients that are very poor in nutritional values. 
Senegalese main dishes - especially for lunch - are rice based and accompanied with vegetables, meat, fish and sauces. Meat consumption is higher among middle and upper class households than poor ones. For the poor, there is mostly rice and a few ingredients. The quality and coloring of the food and the amount of ingredients is an indication of how rich a meal is. For many of the participants, money earned (along with any financial support they can get from their husbands) allows them to put food on the table, however the quality and/or quantity were lacking. Many households in Senegal cannot afford fruits in their diets, and only $1 \%$ of households in Dakar eat fruits (ANSD 2009).

Expenses for fish and seafood are slightly higher than those for meat (12\% against 9\%). Spending for bread and cereal (rice), fish, meat, and vegetables represent more than $25 \%$ of households' food budget (ANSD 2009). Therefore, the high cost of food consumption in Senegal, and Dakar in particular, explains why many families cannot eat enough and are confronted with high levels of children's malnutrition. Hence, poverty strikes families both in rural and urban areas by creating very poor nutritional conditions.

\section{c. Health}

Many families cannot afford access to health care, or live in areas that are remotely located from health facilities. Many mothers, their babies and children, in particular, suffer from many diseases. Child malnutrition is a serious health issue in Senegal because of poor nutrition. Between 2000 and 2006, 17\% of children under 5 years of age were underweight (UNDP 2009). Good nutrition is especially vital for children whose health and development can be stunted by malnutrition, often leading to 
death. Malaria remains a threat for the population, especially during raining season, being the disease that kills the greatest number of Senegalese (ANSD 2009). Poor families do not have enough funds set aside for health prevention (vaccines) or care because all their earnings get primarily spent on food.

Many mothers die during childbirth because of lack of access to health infrastructures. In 2006, 176 per 100,000 mothers died during childbirth and 3 for every 100 babies were stillborn (ANSD 2007). That shows that women are adversely affected by lack of access to health care and/or poor health care. Women travel too many miles from their villages to get to the nearest maternity clinic and often lose their lives or their babies. In urban areas, there are not enough health personnel or equipment in many hospitals. Well-to-do women give birth in private clinics and can afford prenatal and postnatal care, which ensures the good health of their selves and their newborns. Efforts need to be made in regards to the use of modern contraceptives, prenatal care, and childbirth for women in Senegal, in particular for those women in rural areas.

Many participants only go to the hospital and clinics when they are seriously ill. One of the participants was very ill during one of my visits. She told me that she could not afford to go to the hospital because her daughter had the flu and she needed to take care of her daughter's health instead. She used most of her microcredit loan to pay for those health visits and medication. That prevented her from buying fabric to sew bed sheets for sale at the neighborhood market. Microcredit loans often end up being used for health or other household emergencies, leading many recipients to default on their loans and further get stranded for money. Most women in the study would go to clinics at a cheaper cost, however the cost of most medicine remains very expensive in Senegal. 
During the rainy season people often get the flu or battle malaria. These are serious diseases that require good care and expensive medication.

\section{d. Schooling}

Illiteracy rates in Senegal remain high with only $41.9 \%$ of the population being literate (UNDP 2009). Poor people, especially in rural areas, find it hard to enroll and/or keep their children in school. The retention of children, especially girls and teenagers is a serious problem. According to the 2002 households' census, $27 \%$ of children between seven and fourteen years of age in urban areas, dropped out of school to enter the labor market (29\% in the capital Dakar). Many families cannot afford to keep their children in school for lack of finances. Many girls are forced to drop out of school to help with household chores, sell their families products or marry early. School expenses represented 1.4\% of Senegalese households' budget (Fall et al. 2002). Because of all other household urgent needs such as food or health emergencies, families struggle with schooling expenses.

Many of the women in the study find it hard to keep all their children in school. Some participants chose to keep children they deem brighter in school. This does not mean that they do not share the values of middle to upper class parents, for they often reminded me of the importance of education as a means out of poverty. As the participants work with limited resources to take care of their children, they often have to make hard decisions. The majority of the participants cannot afford to enroll their children in private school. A few participants enrolled their children in the neighborhood's private schools that are cheaper and do not require transportation. The 
participants showed real urgency in taking as much care as they could of their children. Research shows that the expenditures of female-headed households are more biased towards nutrition and education than those of male-headed households (Masika et al. 1997).

Health, good nutrition and literacy are pivotal needs for Senegalese citizens. Public school classrooms are crammed with students who cannot get the best out of their education for lack of infrastructure and financial means. Furthermore, rural areas are neglected in terms of schools, resulting in low enrollment numbers for students, especially girls. When children have to walk miles every day to school, it makes it very challenging for them to have a good attendance or good results. Many girls in villages miss the opportunity of going to school because of the time and effort it takes away from their load of chores at home. Many government and development programs work to reinforce the insertion (and reinsertion) of girls in schools, but that remains a daunting task.

\section{e. Housing}

The cost of housing is very expensive in cities and Dakar in particular, as opposed to other regions and rural areas where more land is available. Housing represents $24 \%$ of the expenses of households in Dakar. Many migrants that arrive in Dakar live with relatives or people in their social network. There is a small minority that lives in very rich neighborhoods often along the sea and a Senegalese middle-class that has been shrinking because of dire economic times. That leaves a vast poor and working class, increasingly 
composed of migrants that come from rural areas. Many middle-class neighborhoods in central Dakar have become depressed and as congested as peri-urban ones.

Poor families resort to housing in peri-urban areas of Dakar where they rent one or a couple of rooms at a more affordable price (Fall et al. 2002). Many peri-urban areas are created by migrants to the city who seek affordable housing and rent one or two rooms in very congested buildings. Peri-urban areas of Dakar offer rent at a cheaper cost as all other poor neighborhoods in the city. The majority of the study participants rent rooms in buildings. The conditions they live in are very precarious, but it allows them to get housing and survive.

\section{The Changing Face of Senegalese Households: More Women Are Becoming their Families/Households Breadwinners}

Nowadays, many married women in Senegal find themselves in the role of the financial provider. Though many women who earn a living do not contest their husbands' position as household head, they do acquire more status in their household and have more leverage in decision making. The women in the study, with or without the help of their husbands, strive to take care of their families, especially their children, in a city where the cost of living is very high.

\section{a. The Feminization of Poverty}

Women in developing countries suffer the most from poverty and are victims of illiteracy and lack of economic opportunities. Lack of education and employment adversely affect many women's lives. The study's married participants often feed their 
children without sufficient financial support from their husbands because women in Senegal are their children's caretakers and caregivers. Poverty in Senegal greatly affects women. The gender-related development index (GDI), introduced in the United Nations Human Development Report 1995 captures inequalities in achievement between women and men. Out of the 155 listed countries, 107 countries have a better GDI ratio than Senegal's (UNDP 2009).

During my second focus-group, the son of Victoria, one of the participants, interrupted our discussion to ask his mom for food because he was hungry. Then, Victoria said with great pride: "you see, kids only go to their mothers if they are hungry, not their fathers!" This participant had barely anything left in her cooking pot that day, but managed to make him something to eat before returning to the focus-group discussion. In poor families where husbands are unable or barely able to financially support their households, mothers do anything in their power to feed their children. This phenomenon of female household breadwinners has been described by some scholars as the feminization of poverty. Achuwilor (2002) describes gender variations in the hardships suffered as the result of poverty in many African countries, making women the most disadvantaged in such cases, as the "feminization" of poverty.

Senegalese women sell items such as fabric, clothing, jewelry, shoes, accessories or perfumes and incense. Things are usually sold at credit, where the client pays all or some amount of the item's price at the end of the month or throughout. As women tend to be mobile vendors, they sell items to people they know or are referred to. That is the means by which many women, even without getting microcredit loans, earn money. Hence, most women remain in the informal sector, whether or not they have a stand or a kiosk at a 
market or shopping center. That is how women in Senegal have been managing for decades and able to support their families, especially when they are divorced, widowed or have unemployed husbands.

Many participants tell me: "no husband's dépense ("budget", household allowance men provide their wives daily or weekly) is enough anymore!” Most middle-class Senegalese housewives can no longer solely rely on their husbands' financial support; they need to supplement it for their households' survival. Microcredit opportunities for women represent household survival and livelihood strategies, allowing them to mobilize and use available resources to sustain their economic activities.

\section{b. Female Household Breadwinners}

Opportunities such as microcredit allow women to take financial care of their children and households, especially when their husbands are unemployed. Senegalese women hold $42.4 \%$ of jobs in the informal sector, and usually work in restoration, sales of small items, and services. The role of head of household, traditionally held by men is becoming increasingly claimed by women (ANSD 2009). This phenomenon is the result of male migrations, conjugal instability, female emancipation (divorce because of unemployment and economic hardship), and polygamy where husbands and wives do not live in the same households (Fall et al. 2002). Men migrate to the city to find jobs, leaving behind their wives to take care of all household responsibilities, thus creating the dislocation of families.

African households, especially in urban settings, are becoming increasingly composed of more than one economic unit, featuring other breadwinners than the 
traditional head of household. De Haan (2005) argues that the old assumption of a nuclear or extended family - comprising a male breadwinner, his sometimes even nonworking wife, dependent children, and other family members - needs to be revised, just as traditional patterns of labor division do. Rather than being harmonious entities pursuing an optimal balance, individual household members are currently pursuing ways to improve their situation. That sheds light on the fact that globalization has transformed the image and functioning of African families and households. Old dichotomies of urban versus rural need to be reconsidered in the context of the study because most of the population living in Dakar's peri-urban area of Grand-Yoff migrate from rural areas, and maintain ties to their home communities. Thus the participants become breadwinners in their households, but also financially support family members left behind.

The phenomenon of female household breadwinners, or as many in the literature call them heads of households, brings about precarious conditions or, to the contrary, autonomy for women. The study's participants have to feed their families, pay for their households' expenses, health visits, medicines and children's schooling. As some participants are not able to actualize their economic activities because of unforgiving household conditions, others are able to make some gains and see the fruits of their investment. Women see the household as the entity with which they identify their interests even if they come second best, because there are few other sources or resources and support outside the kinship network (Rakodi 1991). Culturally Senegalese women do not claim the status of heads of households bestowed upon men. Anthropologists have long noted the imbalance between the sexes, the most important one dealing with household headship. Van de Walle (2006) notes that although females may become heads 
of compound and household among the Sereer of Senegal, it is exceedingly rare. Culturally, women in Senegal are not recognized as such.

The majority of the participants would reject the notion that they have become their households' heads, leaving that symbolic status to their husbands. This does not mean that they are unaware of their financial clout. Senegalese women are socialized to entertain a "sutura" (Wolof term for tactful and discrete) that prevents them from "shaming" their husbands. Guérin (2006:553) notes: "Senegalese women’s preoccupation with money stems from household responsibilities to feed and care for family members while men 'do nothing at all.' Women must 'guard against shame' and 'be respectable,' which means honoring ones' debts." This denotes the fact that Senegalese wives have to "cover" for their husbands' failures or inability to be financial providers; which puts a heavy strain on themselves.

In her study of microcredit in rural Senegal Duffy-Tumasz (2009: 250) notes about a woman's decision to share loans with her husband : "Male public authority and female financial autonomy can interact. Publicly divulging consumptive rather than productive loan use would compromise her husband's dignity. Choosing to share her loan and cover her husband's default could also be seen as an example of a patriarchal bargain that provides her with a platform to extract benefits from her husband in the future." Hence, women make calculating decisions that safeguard the harmony of their spousal relations, while personally benefiting them.

Despite conformity to patriarchal traditions, we must note that patriarchy in Senegal is undergoing changes brought forth by modernity and women's economic emancipation. Discussions with the study's participants on the subject reveal that they do 
not contest their husbands' positions as household heads, but want more collaboration or cooperation with them in regards to decision-making. Many men and husbands resent women's financial independence as it threatens their authority and self-esteem. This shows that women's empowerment is not only determined by their financial clout.

\section{c. The Crisis of Masculinity}

Though Senegalese women do not usually contest their husbands' symbolic power as heads of household, they have now acquired a newfound status that reduces the clout of many Senegalese men and husbands. During my first and mixed study-group at the Grand-Yoff's microcredit cooperative, a couple of men did voice their opinion on Senegalese women's acquisition of microfinance loans and their economic freedom. They complained that many women waste their profit at ceremonies. Though applauding new initiatives through microcredit to promote women's economic participation and capacities, the men at the focus-group seemed uneasy at the prospect that women can be trustworthy with handling their monies.

The study reveals that men's discomfort and sometimes harsh criticism of women's entrepreneurship is tied to the economic freedom it provides women. WestAfrican and Senegalese women have traditionally been engaged in market activities, however they have not been able to make substantial gains as they do nowadays with microcredit loans. Men have not felt threatened before because they remained the financial providers. Around the world, in both urban and rural locales, women are shifting into petty trade, factory work, and service jobs, while men face diminishing opportunities in agriculture and wage labor. 
Several ethnographies from rural Africa reveal men's sense of uselessness and their jealousy, or even fear, of their wives. This indicates that times have changed and women are increasingly becoming financially autonomous. Perry $(2005: 217)$ argues, in her study of masculinity in rural Senegal, that "Men's discourse is not of empowerment, but of disempowerment. 'Now a woman just puts her husband down, she won't do anything for him.' 'Women are crooked. They used to help their husbands for Allah and Allah alone. But now all they want is money.' 'You wake up in the morning now and don't even know who the head of the household is!" According to Perry, these frustrated comments from men are the result of their lack of agricultural productivity and their women's financial independence through sales at weekly markets. These comments are not unusual in today's Senegalese society where women's financial participation and weight has become very visible.

\section{Conclusion}

The structures of households in Senegal are very complex and fluid. They are molded by traditional and modern arrangements, economic conditions, and migration from rural areas to the city. All these changes render the composition and functioning of households in Senegal more problematic. High unemployment rates, coupled with poverty, make it very hard for many families to put food on table and afford health care and an education. Recent opportunities such as microcredit loans allow people, especially women, to earn money and take financial care of their families, in many cases taking over their husbands' breadwinning roles in the household. This has changed the image of the Senegalese family, creating much enthusiasm for women's emancipation, but also 
important changes in patriarchal traditions in a society where women remain attached to traditional norms and values. 


\section{Chapter IV. Senegalese Women, Microcredit and Entrepreneurship Introduction}

The credit system in Senegal is diversified, featuring services from banks, microcredit institutions, development projects, cooperatives, networks, and informal finance. Microcredit is tailored to the poor who are excluded from the classic banking system, bringing about financial and social flexibility tailored to people in need, especially women. Microcredit has been popularized as a tool to fight poverty by giving women the means to start their own micro businesses. Senegalese women are very engaged in credit activities, whether from formal or informal microfinance services, for their households' survival and economic ventures.

The main financial activity of microfinance institutions (MFIs) is to collect savings and grant credit to their members. In 2007 there were 10,000 estimated MFIs across the globe with 90 million microcredit beneficiaries (Allemand 2007). There is a more significant number of clients with MFIs than banks in Senegal. In 2008, MFIs had increased by 5.9\%, from 896 in 2007 to 949 , and members also increased from 799,525 in 2006 to 871,035 in 2007(ANSD 2009). Women in Senegal, who are mostly illiterate or have limited formal education, turn to microcredit as a means to start or sustain their small businesses.

This chapter explores Senegalese women's microcredit and business activities. First, I provide a detailed typology of microcredit institutions and sources in Senegal. I then provide a typology of female borrowers through their patterns of savings and credit - from formal and informal microfinance - and their business activities. Last, I provide a 
description of female economic activities which are concentrated in the informal economy, and analyze microcredit's prospects for female entrepreneurship.

\section{Typology of Microcredit Institutions}

Microcredit services are provided or supported by major MFIs, international aid organizations like the USAID, local and international non-governmental organizations, banks, savings and credit cooperatives, and the Senegalese government through two organs: 1) the Ministry of the Economy and Finance and 2) the Ministry of Small and Medium Enterprises, Female Entrepreneurship, and Microfinance. The government provides two microcredit projects to women entrepreneurs at different stages: small and strong micro-enterprises. Many neighborhoods or associations feature their own Women's Credit and Savings institution, such as that of Grand-Yoff where the majority of the study's participants have accounts.

\section{a. Major Microfinance Institutions in Senegal}

There are major MFIs in Senegal such as CMS (Crédit Mutuel du Sénégal), PAMECAS (Partenariat pour la Mobilisiation de l'Epargne et le Crédit au Sénégal), ACEP (Alliance de Crédit et d'Epargne pour la Production) and Microcred who operate throughout the country and have branches all over the capital city. These three MFIs CMS, ACEP and PAMECAS represented 64\% of microcredit clients in 2002 and collected $75 \%$ of savings (Djefal 2007). These credit institutions share many similarities with banks, holding significant financial capital and leverage. However, they cater to a robust margin of the population that is usually denied credit by classic banks. These 
major credit institutions are great competition for women and neighborhoods' credit cooperatives, and have many branches throughout the country, especially in Dakar. They all have branches in the area of Grand-Yoff and are very experienced in recruiting clients, luring them with exciting flyers, packages, and other marketing strategies that the neighborhood cooperatives cannot always match. These MFIs also have websites that detail all their activities and portfolios, along with constantly running TV and radio ads.

Alliance de Crédit et d'Epargne pour la Production (ACEP) was founded as a program to fight poverty with funding from the USAID. Today, it is one of the major MFIs in Senegal. The branch of Grand-Yoff has more female clients than male (60\% of their clients are women) and grants smaller loans than other areas of Dakar because their clients are poor. The branch manager argues that it is risky to give credit to male entrepreneurs who do not have fixed businesses, while female clients, that they deem more trustworthy, are given loans though they usually have unfixed or "mobile" businesses. The majority of ACEP's clients in Grand-Yoff (95\%) are in the informal sector. As it is the custom with other credit institutions, they employ credit agents who visit potential clients to evaluate their assets and determine the amount of credit to grant them.

Created in 1988, CMS is present in all regions of Senegal with over 80 branches as of 2008. They decided to target other cities besides the capital and rural areas as almost all MFIs were concentrated in Dakar at the time. Starting with rural areas, CMS extended its savings and credit services to the capital where a big segment of the population is very poor and in need of financial help. The institution's CEO, Mamadou Touré, argues that the success of their proximity strategy (because they bring banking to the poor) has 
influenced many institutions, including classical banks who imitate their formula (Touré 2008). He further explains that they maintain a sociological proximity which allows them to adapt to the socio-economic realities of their target populations. Hence, MFIs have the advantage of being in touch geographically, socially and financially with their target populations, most of whom are the poor.

\section{b. Government Microfinance Programs}

The government's microfinance programs operate at two levels: a program that funds poor women through small loans and another that give significant loans to women who are strong entrepreneurs. These programs are under the wing of the Ministry of Small and Medium Enterprises, Female Entrepreneurship, and Microfinance. The creation of the latter ministry speaks to the magnitude of microcredit services and their focus on women. A big part of the capital for these government programs has been donated by the Chinese government to support female entrepreneurship in Senegal (ANSD 2008). These projects have the goal of promoting Senegalese women through the creation of sustainable jobs, and hence fighting poverty. That makes the economy more dynamic and gives women more purchasing power for their families' survival and economic activities. Recipients are guided throughout these projects and given lessons in basic accounting and managing.

The small loans program that caters to poor women PCF (Projet de Crédit pour les Femmes) was created in 2002 and gives small loans to women at an interest rate of 5 to $8 \%$. These loans to supporting women whose micro-enterprises or economic activities are at a very small scale or not very lucrative, are regarded more as grants rather than 
credit because the women they target are very poor. These loans allow women to individually start micro-businesses (e.g., sale of frozen fish, vegetables and fruits) or cooperatives. This microcredit program funded 1,456 projects and 535,749 women with a $4.61 \%$ repayment rate of direct loans to women (PCF 2005). This very low repayment rate is results from the fact that most of the program's recipients face dire poverty. The director of this government's small loans project explained in an interview, that the primary aim of the program is to give women sustainable socio-economic tools, rather than getting loans repaid. That project report shows that many women could not repay their loans for lack of financial resources.

The big loans program that targets successful or economically independent female entrepreneurs FNPEF (Fonds National de Promotion de l'Entreprenariat Feminin) was created in 2004 and seeks to promote female entrepreneurship at a higher level. This government project caters to women with solid micro-enterprises by loaning them a very significant amount of money. Women who graduate from the small program, and have a well developed and feasible project, can apply to get these bigger loans. Grantees of these loans have viable enterprises and are beyond the start-up phase. They are usually very experienced women in need big loans to continue or expand their economic activities.

\section{c. Savings and Credit Cooperatives and Networks}

Savings and credit cooperatives and networks are numerous in the country, featuring a prominent participation of women. Hence, many of these savings and credit groups are solely constituted by women and organized along labor, neighborhood and sometimes ethnic lines. Women's savings and credit cooperatives have been increasing all over the 
country, boosted by the recent boom of microcredit services. Women's savings and credit cooperatives are microfinance groups formed and arranged by women who share the same occupation or neighborhood. Savings and credit cooperatives function on the basis of their clients' savings. Each client is also a member of the institution. Once a client has substantial savings, they can then apply for credit and can increase their limits as they repay their loans in a timely manner. The amount of credit also depends on a person's collateral or assets (house, furniture, job etc.). Not all members get credit, some just save their money and are reluctant to ask for credit. The pioneer women's savings and credit cooperative is that of the peri-urban neighborhood of Grand-Yoff where field research was conducted.

The Women's Savings and Credit Cooperative of Grand-Yoff (Mutuelle d'Epargne et de Crédit des Femmes de Grand-Yoff) was created in 1987 as a small fund for the women of that neighborhood with their own savings capital and the financial contribution of ENDA GRAF Senegal, an NGO dedicated to environmental issues and that provides women with skills training. Therefore, the cooperative was a means for the women of the neighborhood to start saving their money formally and put it to work by providing loans to one another. Women residing in the poor area of Grand-Yoff belong mainly to the bottom tier of the Senegalese credit system. The cooperative's activities really picked up in 1996 with the creation of many kiosks in markets, where women could save their money daily, collect it back or get their return in groceries. The women of the neighborhood had their own savings club or tontine and were all involved in crafting (dying fabric, crochet, sewing etc.). Since 1999, the women's cooperative of Grand-Yoff has founded its own health and housing annexes, offering health services and mortgages 
to its members. This cooperative functions more as a family where everyone knows one another, rather than a bank, which is very impersonal because of the anonymity of its members.

In addition to cooperatives offering savings and credit services, there are many kinds of artisans and women's networks for the purpose of financially supporting their members' economic activities. Such a network I was able to visit and follow around Grand-Yoff was RENAFCOS (Réseau National des Femmes Commerçantes), a national network of women merchants. This network of women entrepreneurs is very powerful and comprises many segments throughout Dakar and other parts of the country. The main purpose of this particular network is to fund its female members' business activities through the pilgrimage to Mecca. Members save their money to later afford the very expensive ticket to Mecca, where they buy products (gold jewelry, fabric, clothing) to sell once they return home. An interesting fact about this network of female merchants is their connection to the government. The network's president and committee members are government advisors; this grants them many privileges that other networks or cooperatives do not have.

In interviews, the network's president was very enthusiastic about the support she and the members get from the government. During a meeting they gave in Grand-Yoff, I witnessed such praise for the Senegalese president and his government, which has granted them some humanitarian aid from many donors. Later that night, American donors came over and bought many products that members were selling. The president of the network proudly shared that this is very common and that their connections always grant them such support from international donors. A woman from a very prominent 
religious family (also connected to the government) was also a VIP, along with an advisor to the Senegalese president. Hence, based on this observation and interviews and conversations with the network's president, committee, organizers and members, we can argue that the financial success of this network of Senegalese female entrepreneurs may be tied to their connections to the government.

Though men and women are involved in savings and credit cooperatives or networks, there is a clear overrepresentation of women in these organizations. However, men's membership to microfinance institutions has been more visible in the past few years because of the dire economic situation and massive unemployment. More Senegalese

men are now joining women's credit and savings institutions. The staff of the Grand-Yoff women's savings and credit cooperative informed me that they have been getting increasing demand for credit from men in recent years. The person in charge of credit at FDEA (Femmes Développement Afrique), a women's NGO that offers microfinance services, argued that since microcredit is inclusive by nature, they cannot alienate men from their clients, but still maintain a high quota of women recipients. All over the country, we do note that women remain more engaged in creating and sustaining cooperatives or associations to support their craft.

\section{d. Microfinance Programs from International and Local Aid Organizations}

Many microcredit programs are funded and supported by development or aid organizations, whether international or local. Much emphasis is put on helping women and their groups or cooperatives. The USAID is very active in microcredit, funding or 
providing assistance to many projects and communities in Senegal. One USAID program report argues that Senegalese female entrepreneurs make sure that loans are repaid and have to be prudent because there is simply too much at stake (USAID 2007). This program called Santa Yalla (Praise God), and operating in the southern part of the country, has three branches with a president and treasurer responsible for reimbursement. Women are divided into committees where the entire committee pays back when one member does not reimburse.

Oxfam is an international NGO working in developing countries throughout the world. They adopted the "Saving for Change" program, reaching 250,000 members and operating in over 6,000 villages on 3 continents as of 2009 (Oxfam 2009). Oxfam America started its Savings for Change activities in August 2005 in Mali and brought the approach to Senegal in 2006. The Saving for Change approach is distinct from other joint-lending and commercial microcredit models, because it is savings rather than credit based (Duffy-Tumasz 2009). In the "Saving for Change" model, villagers form their group with fellow villagers without the need for formal financial institutions.

Participating women in the program are called "primary change agents." This savings method is endogenous as women only work with their own capital, saving money after the fifth meeting and starting loaning to one another after the eighth meeting. Two women are chosen in each village to train others. In an interview, an Oxfam employee in charge of the saving for change program argued that this program reaches the poorest people and is a better way to fight poverty. In their 2009 report, Oxfam argues that these loans have a great impact in households and at the village level. 
Tostan is an NGO founded in Senegal in 1991and now working in many African countries. This NGO works to empower communities in Africa in many areas including female empowerment, human rights and the environment. The organization has recently been working with Freedom from Hunger who created the "Saving for Change" program that Oxfam has made famous. Tostan has reached 350 communities by giving small grants to the "management committee" (chosen by Tostan staff) who manages the money as small loans to individuals or loans for collective projects. The average seed funding given to each community is $\$ 400$. As of January 2008, 226 loans to 7,552 beneficiaries have been supervised by Tostan with a $96 \%$ repayment rate. Women represent the highest percentage of beneficiaries; the program gives them access to savings, credit, micro insurance, training, and borrower education. Tostan further puts its female microcredit groups in contact with major MFIs in Senegal to allow two dynamic women in each group access to more capital.

Femmes Développement Afrique (FDEA) is a Senegalese NGO founded in 1987 for the advancement of women in Senegal and operating throughout the country. The NGO created a credit and savings program to further help women economically. The organization offers many types of credit including "express credit" for emergency and credit for events or ceremonies. FDEA also works with Tostan's clients to give them training and financial guidance. The credit program's manager finds that collaboration to be very successful. The organization is also working on a micro insurance project for their members. FDEA support women through all phases of their micro business implementation. The program's manager finds that the problem most Senegalese female 
entrepreneurs encounter is that they buy the same products, which creates extreme competition among them, resulting in low sales and reduced prices.

\section{Senegalese Women and Microcredit: Typology of Female Borrowers \\ a. Patterns of Savings and Credit among Senegalese Women}

Microcredit institutions and services in Senegal target women of all socioeconomic backgrounds. So, which women borrow from which institutions, and for what purpose? There is a myriad of credit activities that women in Senegal engage in for their economic ventures, but also their families' well-being. Senegalese women borrow from major MFIs such as PAMECAS, CMS, ACEP, or Microcred. Women also join savings and credit cooperatives, networks and associations. A smaller number of women have accounts in classic banks; they are usually educated and/or have a steady income. Many women are members of more than one credit institution. Microfinance institutions are financially more supple that classic banks. The latter alienate a big portion of the Senegalese population who are usually poor, illiterate, or do not have collateral to open bank accounts. Microcredit comes to the rescue, offering flexibility and adapting to financial and social needs of poor individuals. However, next to formal banking and microfinance, are strong informal finance practices.

Informal finance features savings and credit practices that do not necessarily respect a fixed financial scheme. Relations between creditor and client rely mostly on

trust. Almost all women in Senegal are members of tontines, the traditional savings and credit pools that are self-arranged among women according to family, neighborhood or 
ethnic ties, but also occupation and networks. People who engage in tontines represent $50 \%$ of the African population and $95 \%$ of West Africa (Lelart 2005). Many women also save their money by giving it to money keepers who give them the total sum at the end of the month, only keeping a small fee for themselves. These money keepers and lenders they also lend money from their deposits and are paid back with a small interest - are often found at marketplaces. Some of the study participants save some of their money with these money keepers and lenders, who are often women.

Saly explained that she values the money lender's services because she has been saving there for many years. She argues that there is an obligation to save money with the moneylender who collects it every day. Saly said: "Cooperatives and financial institutions do not pressure their clients to save money, for one simply has to go there whenever possible, contrary to the money keeper at the market. In addition, the whole MFI process of credit agents coming to my house to assess my assets makes me very uncomfortable." Money keepers and lenders can be categorized within informal finance or traditional savings and credit schemes such as tontines, but are still very salient culturally for the financial needs of Senegalese and African peoples. Informal finance can be very sophisticated and innovative because it is efficient, presents less risks, does not include transaction fees (except for the interest on the loan), and the relations between creditors and clients are very personal (Lelart 2005). Therefore, formal or classic microfinance and banking loans cannot erase these grounded financial practices. Women choose to engage in both formal and informal microfinance through savings and credit activities to guarantee their household and business survival. 


\section{b. Business Activities of Female Borrowers}

Senegalese women entrepreneurs work in many areas. They usually sell fabric, cosmetics, accessories, staples, cereals, juices, fresh and smoked fish, meats, and meals among other goods. The enterprise of acquiring microcredit loans for business purposes is not a panacea for many female micro-entrepreneurs who have to juggle household financial responsibilities and a very competitive and precarious economic market. Most successful are entrepreneurs who sell products that are needed for consumption such as cereals, vegetables, fish, meat, or drinks.

Senegalese female entrepreneurs have considerable experience selling fabric, clothes, shoes or accessories, usually for women. Many entrepreneurs travel overseas or to neighboring countries such as The Gambia or Mauritania where they can acquire products at lower tariff rates. It is the business area for $61 \%$ of the participants in the study. Common overseas destinations for commerce are Dubai, Spain, China or the United States, where women buy products to ship or bring with them back home. Entrepreneurs load cargo ships with products to be shipped to Senegal, and women often share cargos to save on the cost of freight. Not all entrepreneurs can afford to make these trips to import products in Senegal; they would buy it from their peers in Senegal once the products arrive. This is a difficult business for both male and female entrepreneurs because it is very competitive. Marthe, a participant in the study, argues: "I find it more beneficial to travel outside the country to buy goods. However, the crucial part of this business is our ability to sell all the merchandise once we return home because there is intense competition." Here, Marthe is underlining the fact that importing or selling 
imported goods remains challenging for many entrepreneurs in Senegal. Another participant, Astou, explains that her travels to The Gambia to buy fabric are always jeopardized by the fact that her clients constantly default on their payments. Therefore, she no longer travels twice a month as she used to, and as a result faces financial difficulties.

The most common hurdle for these entrepreneurs is that they sell similar products and often end up selling their inventories with great difficulty because of the excessive competition. Many of the participants complained that they were not able to sell all their products for that particular reason. Furthermore, most goods are sold at credit, and many clients default on their payment or do pay much later than the due date. Therefore, many entrepreneurs struggle to pay their loans because they do not receive all payments from their clients in a timely manner. As a result of the global financial crisis of 2008 and 2009, Senegalese consumers did not have the means to shop as they did before, because their income was spent on vital necessities such as food and health care.

Many women (usually through groups or cooperatives) sell processed products such as cereals and juices. Women's cooperatives have promoted the consumption of local cereals and juices and reduced the population's habit of consuming imported cereals and drinks. Roughly $23 \%$ of the study participants engage in this activity. Some participants in the study who belong to a cooperative named "Jooko" (Union) have been processing and selling a wide range of local cereals for more than a decade. They have acquired training in techniques of processing grains into cereals and fruits and vegetables into juices, according to National Food Institute's standards. These participants' cereal production and sale activities are very successful because they are professional and their 
products are perfectly made and safe. They rent a shop where they process their cereals and work every day of the week by splitting into groups. I followed these women for months and could witness their discipline and dedication to their work, which explains the success of their cereal business. Rose, a member of Jokko shared that she often sells cereals until midnight because people are very active at night in Grand-Yoff and she does not always have time before the evening to sell her products.

Many women (individually or through cooperatives) earn money by processing fruits and vegetables into juices. According to Diatou, who is heading a juice processing cooperative, these juices made locally have been proven by doctors to be healthier than sodas or other imported drinks, and most importantly, they promote self-employment for many entrepreneurs in Senegal, especially women. Diatou argues: "Some of the local drinks reduce high blood pressure, others are very effective against constipation. Ginger for example is very known to enhance sexual desire or potency, which explains why it is a favorite. Besides added sugar, which is optional, these juices are natural and very healthy." Natural local juices help people combat many diseases such as diabetes or high blood pressure, which are ravaging the populace in Senegal.

Entrepreneurs who make steady profit on a daily basis are those who sell products used for daily consumption such as vegetables, fish, meat, or other groceries. A great number of women invest their credit into fish, either fresh or smoked. They rise up in the early hours of the morning every day to buy fresh fish from fishermen. They sell it afterwards at the market to earn money that allows them to put food on the table every day. These images of hardworking women are constantly related by many to illustrate the bravery and entrepreneurship of Senegalese women. Anta, a participant who sells smoked 
fish at the market argues that selling fish is one of the most secure businesses because people buy it every day to cook meals. A former school teacher in her late fifties, Anta started selling smoked fish more than a decade ago when she became widowed and had to take care of her family. She had no other recourse but to earn steady money in order to support her family, choosing a business that is very uncommon for educated women, yet very fruitful. Anta also saves everyday at the neighborhood microcredit coop's kiosk conveniently located inside the market. She argues: "Most women do not understand that credit means saving. You cannot profit from a loan if you do not save money. That is why I save a small amount everyday regardless of my substantial savings. The little bit that I save amounts to a big sum after a year!” Anta is successful because she understands what entrepreneurship and credit entail, especially how crucial having savings is to her credit activities.

Many Senegalese women invest themselves in sewing and dressmaking. They either have a sewing machine at home or open a shop where they hire one or a couple of sewers, overseeing the tailoring, buying the fabric, and taking care of the clientele. Many female entrepreneurs acquire loans to buy sewing machines and open tailoring boutiques. Senegalese people get their traditional (and sometimes western) clothing sawn by local tailors. Women and men have their personal tailor (s) and get outfits made for any occasion, especially major ceremonies such as baptisms and weddings. Therefore, every block features a couple of tailoring shops. Roughly $9 \%$ of the participants engage in tailoring activities. This business activity is very competitive because the offer often surpasses the demand. Many women end up closing their shops for lack of enough clients. This business closure was the fate for Aida, one of the participants in the study. I 
was conducting observation the day she was granted her loan at the neighborhood credit coop. She explained to me that her plans were to buy a couple of machines and open a tailoring shop a block down at the market; she already had a master tailor who would work for her and supervise another tailor to be hired.

In her thirties, Aida has two small children and is provided financial support in the household by her husband. Therefore she was not facing harsh survival needs. When I first visited her at home, she told me: "I first started in sales, but it did not work, so I am now investing in tailoring. I lost all my money in a boutique that I opened because my family (relatives) exploited and scammed me. My cousin who was in charge of the store pocketed all the profit until almost all the shop's merchandise was gone." Aida went on to complain about the fact that her immediate family always turns to her for financial help, often taking advantage of her. This is very usual in Senegal where one rarely escapes such pressure from family or relatives. Aida's sewing shop opened a week after she received her loan. I made a couple of visits that week and met with her and her master tailor who was in charge of the operations and was to hire two more tailors. Things seemed to have started well. They were already getting orders and had displayed a few items in the shop's windows. Soon after, I noticed Aida was absent most of the times.

The master tailor told me that she was sick and she later explained to me that she was in the beginning of her pregnancy and could not be at the shop as often as she wanted. Time went by and Aida closed her shop about three months later. She explained that the master tailor conned her out of all the money clients paid for outfits that he never made. Since she was not able to supervise the shop often and trusted him with all the 
operations, he collected all the money and quit the job. Therefore, she had to close the shop and reimburse clients for the money stolen by the master tailor. Aida ended up suffering financial losses out of her business venture. Reasons for her ill fate are many, ranging from lack of proper management of her business (leaving her master tailor to take of all operations) and sickness due to early pregnancy, to a corrupt employee. It seemed that Aida was not invested enough in her business for it to succeed, often missing physically from her place of business. The story of her business failing had repeated itself again.

Stories of people having to close their tailoring shop as Aida are very common because it is a very tough business for micro-entrepreneurs, especially at the beginning stages of their businesses. Coumba sews traditional skirts, made out of expensive fabric and embellishments, in a kiosk at the market. She has hired a tailor who does most of the sewing while she takes care of all other operations. She shared that she was not confident to ask for more credit to buy another sewing machine because her business and financial circumstances did not guarantee she repays that loan. She told me: "Though PAMECAS is offering me more credit, I am not sure how easily I can pay it back. I bought the sewing machine I currently own with tontine money. I ask my clients to make daily deposits until half the skirts' value is paid, and pay me rest once they receive the item. However, many of my clients still owe me money and give all sorts of excuses to not repay me back." Coumba's business cannot grow as she wants because she faces the major dilemma of most business owners in Senegal, clients defaulting on their payments. She recounted many stories of how she would beg for her money or ambush her clients often in vain - in order to receive her payments. 
Unfortunate life circumstances and emergencies can jeopardize the success of many businesses. Another participant, Fatou, who sews bed sheets at home, had to halt her activities because of expensive health care bills, leaving her in a worse financial condition than the one she was in before her loan. She told me that she just finished paying her loan back, but all that money went towards her household expenses. She had to stop working because she was sick and could not afford to go to the doctor nor buy medication. Fatou explained: "My husband has totally abandoned us. He only takes care of his young third wife nowadays. The only financial help we receive from him is that he pays rent for our two rooms, and I have the burden of taking care of everything else in the household. You see, I cannot continue sewing."

Many participants have the will to start or sustain their micro businesses, but the existing financial household demands prevent them from doing so. Bousso who makes traditional incense by hundreds of bottles was facing the same obstacles. During a visit she explained: "All the credit I acquired for my incense business went towards school expenses because school started last month and I had to take care of my two children enrolled in primary and high school. Now, I am more in debt than I was before, and I do not have any other means to invest in my business, let alone pay this loan back. This always happens to me!" Bousso's predicament was a familiar one as I did hear the same complaints from other study participants during the visits made during the period school started.

Some participants work in the food industry, selling meals, sandwiches or snacks. Many women operate their restaurant businesses from home or the marketplace, setting up tables, kiosks or shops. In Senegal, goods are usually sold at credit and though it is not 
always the case for food, most clients pay restaurant bills weekly or monthly. Two participants, Victoria and Sokhna temporarily stopped selling meals because they were not paid by their customers and could not continue running their businesses. Victoria explained: "If you do not sell meals on credit, clients will go to the competition! My clients do not pay their tabs, and my children starve because I cannot cook enough for them. I have too many children and my husband is unemployed. The credit I receive cannot sustain my business and household needs." Sokhna equally complained about the difficulty to sustain her breakfast business, stating: "Today I did not sell anything because we are far into the month and people do not have money left. I have also stopped selling fruits because of that." As employees in Senegal usually get paid at the end of the month, finances become depleted towards the middle of the month.

Another woman, Oumou, who also sells breakfast out of a table set in front of her home, faces the same challenges than Victoria and Sokhna. She explained: "Because clients do not pay their bills on time, I have resorted to selling snacks at the neighboring stadium in the afternoon in addition to selling breakfast. Sometimes I return home very late at night. I have to work very hard because my husband is unemployed and hustles very hard to take care of the rent and other bills." These participants' testimonies underline the many challenges that people who work in food preparation face in Senegal, especially small and informal eateries. Therefore, restaurant businesses, except for established formal and upscale ones, are very precarious.

Female entrepreneurs in Senegal encounter problems because for the most part they do not have solid projects and/or a good understanding of what microcredit entails. Access to credit does not directly lead to entrepreneurship, for many women's micro- 
enterprises fail regardless of access to loans. According to Guérin (2007), the way microfinance is portrayed in the media relies on the myth that the poor are potential entrepreneurs; and creating an enterprise is not solely a matter of access to credit. It requires skills and qualifications, access to information and economic networks, and the existence of local markets. However, the existence of local markets is not a sine qua none for entrepreneurship, because many entrepreneurs fall prey to a precarious informal economy and excessive competition.

\section{Microcredit and Prospects for Female Entrepreneurship in Senegal \\ a. Female Entrepreneurship and the Informal Economy}

Senegalese women are overwhelmingly represented in the informal sector because most of them are illiterate or have limited formal schooling. The sample of women in the current study works in informal sector, as is the case for the majority of women in Senegal. Poverty in Senegal is characterized by large households, where the male head is often not very educated and his economic activity is not very fruitful (Gueye 1998). The majority of poor urban households belong to the informal sector of Dakar and other cities. The informal sector works best for most Senegalese people in many ways because they are able to use their skills, avoid paying taxes, and not have to rent shops or units to sell their items. The informal sector is characterized by a very broad range of activities, products, and approaches to revenue generation. Although the sector is subject to the same laws and principles of economics and markets (i.e. supply and demand) as the formal sector, it has a number of different characteristics (Roy et al. 2006). 
The Senegalese informal sector works on the basis of unrecorded activities. The dualistic nature of the economies of developing countries (formal and informal), creates in return a dualism of the financial system because economy and finance go hand in hand (Lelart 2005).

One of the essential features of the very small production and service units in the informal sector is that they are established by individuals who have little or no skills and capital. In fact, the lack of alternative wage employment has forced many, especially the poor to seek self-employment by setting-up their own small production, trade or service unit. These units, therefore, almost by definition have a capital constraint. Informal financial systems such as communitybased savings and contributory saving schemes by small groups of families or individuals, have also been playing a small but increasing important role in mobilizing and channeling resources into the informal sector (ILO 1991:35).

The informal sector of developing countries has been criticized by many scholars and economists who find it detrimental to economies. However, the study shows that it is the best environment for most workers in Senegal, especially women, who do not have all the requirements or means to strive in the formal economy. The informal sector accounts for $10.7 \%$ of the Senegalese GDP (ANSD 2004). The informal economy relies heavily on informal finance, and many microfinance services fall in that financial realm. Informal finance - featuring tontines and market money keepers lenders - relies on trust, solidarity and reciprocity. Women in Senegal, as is true for their counterparts in other developing countries, are overwhelmingly represented in the informal economy. A study of women entrepreneurs in Sudan found that Sudanese women are heavily concentrated in the informal sector, indicating that the situational factors of women within the family, have been found to force them to become involved in the informal sector, and that these factors 
are directly linked to poverty (Sid Ahmed 1998). Therefore, the informal sector represents a business rescue for women in poor countries.

The main obstacles for the informal sector in Senegal are a lack of access to credit for entrepreneurs and difficulties to sell products for $63 \%$ of workers because of excessive competition (ANSD 2004). As mentioned earlier, these are the main difficulties female entrepreneurs face in Senegal. Many microcredit experts interviewed in the study argue that entrepreneurs, especially women, need to be more creative in order to escape the intense competition they face in regards to their sales. However, women do not have enough outlets to get training that can help spark such creativity, especially when they have very limited financial means. The lack of regulation of the informal economy makes it even harder for them to be in control of their micro-businesses. Only strong entrepreneurs can strive in such a precarious economy and an offer that lately supersedes the demand due to tough financial times. Female entrepreneurs who are financially privileged, savvy business women, or who do have strong economic or political connections usually fare better economically. Furthermore, the fact that these women have easy access to enough credit for their enterprises allows them to make gain even in an unforgiving informal economy.

\section{b. Prospects for Female Entrepreneurship in Senegal}

The hope for many is that microcredit projects and loans geared towards women in developing countries help them start and run their own micro-enterprises. Most Senegalese women struggle to make ends meet and feed their families, especially now that most husbands are unemployed or have unreliable sources of income. Therefore, 
prospects for entrepreneurship are conditioned by women's household structural conditions and socio-economic environment. Many factors including women's households' conditions, education, health, access to credit, skills and training, and the economic market determine prospects for female entrepreneurship in Senegal.

The study participants complain about their loans high interest rates and the usual short repayment time. This is a major inconvenience for most borrowers in Senegal. The major emphasis placed on repayment often limits the growth of women's entrepreneurship. Seeing microcredit as a female enterprise can be limiting because it overlooks all the household dynamics in play. Furthermore, a culture of saving fuels that of credit, and though many women understand they must save in order to pay their loans and sustain their business ventures, they simply cannot have money left once they take care of their selves and families. Microcredit institutions focus on fostering high repayment rates and savings, often overlooking the many constraints women face in the household.

Women's structural household conditions determine the wellbeing of their selves and families. Prospects for female entrepreneurship in Senegal and elsewhere in the developing world have to take the household into account. There are multiple income streams flowing into households as well as social pressures from within and outside of the household that condition the outcomes of projects aiming to reduce poverty and empower women ( Duffy-Tumasz 2009). Pivotal areas such as health, education and nutrition are at the center of households' well-being. Lack of access to health care and illiteracy plague many Senegalese women (and their children) who are often struggling 
very hard on a daily basis to feed their families. Therefore, loans are spent in many cases on health emergency, schooling fees or food for the family.

When women lack power of decision in the household, their freedom in engaging into businesses can be jeopardized. Many wives have to negotiate very hard to get permission from their husbands in order to work outside of the household. Others cannot be absent from home because they have many children who need their attention and are very young. All these factors complicate the matter of microcredit and entrepreneurship. Credit does not work for all women because not all of them meet the social and economic requirements to successfully start or sustain micro businesses.

Access to credit, skills and training, and a suitable economic market and environment are necessary for women to thrive. Many women cannot meet the minimum collateral that MFIs require (though much less than classic banks) because they are destitute and hence, cannot get loans. And, government microcredit programs targeting poor women do not reach all of them. Those poor women who can get microcredit loans often lack some training and skills, and because they are usually illiterate can hardly understand the modalities of the credit granted to them. Non-governmental organizations, development and government programs do offer training (such as basic accounting) to their credit beneficiaries, especially women, unlike major MFIs who run many of their operations along the banking model, although catering to poor people. Microcredit services from development projects often offer an integrated approach whereby additional services such as education, health care, or nutrition classes are offered to help populations better strive economically and make a substantial profit from their loans. 
Hence, the survival of women's microenterprises requires more than just access to credit and decent household conditions.

The anticipated economic impacts of microcredit are often hard to measure because of the tough financial realities of households in poor countries. The social and financial weight Senegalese women and their households face inhibit the potential positive impact of microcredit, which explains the inability to save from many credit recipients (Sarr 2005). Indeed many of the study participants explain that they are unable to save money as a result of the hardships they face on a daily basis. That renders their prospects for entrepreneurship very gloomy. Participants would complain "Money just comes and goes. I can never keep it because something or someone needs to be taken care of" or "All the money has been eaten." I have often heard such statements from both male and female breadwinners during my field-work.

Many women entrepreneurs in Senegal and participants in the study are able to profit from their credit and business activities. From favorable household conditions to smart and safe business and credit practices, many women micro-entrepreneurs have become success stories.

\section{Success Stories}

The informal sector works for many women entrepreneurs in Senegal, regardless of all its hurdles. Some of the participants recorded success stories out of their business. The most potent success comes from Marie who owns an informal business making school uniforms, and generates substantial profit. She now receives big loans from the 
neighborhood microcredit cooperative due to her substantial revenues. Here, Marie relates her journey navigating the waters of entrepreneurship:

"I hope my business becomes soon a formal one. The reason why I am successful is due to the fact that my project was well thought and very feasible. In the beginnings, I asked nuns in a convent for material help. They gave me two sewing machines that I added to the ones that I already owned. I then hired two tailors and started my business sewing school uniforms. I pitched my idea to some schools who became interested in making uniforms. Slowly, but surely I started to make profit and build a client base with many schools. I require a deposit to start the work, and then deliver the uniforms once the entire bill has been paid off by the schools. Today, I have many contracts with private schools in Dakar. For microcredit to work, there is a need for feasible projects that can be very productive."

Marie's words are echoed by microcredit and microenterprise professionals as well as entrepreneurs. However, all micro-entrepreneurs do not have the same living conditions or social capital. A divorced mother of two children (one of high school age and another in primary school), Marie is a high school graduate. She previously owned a restaurant business downtown that was not successful and had to close. Therefore, with formal education, previous business experience, not having to respond to a husband, and only having two children to take care of, Marie does not face the same disadvantages of many female micro-entrepreneurs in Senegal and in the study. Marie's case outlines the required conditions to facilitate and maximize success for micro-entrepreneurs in Senegal, especially women. However, for most micro-entrepreneurs, especially women, long term business goals are not always feasible or desirable. In their study of microentrepreneurs in urban French West-Africa, Roy et al. (2006) argue that the perception of enterprise growth is a somewhat western construct and that many entrepreneurs gauge 
success simply by their basic needs and those of their household. The goal and objectives of many are directly in line with their priorities, which are to provide for their basic physiological and safety needs and those of their household. This argument sheds light on how household needs are intimately tied to micro-entrepreneurship in poor countries. Another participant, Mariama, attributes her success to the fact that she is the second of her husband's three wives. She argues that it grants her a lot of freedom to travel and invest her time in business activities. Mariama argues: "I travel to Mali and Guinée to buy fabric. I travel many months out of the year. Having co-wives is freeing for me because I only spend a couple of days a week with my husband, and the other wives take care of him when I am away. He is much older than I anyway. Once I left to spend six months in New York where I worked as a cook in an African restaurant." Mariama's testimony shows that household structural conditions are pivotal in the success of women's micro-businesses. In her case, having co-wives lightens her responsibilities and frees her from home when she needs to devote herself to her activities. Like many people in Senegal, her shop is cut of a room in her house that opens on the street, which allows her to not pay rent as she lives in her husband's home. Her shop is filled with a collection of beautiful fabric, cosmetics, and other goods. She states that she makes substantial profit from her business and is able to acquire substantial credit from Microcred, which she pays back very easily.

Two other success stories come from Diarra and Raki who sell juices, iced water, and ice from home. One of Diarra's legs has been amputated as a result of complications from diabetes. As a result she quit her part-time nursing job and has been working from home, selling juices, iced water and ice. Diarra explained to me: "My husband suggested 
I open an account at CMS. I started saving money at the MFI soon after and making juices that are stored in my refrigerator along with cold water and ice for sale. I bought another oversized refrigerator solely for my business. People around here love my drinks because they are clean and everything is sanitized. I make a lot of profit from my drink sales.” During many visits I witnessed Diarra and her help, a young girl she hired as a maid, sanitize bottles and utensils to make drinks; it was indeed very sanitary. Diarra who cannot bear walking on an artificial leg prefers to stay home, where she is able to supervise everything in the household.

Raki also makes profit from her sales of iced water and ice. She has hired two young women who sell most of it daily at taxi and bus stations, while the rest is sold from home to people in the neighborhood. According to Raki she saves more at the MFI than she takes credit because she makes steady profit from her business. She fears obtaining too much credit because she finds the interest rates too high. Like Diarra, Raki belongs to a tontine that brings in very substantial money and savings. Therefore, these two participants are savvy at diversifying their savings and credit activities and conducting businesses that bring money on a daily basis.

\section{Summary}

Prospects for female entrepreneurship in Senegal cannot be the direct result of access to microcredit, but rather depend on many factors that cannot exclude heir households' structural conditions. In addition to favorable household conditions, women - especially those poor or illiterate - need skills and training (such as basic accounting), and local markets that are suitable to their productivity and business activities. 
Furthermore, an understanding of the credit system and the economy, a culture of saving and sound business projects are necessary for Senegalese female entrepreneurs to strive economically. 


\section{Chapter V. The Impact of Microcredit Activities in the Household Introduction}

Many women in poor countries acquire microcredit loans in the hope of starting or sustaining their business activities that will allow them to improve their living conditions. Because the general rhetoric of microfinance and microcredit is intimately tied to profit from micro businesses, women's hopes of earning money through loans are hyped. As elaborated in previous chapters, the reality of microcredit or microfinance is not a panacea, but rather presents many challenges to women who embark on its often treacherous journey. Many female borrowers remain in poverty and are unable to improve their households living conditions.

This chapter explores microcredit's impact, or lack of, in the households of the study participants. First, I discuss women in the study who were able to reinvest their profit in the well-being of their selves and family members, hence making an impact in the household. Then, I focus on other women who had to invest all their loan amounts into their households' needs, thereby missing their original business prerogative. Thirdly, I explore cases where loans invested in the household did not make a significant impact. Finally, I elaborate on the few women in the study who invest their credit into their businesses and did not have to financially support their households because their husbands took care of major household expenses, thereby creating a financial ripple effect. 


\section{The Significant Impact of Microcredit on the Well-being of Female Recipients and their Household Members}

For some participants, microcredit makes a real impact on their well-being and that of their household members. In these cases, recipients are able to take care of pivotal areas of well-being in their household (i.e. nutrition, health, schooling, rent) out of the profit they make from their business activities. Women are seen as particularly important conduits of microfinance loans with an altruistic propensity to utilize income for social development, such as the schooling of children, improved household nutrition, or investment in a home (Roy 2010). Roughly $81 \%$ of the study participants do invest into their household, especially food, health care, education and rent. Most women in Senegal put the need of their children and husbands (and other extended family, especially inlaws) first. The primary concern of mothers in Senegal is to take care of their children who usually turn to them for any need they have. Masika et al. (1997) found in their study of gender and urban poverty that female headed households' expenditures are more biased towards nutrition and education than those of male headed households.

Many women neglect their health or well-being to take care of the well-being of their children. In his study of women and credit in urban Java, Lont (2002) found that wives are not much concerned with their own consumption needs, but are rather primarily concerned with providing food for their families, avoiding embarrassing scenes with screaming children and ensuring they can sustain the reciprocal payments to neighbors, friends and relatives. This observation of Indonesian women is consistent with Senegalese women as well, who acquire loans to enhance the well-being of their families, which in many cases means providing living conditions that are still precarious by many 
standards. In a focus-group I conducted with men and women residing in Grand-Yoff, the men among the group made the remark that nowadays the majority of Senegalese households financially rely on women (wives, mothers) who take care of children, provide for food, health and schooling expenses.

Members of the cereal coop Jokko also shared that they reinvest most of their earnings into the household, namely food, health, education and rent. Rose, a member of the coop works day and night making and selling cereal products from their production unit and shop, her home and the marketplace often until early morning. The impact of microcredit in the household of these coop members is significant because their earnings are regular and their products are always in demand, trusted for their quality. The women share that they would not have been able to take care of their children's needs had it not been for their work. Some even take care of their grandchildren whose parents are unemployed or cannot provide enough for them.

Raki invested the profits she made from her cold water and ice home-business into household expenses such as food, schooling, health and clothing. She explained: "I even buy my husband's clothes now that he is retired. He can only contribute a little towards household expenses. I had to get rid of the second refrigerator for my business use and only keep one refrigerator because my electricity bill was too expensive." Raki would often point out that Senegalese women nowadays are the ones taking financial care of their families, though they still respect their husband's authority as head of household. During my visits her husband would sometimes interject into conversations to inform himself about our discussions. Though his wife was the primary breadwinner, he was still the master of the household and, as is customary in Senegal, was treated as such. 
Women reinvest their earnings into the household to keep the continuity of their husbands' financial support. Hence, many Senegalese women are "backing" their husbands in becoming their households' main financial breadwinners. Thorsen (2002) argues that the women she studied in rural Burkina Faso maintain that they only help their husbands in areas that are his responsibilities (school fees and materials), hence keeping within the norms of showing respect for the husbands, although their own accounts suggest that they contribute substantially to household consumption. Therefore, the financial investments of female recipients into their households are a response to the lack of financial support from their husbands.

Anna, another participant in her fifties, lives in a big house with most of her nine children and their families. She invests financially in her household's needs including food, health care and schooling. Her older son manages the household finances as she often travels back to the village for business and social purposes. Participants who have older children or live with adults other than themselves usually rely on the help of the grown-ups in their households. This frees them to devote more time to their businesses and social life, which in turn enhances the well-being of their household members and themselves. The household impact of microcredit is often facilitated by family members, relatives or social networks that play an important role in the lives of female recipients.

Aissatou, the mother of my research participant, is a married woman in her forties. She takes care of her three children and her sister's daughter. When her husband, an ex police officer, got laid off, she moved into the house she inherited from her mother. She takes care of my assistant's private university tuition and her other two children's education. The house is very small and needs more construction and renovation, but she 
was able to fix its two rooms, bathroom and kitchen to move in with her family. Aissatou complains a lot about her family's living conditions and the state of poverty in Dakar and Senegal. Here is such an account:

"I invest in food, schooling, health, clothing and anything else that my family needs. When school starts, it is very tough for families in Senegal because we run everywhere to find money. I am thinking of asking for a loan to travel to Mali and buy fabric to sell. My relatives in the U.S. do not call anymore because of the financial crisis there. They cannot send remittances anymore. My niece whose mother is in Spain is not enrolled in school because her mother has not sent money for her schooling expenses yet. There are so many families of eight in Grand-Yoff who only rent one room and because of that issues of incest are rampant here. The government does not work for the people, they are only concerned with embezzling money. Many families only rely on microcredit and many loans are not very substantial anyway. If microcredit ceases, this country will be on fire!"

Aissatou's complaints are elaborate and insightful as they show the scope of poverty and the problematic nature of the impact of credit in households because, as helpful as microcredit can be, it is not enough to solve most well-being issues. However, Aissatou knows how to strategically acquire loans and conduct businesses that can help her take care of her family needs. Microcredit is not in itself an asset because it is also micro-debt; it only becomes an asset when women have sufficient future production for consumption smoothing or access to sufficient labor and markets to make profit from risky microenterprises (O’Laughlin 2007). Therefore any household impact of microcredit can easily be jeopardized by the labor or socio-economic conditions of loan recipients. 
Diarra also invests her business profits into the well-being of her household. She makes enough profit from her juice sales to take care of household expenses. When her leg was amputated as a result of complications from diabetes, she needed a lot of medical care and her bills were very expensive. Diarra explained: "My son was already admitted to a university in Montpellier, France, and we were so proud! Unfortunately, all the money saved for his university expenses had to be spent on my hospital bills. We were all devastated he could no longer attend that school in France. He ended up going to school here in Dakar. He is now a high school teacher." Diarra's story sheds light into the complex nature of microcredit's impact, for it is certainly a relief that it helps with most of her household needs. But that impact has its limitations because families hope and dreams - in Diarra's case, her son's hope to attend a university in France - are often jeopardized by emergencies, and eventually, the most important needs come first. Furthermore, we can argue that had Diarra's savings for her son's tuition to attend school in France not been used for her hospital bills, she would not have been able to be healthy today and take care of her family financially.

Marie, who is the most successful in her business, does not struggle to feed her family anymore. Her school uniform sewing business does well enough for her to take care of her household needs. Both her children are in private school and she has been building a house on land that she bought many years ago with credit. She hopes to move soon to her new house from the two bedroom apartment she is renting in Grand-Yoff. The impact of microcredit in Marie's life, household and business is tremendous. However, she is in the minority of female loan recipients, who even when they have 
purchased land (usually from credit institutions and cooperatives), can hardly find funds set aside from substantial business profits to help them build their houses.

The positive or negative consequences of access to credit for women can only be ascertained if the question of where these women stand within their households is taken into account (Lont 2002). Indeed, the more disenfranchised women are socially, economically and in their households, the more problematic or insignificant any impact of microcredit will be. That brings us back to scrutinizing again the impact really needed from microcredit to lift poor populations out of poverty. Is this impact just limited to food, health care and education expenses? These three pivotal household well-being areas are certainly a priority. Housing also remains a big issue in Senegal, especially for poor families who struggle to pay rent.

Many families, struggle to pay rent that is often very expensive even in the poorest parts of the capital. Credit institutions including the Grand-Yoff neighborhood coop offer housing services and many of their members have been able to acquire land or mortgages through savings and credit. Some of the study participants have taken advantage of such housing services or opportunities, and many have moved to their homes. These services from MFIs are usually more affordable or flexible than classic banks. However, housing remains very challenging for the majority of families in Grand-Yoff who rent one or a couple of rooms. This is the case for another participant, Astou, a divorcee who lives with five of her seven children in a rented roomed she split in two with a curtain. She, or her oldest daughter, cook one meal a day for lunch and save some of it for dinner. Astou struggles very hard to survive because her clients often default on their payments or pay late, rendering her business activities and profit very irregular. 
Astou pointed out: "My oldest son dropped out of high school and my youngest daughter attends a private school next door. I cannot participate in social activities because there is no money for that. It is hard for us to eat enough because times are tough, but I do my best to feed my family. I wish I could help my oldest son get a visa and buy a ticket to Europe or the U.S." Astou's story is compelling and though she invests her hard earned and unstable profits into her household, it is clear she needs more financial help. Her rent of 27,000 CFA (about $\$ 60.00$ ) a month for one room takes away from other household needs. Though she is able to provide breakfast, lunch and dinner for her children, she cannot keep up with schooling expenses for all of them. It was not surprising for me to find out that her teenage son had dropped out of school. I often found him at home with nothing to do. It seems he did not have the social and financial conditions that would favor his schooling.

For Sokhna, a married woman in her thirties who rents a room with her husband, raising her children in Grand-Yoff is not an option. She explained: "I take care of household expenses, but my three children are in the care of my mother back in the village because the cost of living is too expensive in Dakar. In the village, they have a better life because my mother takes good care of them with the money I send her. I take care of their food, schooling and health expenses." Sokhna is making the difficult choice of letting her mother in the village take care of her children while she works in the city and sends them money from the profits of her sometimes precarious breakfast sales. Her husband who is unemployed hardly brings any money home, so she remains her household's main breadwinner. Microcredit does make an impact in Sokhna's household because she had to make livelihood strategies that would allow her to provide for her 
children, notably entrusting her children's care with her mother in the village. Many women who migrate to Dakar, for work or to join their husbands, often live their children behind, sending remittances to the village. Unfortunately, many women end up investing all their micro loans into their household needs rather than investing them into their businesses.

\section{Loans Directly Invested in the Household rather than Businesses}

In 2008 , the cost of commodities in Senegal rose about $10 \%$, making households more vulnerable. According to a national survey of households in urban areas, nine out of ten households suffered from the rise in cost of commodities in 2008 (ANSD 2009). Hence, there is poor nutrition in many households where the number of meals has decreased (two or less meals a day). As a result, 69 to $90 \%$ of households have reduced their meat, dairy products and fish consumption. Another consequence of the rise in cost of commodities was that more funds went towards food, creating neglect in other areas of need for households such as health care and education (ANSD 2009). Therefore, financially taking care of their households is a tremendous challenge for many women in Senegal, especially microcredit recipients.

In some cases women invest their loans directly into the household because there are pressing demands. Victoria who is among the poorest in the study's sample takes care of her family needs. Her husband who weaves African cloth earns very irregular income. She wasn't paying rent as she, her children and husband lived with relatives. She could not continue her home-based breakfast business because her clients constantly defaulted on their bills. She took another loan that went exclusively towards household needs. The 
informal economic sector overlooks the structural factors that marginalize the poor, and informal and home-based small scale work for women reproduce gendered domestic resources (Goetz and Sen Gupta 1996). When I visited her during the period school started, she complained about many issues to me: "I do not have enough money to buy school supplies for my children. I can only enroll one of them in school for now. My neighbors often help me feed my children and provide them with school supplies."

Victoria is the next door neighbor of my research assistant who confided in me that Victoria's children are usually limited to eating steamed rice at meals, and that she and her mother, Aissatou, have to provide them food. During a visit, I found Victoria's youngest son, who is the only one enrolled in school, getting help with homework from my assistant's brother. Such cases underline the importance of social capital and social networks for poor women who often require help from relatives and neighbors for their households' survival. The precarious nature of Victoria's home-based business forced her to take another loan exclusively for household needs that she could not repay, hence ending up in even steeper debt and poverty. Microfinance organizations create and structure their services in ways that help them to gain control over their borrowers' lives. In doing so, MFIs often drive their clients, who have little room to maneuver, in even deeper poverty and insecurity (Huq 2004).

Bousso, a widowed woman in her fifties lives in her father's house and takes care of her two children in elementary and high school. She no longer takes care of her oldest son who is a university student. Like many of her counterparts, she invests money into her household for food, health, schooling, clothing and other needs. Bousso gave this account: 
"As a widow, I have to take care of myself and my children alone. All of my loan was invested into schooling expenses for my children. The pension I receive from the government is so insignificant, it can hardly take care of much. As of now, I only enrolled my little boy in school until I can pay for my daughter's high school fees. Microcredit does not work for me. It always puts me in a worst financial situation every time!"

Bousso has consistently complained about her inability to invest her loans into her incense business because of household's dire demands. Though her loans make an impact on the well-being of her household, they divert from their primary objective which is business oriented. The idea that credit can create empowerment is overly simplistic, and in many cases, the provision of credit (or debt) worsens the position of women rather than improving it (Lont 2002; Mayoux 2002). Victoria and Bousso's difficult household circumstances are an example of this. As they acquire credit and debt, their household structural conditions prevent them from investing the loans into their businesses.

Fatou, a woman in poor health is left to take care of her seven children as her husband, a retired police officer, neglected them in favor of his third wife. He only pays for their two rented rooms. Fatou struggled to feed her family and ended up investing all her loan directly into the household rather than her bed sheets sewing business. Her choice of paying for her daughter's hospital bills rather than her own demonstrates the daily dilemmas poor women (and men) face in taking care of their households. Fatou lamented the lack of support she gets from her relatives and social network. Since times are rough, most people she used to help refused to help her in return. She used to take care of many of her relatives who nowadays "refuse" to lend her a hand. Fatou appeared at times to lose hope in her social network, feeling that the reason she is abandoned by 
many is because she no longer has the middle-class status she did years ago. That highlights the importance of social capital in assessing the impact of microcredit.

The poor generally do not have conventional collateral and microfinance schemes often overlook the structural conditions of their targeted poor populations. Microfinance schemes however, often display a lack of knowledge about how the poor establish and maintain their social relations (Smets and Bahre 2004). Indeed, poor women might lack the social capital that allows them to create and secure finances. Widowed, divorced and single women, or those whose husbands are retired or unemployed, find it often impossible to acquire access to credit. If they can provide the minimal collateral that some credit institutions or cooperatives require, that only guarantees them very small loans which cannot alleviate their difficult living conditions. Many scholars such as Ananya Roy (2010) question whether "poverty capital", and specifically microfinance, will ensure financial inclusion, on fair and just terms, for the world's poor. The poorest women in the study became even more excluded from the financial system because many end up in even more debt than before acquiring loans.

The fate of many women in the study who resort to "loan swapping", paying one loan with another because they have to rely on loans to survive, is a familiar one all over the global South. Many cases of poor women trapped into the vicious cycle of microcredit debt have been reported in India and Bangladesh. For instance, the New York Times (2010) reports the case of a 38 year old female farmer in an Indian village struggling to pay back a debt of almost $\$ 2,000$ incurred through microloans of $\$ 400$. The woman explains that she took her first loan hoping to reverse several years of crop failure brought by the drought and soon ran into trouble paying back the first loan; she then took 
another loan, and another. She admits she has no idea how she will repay it. The impact of these microloans soon become null for they do contribute to the improvement of the borrowers and their families lives, and often make their living conditions worse as loans cannot be repaid. Women in the study who directly invested their loans into the household could not make much of an impact because their families' survival demands are so dire that the loans were insignificant.

\section{When Microcredit Fails to Make a Significant Impact in the Household}

For some participants microcredit did not make a significant impact in their household. This is problematic because microcredit's premise and purpose of poverty alleviation is not fulfilled. In these cases, loan recipients are in further debt without having substantially alleviated any of their issues. They are unable to extract enough (if any) profit from their business ventures to take care of their household needs, or have directly invested all their loan amounts into the household. Many end up being in worse financial conditions than they were in before acquiring loans. Microcredit can have positive effects on the poor, but in many instances its impacts seem to be insignificant or negative (Lont et al. 2004).

As explained earlier, in the case of Victoria and Fatou, they had to invest all or most of their loans into their household needs rather than their businesses. Even then, their loans did not make a significant impact in their households because the amounts were very little to solve their most demanding needs. This shows that small loans do not necessarily matter in cases of dire poverty or household emergencies. Credit does not necessarily contribute to female autonomy, or to empowerment in terms of financial self- 
sustainability and poverty alleviation (Mayoux 2002). Indeed many women can neither fulfill their household nor business needs. The enthusiasm about microcredit as a significant tool for poverty alleviation is often detached from the household realities and variables that are keys in influencing women's financial empowerment.

When women face survival issues in the household, they cannot invest their loans into their businesses. Furthermore, they become trapped in a vicious cycle of credit/debt and poverty, and are most likely to default on their loans or incur high penalties because of their late payments. That underlines the importance of social capital for poor women borrowers, notably the lack of financial support from husbands and other family members. Many women in the study have husbands who are either retired, unemployed, or work in the informal sector with unpredictable income. Fatou blamed her financial ill fortune on the fact her husband ceased to take care of her and her children when he married his third wife. When her daughter became ill, she spent all her monies on her daughter's hospital bills, while her own health and sewing business suffered.

It is very crucial in analyzing the impact of microcredit to scrutinize the cycle of debt where many women find themselves, especially when they end up borrowing from different sources and have to swap one loan for another. It is a relentless process that eventually leaves women with debt they cannot pay back, but also that jeopardizes their social relations, for many resort in the process to borrowing from their relatives or social network. When women have paid a loan back, they might have defaulted on other loans or have put their families' survival at great risk. Therefore, the impact of microcredit in the households of many poor women who lack a providing spouse or the structural conditions to earn a living, might be very insignificant. Tough the most disadvantaged 
women in the study might have paid their loans back, their households could not benefit from a significant impact of microcredit.

\section{Cases of Women who primarily Invest their Credit into their Businesses: a Financial Ripple Effect for the Household}

A few women in the study did not have the need to directly invest their business profit or loans into their households because their husbands are the main breadwinners. Instead, they invested all or most of their funds into their businesses. The fact that the women's husbands are the main financial providers, free them from financial responsibility for household expenses. In each case, the participants would selectively participate financially into household expenses, or only do so when necessary. These women take care of their own well-being and/or emergencies.

Saly and Mariama invest all or most of their loans into their business activities because their husbands provide for food, health, schooling expenses and rent. Therefore, the impact of microcredit can mostly be measured in regards to themselves, but also the well-being of their family because this creates a ripple effect. Their economic independence, as a result of making profit from their microcredit activities, lightens their households' overall financial load. Saly indicated: "I do not need to turn to my husband when I need money to take care of myself. I have to take care of my parents, siblings or relatives in need. I invest money sometimes in school expenses by buying clothing for the children when school starts. I only chip in when needed." The fact that Saly makes money does help her husband take care of his family, especially the children. Saly's testimony is very telling because most women in Senegal neglect their own well-being 
for their households. Many women, whose husbands have been providing for the household, still struggle to take care of their own needs. Therefore, they must earn money to attend to their own needs.

Another study participant, Mariama, explained: "My husband takes care of the household expenses. I only invest into the household when it is necessary. I come from Mali and the Bambara men always provide for their families. It is a matter of pride for our men.” Mariama then goes further to contrast men in Mali to Senegalese men, reflecting on the fact that Senegalese women dire economic conditions are mostly as a result of the fact that "their" husbands "refuse" to earn money by staying home and opting for an easy life. Mariama's assessments reflect her understanding of gender roles that consider husbands as breadwinners. In her case, however, in addition to having a husband who provides for household expenses, she is able to earn substantial money with her microcredit activities.

The household impact of microcredit in cases where recipients' husbands financially provide for the household is worth noting because it creates conditions for durable impacts on the well-being of household members. In these cases, women are better able to maximize profits from their micro-enterprises and can have savings set aside for future projects and emergencies. That reminds us that microcredit favors the women who are in good financial situations, for they have household conditions that allow them to profit from their loans. Duffy-Tumasz (2005) argues that microfinance is not an effective poverty alleviation tool in the Senegalese urban context she studied because microfinance has potential for exacerbating inequalities among women, in contrast to the relatively egalitarian power relations of local tontines. Indeed, the conditionality of microcredit 
loans, i.e. high interest rates and unforgiving repayment schedules, trap the poorest into a vicious cycle of poverty. Hence, women who have more social capital fare better, and the impact of microcredit in their household is more significant due to the effect of a financial trickledown.

\section{Summary}

The impact of loans given to poor women can be limited and offers many lessons. Some women in the study are able to reinvest their business profits into the nutrition, health, schooling and other needs of their households. For other female borrowers, microcredit fails to make a significant impact on the well-being of their selves and households. They often become trapped into a vicious cycle of poverty and debt because of a tremendous lack in social capital. Many women in the study share the sense that most Senegalese men can no longer be their households' financial support. It appears that there is a reversal of roles in terms of household financial support where women have the double burden of becoming their families' breadwinners and still remain their family caretakers. In the end, the presence or absence of a providing spouse and overall existence of a support network contributes to the impact of microcredit in the household of female borrowers. 


\section{Chapter VI. Microcredit and Social Capital \\ Introduction}

Microcredit borrowers rely on their relations and networks - "social capital" - to conduct their business activities and take care of their survival needs. The basic idea of social capital is that one's family, friends, and associates constitute an important asset that can be enjoyed, called upon in times of need, or leveraged for material gain. In development theory, the concept of "social capital" offers a way to bridge sociological and economic perspectives, thereby providing potentially richer and better explanations of economic perspectives (Woolcock and Narayan 2000). Microfinance models and programs have banked on the poor's support systems, especially their social networks, as is the case for women's credit groups, to ensure high repayment rates, but also reduce their administrative costs. Hence, social capital is a determining factor in the design, process and success of microcredit services both on the lender's and borrower's ends. The focus on sources of social capital for the poor, especially women, is very important in analyzing the effectiveness and impact of microcredit.

In this chapter, I first offer an overview of why and how the concept of social capital has influenced the design and delivery of microfinance models. Secondly, I explore how family and household members are a source of social capital for female microcredit borrowers in the study. Thirdly, I take a close look at the involvement of borrowers in social and business networks and associations. Finally, I discuss reasons why formal education, training, skills and business experience are a significant source of social capital for female microcredit borrowers and entrepreneurs. 


\section{Social Capital in Microfinance Models}

Social capital has been a central concept in social sciences since its creation in the 1980 's because it is at the heart of human beings' collective life. The concept of social capital has been the focus of influential scholarly writings from famous French anthropologist Pierre Bourdieu and American sociologists Robert Putnam and James Coleman. Bourdieu (1992:119) defined social capital as "the sum of resources, actual or virtual, that accrue to an individual or a group by virtue of possessing a durable network of more or less institutionalized relationships of mutual acquaintance and recognition." Policy makers have been relying on social capital theories to design development interventions towards poverty alleviation. Development and microfinance programs are sought to strengthen and develop the social capital of their target populations. In contrast to earlier basic needs or welfare approaches to poverty alleviation, the potential of social capital theory lies in its recognition of social networks and associational life as resources for fueling development from the bottom up (Rankin 2002). Microcredit or microfinance models have been specifically designed according to the idea that the poor's social networks or associations allow for the trust and reciprocity necessary to their success in acquiring and using loans.

Family members, social networks, formal education, training and business experience are great sources of social capital, for they provide microcredit borrowers the ability to succeed in their lives and business activities. Microfinance programs bank on their borrowers' social capital because it allows them to minimize their operation costs, especially in group lending where they put the responsibility and pressure of loan repayment on the groups of borrowers who must not default on their payments for fear of 
not being able to get further loans. Mainstream development agencies such as the World Bank and the CGAP (Consultative Group to assist the Poor), the populist Grameen Bank and many microfinance institutions have designed models through which the poor receive credit on the basis of their membership in self-regulating solidarity groups. According to Mayoux:

The existence of social capital in the form of indigenous networks and norms of association is seen as substituting for financial collateral in the selection of loan beneficiaries and loan disbursal and recovery. It is also seen as enabling the targeting of poor women in view of their limited access to resources (and also, often implicitly, their inherently co-operative nature). This decreases both costs and risk, thereby enabling rapid expansion for large scale poverty-targeted delivery. These prescriptions are informed by the experience of large-scale microfinance provision by programmes like Grameen Bank in Bangladesh (2001: 438).

In group lending, each member feels the urge, and pressure from all members of the group, to repay, for the fate of the group relies on her or him. Hence, notions of "solidarity" and "trust" are the heart of social capital when it comes to group-based microcredit. However, many scholars have been questioning this enthusiasm about social capital and in particular notions of solidarity, trust and reciprocity as key to financial sustainability, poverty alleviation and women's empowerment.

Microcredit programs (à la Grameen Bank) are aimed at strengthening social capital and contribute to female empowerment. However, sources of social capital for female borrowers can be treacherous. Policies by the World Bank and the United Nations, as well as some studies on urban poverty assume that people form harmonious communities within a free market society, and thus fail to acknowledge the potential for conflict 
(Bahre 2007). Family units (including extended family members) and social networks are not always harmonious, and present female borrowers with a lot of hurdles. For example, many of the study's participants do not have spousal financial support, and often struggle with power of decision. That can tremendously jeopardize their loan use as they might not be able to invest it into their business because of household needs or lack of control over their loans. Spousal relations are a key component in the analysis of microcredit as it relates to women and the household. Furthermore, extended family members such as inlaws that reside with female borrowers also play a pivotal role because they are part of the household decision making. Many of the participants in the study are very mindful of their in-laws, especially mother in-laws, that often have a say in their marriages from the support they get from their husbands to how they raise their children.

Social networks can also reproduce social inequalities among women, leaving the most disenfranchised on their own. The mere formation of solidarity groups does not guarantee progressive outcomes and may in fact perpetuate existing social hierarchies (Rankin 2002). Romanticized views of social capital in the development and microfinance literature as they pertain to women mask the realities of poor women across the globe struggling daily to pay their loan back, often at the risk of losing their social ties. Some scholars have questioned the underlying assumption of micro-credit programs that the material benefits borrowers receive in the form of access to credit are an acceptable exchange for their contributions in the form of social capital and interest rates; instead many programs deplete the social capital of borrowers (Tata and Prasad 2010). Many borrowers become estranged from relatives and friends after borrowing money from them, often to repay their loans, and not being able to pay them back. Therefore, 
microcredit might indeed harm the social capital of borrowers who feel the pressure to repay their loans.

\section{At the Household Level}

We can argue that the first and most basic source of social support or capital is the family unit. In Senegal, most households are complex in nature, including both nuclear and extended family members. Household members play an essential role in the lives of female microcredit borrowers and are a source of support in their daily activities. Spousal support is an important source of social capital for married people, especially women who need their husband's support with finances and decision making in the household. Roughly $70 \%$ of the study's total population of women (and $74 \%$ of the closely studied participants) are married, while the remaining are divorced or widowed. The average number of children per women is 6 . Therefore, in these women's households there are quite a few mouths to feed, when one adds their husbands and/or extended family members who might live with them.

As discussed earlier, most women in the study $(80 \%)$ are financially supporting their households. Most participants' husbands are retired, unemployed or have very irregular income. Only a few husbands earn a steady income that allows them to be their households' breadwinners. Among the participants in the study, $87 \%$ are financially responsible for their households' nutrition, while $74 \%$ pay for children's schooling expenses and $70 \%$ pay for health visits, treatments and medicines. That leaves these women in the same predicament as their divorced or widowed counterparts who are left to fend for themselves and their households. Many husbands do participate financially, 
however the daily allowance, dépense quotidienne, they provide their wives is hardly enough to cover for food, let alone all other needs such as doctors' visits, medicines, school expenses or transportation. As Aissatou noted: “No man's dépense is enough nowadays. As wives, we always have to find ways to supplement it.”

Spousal support is not only limited to finances, but also matters in terms of decision power and negotiation leverage for women in their households. Many women have to ask their husbands' permission to acquire loans or engage in business activities. Others hide their loans from their husbands for fear that they would take control of it. In their study of women and credit in rural Bangladesh, Goetz and Gupta (1996) found that husbands actually control their wives credit's investment and income generated from it. Therefore, female borrowers might not receive the spousal support they need and find that their married life and responsibilities may interfere with their acquisition of loans and business aspirations. That brings to light the idea that social capital does not necessarily contribute to female borrowers' entrepreneurial success or empowerment.

Senegalese women culturally 'stand behind their husbands' and would often share their loans with them. Some of the participants mentioned that they care about their husbands' masculinity and do not want them to feel worthless because they cannot provide for the household. Therefore, many women back their husbands financially so that they can retain their symbolic power as providers. These are negotiations tactics that allow women favors and consideration from their husbands and improve their spousal relations. In their study of women and microfinance in the rural Senegalese town of Gossas, Kah et al. (2005) found that women help their husbands financially because it lifts their voice in the household and their husbands listen to them more often. According 
to the authors, when income earning wives in the community pay for school fees and medicines for their children, what are usually husbands' responsibilities, their standing within the family changes greatly as they enjoy greater freedom and influence. Here, microcredit increases the social capital of female borrowers when they reinvest their business profits into the household and help their husbands financially.

In most of the development and microfinance literature there are shortcomings in the discussions of social capital within the household from a gender perspective. The ideal household is generally treated as the basic unit of impact assessment, and assumptions are made about mutual rights and responsibilities in, for example, collateral requirements under which women must get their husband's signature in order to acquire a loan (Mayoux 2001). Intra-household relations in Senegal make women vulnerable to their husbands and often times in-laws. Gender inequalities in access to power and resources characterize many Senegalese households, whether they are nuclear or comprise extended family members. Most women in the study do not encounter resistance from their husbands in their decision to acquire loans, but a few report that they must hide it from their spouses for fear that the latter would ask for it.

Acquiring loans requires tact and discretion because one does not want to make it public at the risk of having spouses, relatives or friends borrow money or ask for financial help. Women's ability to use savings and credit can be limited by vertical relations within households and kin groups. Furthermore, husbands do not often trust that their wives are smart or savvy enough to engage in microcredit activities that can result in substantial profits; many fear that their wives would not be able to pay their loans back, which would put their families in deeper predicaments. While women are also afraid of 
defaulting on their loans, they feel the pressure and obligation to earn money in the absence of a non-providing husband.

Married participants in the study whose husbands financially provide for the household are freed to invest their loans into their business. For these women in the minority, spousal financial support is a great source of social capital because it avoids them having to invest their loans or revenues from them into their household demands. However, these women mentioned that they still have responsibilities towards their children and extended family. For instance, many are financially responsible for their aging parents and some siblings. Furthermore, they might have to occasionally supplement the household allowance provided by their husbands. Most importantly, they do have enough collateral or social capital at the household and financial level, to be able to maximize their chances at succeeding in their microcredit activities.

Older children and extended family members are also a source of support for female borrowers who need assistance with household chores in order to attend to their business activities. The teenage or adult daughters or relatives of the women in the study help them with cooking, cleaning and child care. Rose's teenage daughter is the one who takes care of household chores, as her time is spent between making cereals at their coop's shop and selling them at the marketplace. Therefore, Rose who is a widowed woman in her late forties, can attend to her business activities with the help of her teenage daughter. Polygamy also enhances the social capital of many women who share their household's responsibilities with their co-wives. For instance, Khady, Diarra and Mariama all benefit from the fact that not living with their co-wives frees them from attending to their 
husbands' needs everyday of the week. In these cases, polygamy empowers women and contributes to their personal, social and financial autonomy.

Some participants do not have to pay rent because they live in other family members' houses. Victoria, one of the poorest women in the study, lives for free in her relatives' house with her children and husband. Bousso and her children live in the house she inherited from her father along with her siblings and their family, while Aissatou moved into the house she inherited from her late mother with her husband, two children, niece and nephew. For these women, not having to pay rent provides them with financial and social support. Their fate is certainly different from that of Astou who struggles to pay her monthly rent for the one room, split in two, where she lives with her five children.

\section{Social, Credit, and Business Networks}

People connect through a series of networks where they tend to share common values with other members. To the extent that these networks constitute a resource, they may be seen as forming a kind of capital. Membership of networks and a set of shared values are at the heart of the concept of social capital (Field 2008). Belonging to social groups or organizations is an important source of social capital for female borrowers who join networks of savings and credit or business, which contributes to their entrepreneurial success. Most participants in the study belong to the neighborhood's women's savings and credit institution (Mutuelle D'Epargne et de Crédit des Femmmes de Grand-Yoff) where they save money individually and collectively and acquire loans and mortgage as well. The structure of group-based micro-credit programs can provide opportunities for micro-business owners to increase entrepreneurial networking and social capital which, 
in turn, can influence business performance (Tata and Prasad 2010). Many women in the study also belong to trade networks or groups such as the women's cereal coop, Jokko, where about a dozen women process cereal into finished products that they sell collectively out of their processing shop and individually. Another women's association in Grand-Yoff is that of Renafcos, a national network of female merchants. We must not neglect the traditional and predominantly female self-selected saving schemes, tontines.

Tontines remain very important social and financial networks for women because they are self-selected savings groups and provide them with an opportunity to reinvest their money into important household and business needs. Tontine members contribute regular amounts with each member taking turns to receive the contribution of the whole group, thus getting access to a lump sum from a series of small contributions. However, tontines are not always as reliable as microcredit loans because there is no guarantee that all members will necessarily make their scheduled deposits, or that they will make it on time. Furthermore, politics are often involved whereby the tontine leader might have favorites among the members. As such, many members do not always get their money on time or as promised.

A shortcoming of much of the literature on microfinance and women's empowerment is the idealization of 'community' seen as a prime source of social capital, focusing on harmonious horizontal relations between women (Mayoux 2001). Stories of people in charge of tontines embezzling their members' money are multiple, making it harder to join or trust tontines. Many participants in the study no longer trust tontines and exclusively save their money with MFIs, what consequently might grant them a better credit history with the institution and more chances to acquire bigger loans. The conflicts 
experienced within tontine networks are an example of the erosion of trust and reciprocity among women, putting to question the romantic notion that associations of women always feature tacit or enduring trust and solidarity. Bahre (2007: 52) argues: "Solidarity is not opposed to conflict, nor does conflict necessarily take place outside of the realm of solidarity. Instead rivalry, conflict, jealousy, and aggression can be at the heart of solidarity networks." The lack of reliability of tontines, forcing many women to blindly turn towards MFIs, puts them at the risk of jeopardizing their financial future because of high interest rates and unforgiving repayment schedules.

Many women belong to cooperatives where they save their money in order to fund their business ventures. Cooperatives in Senegal are dominated by women who take up activities that usually follow gender divisions of labor. Female members of these cooperatives share the same craft, i.e. tailoring, knitting, weaving, food processing, restoration and commerce among other business activities. As most forms of networks, cooperatives are a great source of social capital for women because they provide their members with financial security, connections and often training and skills. However, social and business networks and groups require a lot of work for their members to sustain all the benefits they provide. Connections require work, and solidarity within networks is only possible because membership gives rise to profits, both material and symbolic (Bourdieu 1980). For instance the cereal coop Jokko had merged in its beginnings with another coop, Ndamlee, processing fruits and vegetables into juices. However, Ndamlee has never been as successful as Jokko, but rather is an example of a failing business. 
In an interview, Diatou, Ndamlee's president said: "One must be very patient and dynamic to remain in a coop. Many members neglect the work because they give priority to their personnel activities. Sometimes I have to pay our processing shop's rent by myself or with other members who are more committed to the work. We still haven't paid rent for this month.” During the interview, a member of the coop passed by in a hurry and Diatou stopped her to remind her that her services were needed. The member reassured Diatou that she would come later and hurried back. But, Diatou did not seem convinced. As she mentioned, many members are not as dedicated to the coop's work as they should be. That showed the amount of work and stress that coops' leaders go through in order to get the members to commit to the work. It is not surprising that this coop is not as successful as Jokko. They decided to split from Jokko because they could not work together anymore and found it better to be autonomous from each other. Members of Jokko hinted that Ndamlee's lack of success is due to the fact that its members are not "serious" workers and that their president is not open and dynamic enough to lead the coop.

Jokko and Ndamlee are, respectively, examples of a successful and a failing cooperative. One important point to note is that members of the failing coop Ndamlee live in a middle class area and in a housing community for military officers. Hence, these women are all wives of government employees and do not face the same realities of the members of cereal coop Jokko in Grand-Yoff. These two cooperatives have both received credit and training from the Grand-Yoff's women's savings and credit institution and continue to be involved in group-based credit programs. Ironically, the women members of Jokko are the ones who have been able to make their business thrive and are able to 
provide for their families on their own. The success of the Grand-Yoff's coop shows that microcredit can indeed create conditions for the acquisition and increase of social capital through associations. Furthermore, social capital plays an interesting role here by highlighting the fact that the middle-class coop members already have enough safety net to not be dedicated enough to their work, while the coop members residing in Grand-Yoff have to work hard to create and maintain the conditions that guarantees their financial success. However, middle and upper-class female members of social and business networks are better suited to succeed in their microcredit and entrepreneurial pursuits because they have more social and financial collateral and support. Therefore, microcredit can indeed reproduce inequalities among women, leaving the poorest to remain disenfranchised.

Social and business networks are at the core of associational life for female entrepreneurs in Senegal. The members of a national network of female merchants, Renafcos, know too well the benefits that their association provides them. Because of the political ties of their president, a government advisor, and women in their committee, they are given privileges that other female networks and groups do not have. As patronage is a reality in Senegalese politics, people tied to the government usually acquire favors that others normally would not. As mentioned earlier, this network benefits from very significant amounts of credit and donations (from foreign donors) among other favors. These favors are far beyond those of the neighborhood cooperative or other women groups in Grand-Yoff. This highlights the fact that individuals and groups of people are able to acquire unequal amounts of social capital according to their socio-cultural, political or financial leverage. In that regard, Bourdieu (1980:2) argues 
that the notion of social capital was the sole means of describing the principle of the social assets which was visible where different individuals obtain a very unequal return on a more or less equivalent capital (economic or cultural) according to the extent to which they are able to mobilize by proxy the capital of a group (family, select clubs etc.). Therefore, the connections women groups possess, in terms of credit and business, influence their clout and consequently their social capital.

\section{Formal Education, Training, Skills and Business Experience}

Formal education is a very important asset, especially for women in developing countries, who are the most disadvantaged in that regard. Acquiring formal education, a high school degree and university degrees opens the door to formal jobs. Hence, formal education is a major source of social capital. Many poor women in poor countries, and Senegal in particular, are illiterate and that in itself alienates them from entering the formal economic sector or acquiring loans from classic banks. Training, skills and business experience are also important sources of social capital for women entrepreneurs. Roughly $35 \%$ of the women in the total study population are illiterate, while $36 \%$ have only acquired a primary school education and $26 \%$ have acquired a high school education, with only $3 \%$ obtaining a high school degree. We must note that a minority $(13.5 \%)$ of these participants have acquired training and skills towards their business activities. The fact that only a quarter of the study population have obtained some highschool education and less than 5\% a high-school degree explains that this sample belongs to the informal sector, and covets microcredit loans for their household and business survival. 
Illiterate women or those with little formal education find it hard to understand the financial conditionality and delivery process of microcredit. No woman in the sample of 23 closely studied cases has obtained their high school degree, however $35 \%$ have acquired some secondary school education. These women are the ones who are usually the most successful or savvy in their businesses because their level of literacy is potent enough for them to acquire basic understandings of the financial facts and implications of loans. Marie, the most successful participant, has almost completed her high-school education and acquired secretary and accounting training. Before embarking on her school uniform sewing business, she previously owned a restaurant business downtown that ultimately closed doors. Therefore, Marie has most required conditions to ensure her business success: formal education, training and business experience. These contribute greatly to Marie's social capital as a woman, especially since she is divorced with two daughters, and an entrepreneur.

Another participant, Khady, who runs her husband's dry-cleaning business, is betteroff than most women in the sample because she has acquired high-school formal education along with secretary training and teacher's experience. She is able to manage her family dry-cleaning business thanks to her education. Her husband mostly lives with his second wife in a suburb of Dakar, where he owns a livestock farming business. Khady is financially independent from her husband and takes care of her household with her profits from their dry-cleaning business. Polygamy allows women who have co-wives, to maintain different economic spheres among themselves. Diarra is equally successful with her home-based juices and ice business thanks to her high-school education, along with secretary and nursing job experience. An amputated leg does not prevent her from 
running her business. Her education, training and professional experience have allowed her create and run a successful business from home. Formal education, training, skills, professional or business experience are each important variables in the success of women entrepreneurs.

The irony with the conceptualization and design of microfinance services is that they are catered to poor women, who often hardly have the required social capital to strive in their micro-businesses. Business experience, training and skills are helpful to illiterate women or those with less formal education. The study found that most microfinance institutions do not offer the training and skills workshops - especially financial guidance usually included in the programs of many development organizations and women cooperatives. Training and skills workshops range from basic accounting skills to professional training and skills learning. The study participants who are members of the Jokko and Ndamlee coops have received intensive training from the neighborhood women's savings and credit coop that offers its members training and skills workshops through the NGO Enda Graf that it shares locals with. These coop members have received training in food processing and accounting, and attend periodic follow up meetings with trainers at the women's savings and credit institution.

Many study participants complain that they lack financial guidance in their microcredit activities along with training and skills. These services are always available to women borrowers and often make the difference in their business success. Many women join coops in order to receive training and skills, but also a financial backup by virtue of members' savings and credit. Hence, the social capital of borrowers who belong to coops, networks and other groups can be more significant than individual borrowers. 


\section{Summary}

Female microcredit borrowers rely on their associational life and social networks to succeed in their lives and businesses. Household members, kin groups, communities, social and business networks, formal education, training, professional and business experience are all important sources of social capital for female borrowers. Sources of social capital for the participants in the study can be dependable and enriching, but in many cases reveal themselves to be treacherous, jeopardizing the survival of their households and businesses. Support from husbands and household members can provide women with the personal and financial support they need to strive in their businesses. On the other hand, many women's credit and business involvement are limited by their husbands' lack of support or cooperation, or other dire household conditions. Social, credit and business networks and groups provide women with credit and entrepreneurship opportunities, but also have the potential for conflict and lack of trust and solidarity. Finally, female borrowers who have acquired some - preferably substantial - formal education, training, professional or business experience strive better at their credit activities and entrepreneurship. 


\section{CONCLUSION}

Microcredit offers Senegalese women, especially the poorest, an opportunity to financially take care of their household needs and create or sustain their microbusinesses. My study analyzed the impact of microcredit on the well-being of Senegalese female recipients and their household members, notably in the areas of nutrition, health, and education. The study has shown that microcredit is not always the panacea it is often portrayed as in the media and development and scholarly literature. For most of the study participants who are women faced with difficult living conditions, acquiring loans does not always have a happy ending. In most recent years, many studies, especially those focused on the South-Asian context (India, Indonesia), are questioning the "promise" of microcredit and exposing its negative financial and social consequences. Microcredit has become a response to the failure of the Senegalese welfare state in providing enough and adequate basic social services for households, such as education and health care.

\section{Household Impact of Microcredit on Nutrition, Education, and Health and}

\section{Drawbacks}

The majority (81\%) of the participants in the study invest their credit or revenues from it into their household because of the absence of a providing spouse. Many participants' husbands are retired, unemployed, or earning irregular income. Hence, many married women in the study have to financially support their families just as their widowed and divorced counterparts. But, the impact this microcredit investment makes is not always a significant one. The majority of the women in the study are engaged in business activities that are not always as fruitful as they wish. Many participants who sell goods suffer from clients defaulting on their payments, what prevents them from making 
steady earnings and paying their loans back easily or on time. These women struggle very hard to make ends meet and financially provide for their families. This shows that the socio-economic and household structural conditions of female loan recipients strongly influence the impact of microcredit.

Many of the participants are faced with harsh survival needs that often compete with one another, forcing them to give priority to the direst needs or emergencies. In some cases, women in the study cannot afford to enroll some of their children in school because funds need to cover for food or medical care. Hence, the economic conditions of female recipients strongly determine the impact of microcredit on their household wellbeing. The poorest women in the study were not always able to invest their credit into their businesses, often using all their loan amounts to take care of their households, especially their children. Here, microcredit fails to fulfill its promise because women are not empowered to earn money with their loans, but rather spend it all into the household, becoming trapped into further debt and poverty. This questions the idea that entrepreneurship is the central tenet or function of microfinance because many women, especially the poorest, end up using their loans towards their household, rather than their micro-businesses. Furthermore, many participants in the study, especially the poorest, cannot acquire enough credit to make a significant impact on their well-being and that of their household members. Therefore, the amount of loans matters in assessing the household impact of microcredit.

Taking care of the education, health and nutrition of their household (especially children) is crucial to the women in study. This correlates with the many findings in the literature on gender and development, and microcredit that show that women financially 
invest into the well-being of their children and household, especially food, health and education for their children. As the study shows often times participants have to put the direst needs of the household first, and those needs are usually short-term. Therefore, putting food on the table can prevent the female recipients, temporarily or permanently, from enrolling all their children in school or taking care of all health needs. This puts forth the question of how durable the household impact of microcredit is. If providing for food or paying for hospital bills prevent microcredit recipients from enrolling their children in school, then we can argue that specific impact - though vital - is short-term as outcomes of education are more lasting. Hence, the impact of microcredit for the poorest recipients might just be temporary because the most pressing needs are usually of a shortterm nature. On the other hand those female recipients that are more successful can enhance the well-being of their household by taking care of long-term needs.

\section{Social Capital and its Impact on Microcredit}

The study shows that a providing spouse, formal education, training, business experience, and belonging to social and business networks facilitate women's success in their microcredit and entrepreneurial activities. For the minority of women in the study whose husbands are their household breadwinners, microcredit makes a real impact on the well-being of their selves and their household members. These women are able to improve the well-being of their families by taking care of additional needs. Formal education is a very important asset for female borrowers because it helps them understand the financial conditions and ramifications of their loans. The women in the study who have acquired some high school education fared much better in their credit and business operations than their uneducated counterparts. The participants who belong to 
cooperatives that make profits from their production and sales are able to earn a steady living and take care of the health, education and nutrition of their households. Therefore, one of the most important conclusions of the study is that the household impact of microcredit is intimately tied to the borrowers' household conditions and social capital.

Many women in Senegal give priority to ceremonies where they have to make a financial commitment, whether or not their finances can handle it. Some may consider these to be irresponsible decisions from women who cannot financially handle participating in ceremonies, but for many Senegalese women and participants in the study, forgoing their financial participation and responsibilities in ceremonies is a social and cultural risk they cannot take that would compromise their social and symbolic capitals. Therefore, priorities in the lives of female recipients are diverse, and not limited to pivotal survival needs such as food, education or health care for the household.

\section{Conditionality and Delivery Process of Microcredit}

Ironically, and in contrast to its premise and promise, microcredit is usually delivered in a standard fashion that makes it difficult for the poorest women to take advantage of it. The Financial conditionality and delivery process of microcredit are very problematic and often trap women in a cycle of poverty and debt. The majority of the participants complain about the high interest rates of loans, the short repayment time, and many penalties they incur once making late payments. Furthermore, many loan recipients in Senegal, as is the case in most developing countries, default on their loans because of dire economic realities. To avoid defaulting on their loans, recipients borrow from more than one institution and become victims of "loan swapping," paying one loan with another. Hence, borrowers end up owing money to more than one microcredit institution, 
neighbors, relatives or friends. This erodes their social capital and jeopardizes their social relations.

Microcredit loans seem to have taken over the traditional microfinance selfinduced schemes, tontines, because they are formal and often more reliable. However, tontines have retained their social and financial salience because many women who become disillusioned with microcredit revert back to them. Furthermore, female borrowers remain engaged in both informal and formal microfinance to guarantee their financial longevity. Mixing different methods or sources of microfinance proves to be efficient for some of the study participants. The study also shows that savings are beneficial to borrowers' activities, and often a prerequisite to acquiring and managing credit. Membership in cooperatives or business and credit groups (most of which are women's) is granted after saving a required amount of money, which will boost members' economic activity and encourage saving habits among them.

The findings in this study confirm that the conceptualization and delivery of microcredit cannot be severed from their targeted populations' daily realities. Microcredit fails to result in female empowerment if the household and socio-economic conditions of female recipients are not favorable to their success. The literature on microfinance and gender and development is often very enthusiastic about microcredit's potential for female empowerment. However, the study finds that microcredit inherently has a potential for positively and negatively impacting the lives of female borrowers. Therefore, this research contributes to development and gender studies by showing the adverse effects of microcredit on the lives of female recipients and their households. This 
contribution is an important one, for it warns us that the "promise" of microcredit is not systematically nor easily delivered.

The study further dispels the myth that high repayment rates mean success or empowerment for female recipients. Many female borrowers acquire more loans by borrowing from more than one institution or their social relations, hence hurting their social ties and social capital. These borrowers - as is the case for many study participants - often fail to sustain their business activities or support their households because they become trapped into a vicious cycle of debt. Hence, high repayment rates do not necessarily mean success, but rather mask the detrimental unintended consequences of microcredit loans. As a result, microcredit can reinforce inequalities and poverty, as the poorest of the poor it seeks to help might not have the required structural conditions to take advantage of it.

\section{Female Entrepreneurship in Senegal}

The study draws attention to the fact that the Senegalese informal sector is the niche for most women entrepreneurs because of their socio-economic disadvantage, their high levels of illiteracy, and lack of access to many markets. As microcredit services and strategies try to fill the gap in terms of women's access to credit, female entrepreneurs still remain primarily represented in the informal sector because of their structural limitations. Therefore, female borrowers need access to bigger and more important economic markets in order to strive in their entrepreneurship. As noted in the research, the extreme competition among saleswomen, because they usually sell the same items, makes it very hard for them to make substantial profits from their microcredit activities. We must note that the trend of female cooperatives that process and produce local goods 
is making an economic impact by starting a dynamic and promising local industry.

Hence, micro-lending to Senegalese has great potential of boosting the national economy through female cooperatives' production and sales.

\section{Economic Freedom for Women and Spousal Relations}

The study shows that women's economic freedom does not necessarily lead to equal status in marriage. Most women in the study do not feel the need to question their husbands' symbolic power. That contrasts with many theories in the feminist and gender and development literature that argue for women's need to be equals with their husbands as a result of economic empowerment. What matters to most of the participants is that they may have their own funds, and hence be able to positively impact their household's well-being. In turn this may result to more social capital. Economic empowerment provides women with "something of their own:" a private fund. Women do not see this as coming in contradiction with the fact that their husbands remain "heads of household."

Many participants do not share the details and amount of their loans with their husbands or close relatives because they are afraid to jeopardize their financial security. This was found to be true in other societies, such as among Guatemalan women, where this phenomenon is referred as "parallel economies," where women have funds household funds are considered to be separate from their husbands (Ehlers 2000). The meaning of these loans for women goes far beyond the practical needs of the household. They are a source of self-worth, pride and dignity for them. Hence, microcredit loans provide women with a "space" of their own, where they can manage their money on their own terms. However, in cases where the husbands of female recipients control their wives' loans, acquiring credit can lose its purpose and resonance for women. Therefore, 
instead of leading to female empowerment, acquiring credit can reproduce existing inequalities in the household.

\section{Recommendations}

The most responsive microcredit models in Senegal are those of development organs, (mainly NGOs), women's cooperatives and groups because they adopt integrated approaches, thereby addressing women's needs in conjunction with micro-lending. NGOs and cooperatives usually offer training, skills and basic accounting or numeracy workshops, financial guidance, healthcare plans, or health and literacy workshops to their clients. Many participants who are members of the Grand-Yoff women's savings and credit institution have received training and guidance pertaining to their business and credit operations. These integrated models are efficient alternatives to traditional models of microcredit, usually applied by MFIs and banks.

For microcredit to be a sustainable development strategy for Senegalese women, it is recommended that credit institutions offer their clients, especially women, other basic services that are pivotal to their well-being and entrepreneurial success. In addition, microcredit services and programs will be better suited to their clientele by lowering their interest rates, reducing their penalties and fees, and offering repayment schedules that are more flexible. The development shift from passive assistance for women and families to microcredit strategies needs to retain the provision of basic services needed for the survival of households. For that reason integrated development approaches are wise strategies because they guarantee the sustainability of development interventions, for one cannot "just simply give - or lend - money to the poor." 
A municipal advisor at Grand-Yoff city-hall was correct in coining Grand-Yoff "the mirror of Senegal" because of its ethnic diversity, but also the fact that it displays most of the ills in the country. In that regard, peri-urban areas in Senegal, and most developing countries, provide great insights into the lives of the poor. Hence, there is a need for a paradigm shift in development studies and programs to put more attention on the realities of the urban poor who might be as disadvantaged as rural ones. If there are more infrastructures in urban areas of developing countries compared to rural parts, it still remains that the urban poor has to struggle for access to basic services.

Findings in this study can be correlated to the realities of women in other poor, urban and peri-urban areas of Africa and the developing world. Lessons learned from Senegalese women and their involvement with microcredit shed some light into the livelihood and survival strategies of poor African women, and the sustainability of microcredit as a tool for poverty alleviation. 


\section{BIBLIOGRAPHY}

Allemand, Sylvain, ed.

2007 La Microfinance n’Est plus Une Utopie! Paris: Editions Autrement.

Achuwilor, John Setuni

2002 Household Economy in Ghana. In Household Economies in West Africa:

Geopolitics and Conflicts. Les Economies Domestiques en Afrique de 1'Ouest:

Géopolitiques et Conflits. Abdou Salam Fall and Omar Saip Sy, eds. Pp 1-36.

Dakar: CODESRIA/OXFAM.

Bahre, Erik

2007 Reluctant Solidarity: Death, Urban Poverty and Neighbourly Assistance in South Africa. Ethnography 8(33):33-59.

Berthelemy, Jean-Claude, with Abdoulaye Seck and Ann Vour'ch 1996 Growth in Senegal: a Lost Opportunity? Paris: OECD.

Bourdieu, Pierre

1980 Le Capital Social: Notes Provisoires. Actes de la Recherche en Sciences Sociales.

Bourdieu, Pierre and Wacquant L.

1992 An Invitation to Reflexive Sociology. Chicago: University of Chicago Press.

Cassar, Alessandra, with Luke Crowley and Bruce Wydick

2007 The Effect of Social Capital on Group Loan Repayment: Evidence from Field

Experiments. The Economic Journal 117(517).

Collins, Daryl, with Jonathan Morduch, Stuart Rutherford and Orlanda Ruthven 2009 Portfolios of the Poor: How the World's Poor live on \$2 a Day. Princeton:

Princeton University Press.

Cornwall, Andrea, with Elizabeth Harrison and Ann Whitehead

2007 Gender Myths and Feminist Fables: The Struggle for Interpretive Power in Gender and Development. Development and Change 38(1):1-20.

Cornwall, Andrea

2007 Myths to Live by? Female Solidarity and Female Autonomy Reconsidered.

Development and Change 38(1):149-168.

Creevey, Lucy E.

2006 Supporting Small-scale Enterprises for Women Farmers in the Sahel. Journal of International Development 3(3):355-386. 
Cissé, Babacar

2008 Le crédit Mutuel du Sénégal, un Exemple de Réussite Institutionnelle.

Microfinance et Développement.

De Haan, Leo, and Annelies Zoomers

2006 How to Research the Changing Outlines of African Livelihoods. Africa

Development: XXXI(4).

Djefal, Sabrina

2007 La Microfinance entre le Marché et la Solidarité. Paris: CPI.

Duffy-Tumasz, Amelia

2005 Credit and Co-Wives: Exploring Empowerment in Senegal. CUREJ :1-40.

Duffy-Tumasz, Amelia

2009 Paying back comes First : why Repayment means More than Business in Rural Senegal. Gender and Development 17(2):243-254.

Ehlers, Tracy Bachrach

2000 Silent Looms: Women and Production in a Guatemalan Town. Austin: University of Texas Press.

Fall, Abdou Salam, and Omar Saip Sy, eds. 2002 Household Economies in West Africa: Geopolitics and Conflicts. Les Economies

Domestiques en Afrique de l'Ouest: Géopolitiques et Conflits. Dakar: CODESRIA and OXFAM.

Fall, Yassine

2003 Gender and Social Dimensions of IMF Policies in Senegal. The Development Gap.

Field, John

2008 Social Capital. New York: Routledge.

Fisher, Monica G., with Rebecca L. Warner and William A. Masters

2000 Gender and Agricultural Change: Crop-Livestock Integration in Senegal. Business \& Management; Human Geography; Planning 13(3):203-222.

Flower, Alan F

1998 Authentic NGDO Partnerships in the New Policy Agenda for International Aid:

Dead End or Light Ahead? Development and Change 29 (1):137-159.

Freudenberger, Karen Schoonmaker

1994 New Technology for Rural Women: Paradoxes of Sustainability. Development in Practice 4 (1):13-22. 
Goetz, Anne Marie, and Rina Sen Gupta

1996 Who Takes the Credit? Gender, Power, and Control Over Loan Use in Rural

Credit Programs in Bangladesh. World Development Journal 24(1):45-63.

Gueye, Bineta

1998 Pratiques Sociales du Développement: les Actions du Développement,

Dimensions Locales et Sectorielles. M.A. thesis, University of Paris I.

Guérin, Isabelle

2006 Women and Money: Lessons from Senegal. Development and Change 37 (3):549570 .

Guérin, Isabelle

2007 Gare au Mythe du Pauvre Potentiellement Entrepreneur! In La Microfinance n'Est plus Une Utopie! Sylvain Allemand ed. Pp 158-163. Paris: Editions Autrement.

International Labour Office

1984 Rural Development in Africa. ILS: Geneva.

International Labour Organization

1991 The Urban Informal Sector in Africa in Retrospect and Prospect: an Annotated

Bibliography. Geneva: International Labour Bibliography 10.

Johnson G. Wesley, Jr.

1971 The Emergence of Black Politics in Senegal; the Struggle for Power in the Four Communes, 1900-1920. Stanford: Stanford University Press.

Kane, Abdoulaye

2001 Financial Arrangements across Borders: Predominant Participation in Popular

Finance from Thilogne and Dakar to Paris. A Senegalese Case Study in Women and Credit. In Women and Credit: Researching the Past, Refiguring the Future. Beverly Lemire, Ruth Pearson, and Gail Campbell, eds. Pp 295-317. Oxford: Berg Publishers.

Kah, Jainaba M.L.,with Dana L. Olds, and Muhammadou M.O Kah 2005 Microcredit, Social Capital, and Politics. Journal of Microfinance 7(1).

Lelart, Michel

2005 De la Finance Informelle à la Microfinance. Paris: CPI.

Lo, Marieme S.

2007 Self-image and Self-naming: a Discursive Analysis and Social Ontology of

Women's Microenterprises in Senegal and Mali. Paper presented at the African

Studies Association Annual Meeting, New York, October 18-21. 
Lont, Hotze

2002 Negotiating Financial Autonomy: Women, Income and Credit in Urban Java. In

Women and Credit: Researching the Past, Refiguring the Future. Beverly Lemire,

Ruth Pearson, and Gail Campbell, eds. Pp 295-317. Oxford: Berg Publishers.

Huq, Hamidul

2004 Surviving in the World of Microdebt: a Case from Rural Bangladesh. In

Livelihood and Microfinance: Anthropological and Sociological Perspectives on Savings and Debt. Hotze Lont, and Otto Hospes, eds. Pp 43-56. Amsterdam: Eburon Academic Publishers.

Lont, Hotze, and Otto Hospes, eds.

2004 Livelihood and Microfinance: Anthropological and Sociological Perspectives on Savings and Debt. Amsterdam: Eburon Academic Publishers.

Mahmud, Simeen

2003 Actually how Empowering is Microcredit? Development and Change 34(4):577605.

Mainsah, Evaristus, with Schuyler R. Heuer, and Aprajita Kalra

2004 Grameen Bank : Taking Capitalism to the Poor. New York : Columbia

University.

Masika, Rachel., with Arjan de Haan and Sally Baden

1997 Urbanisation and Urban Poverty: a Gender Analysis. Bridge (54):1-18.

Mayoux, Linda

2001a Women's Empowerment Versus Sustainability? Towards a New Paradigm in

Micro- finance Programmes In Women and Credit in Researching the Past,

Refiguring the Future. Beverly Lemire, Ruth Pearson, and Gail Campbell, eds. Pp

245-269. Oxford: Berg Publishers.

$2001 \mathrm{~b}$ Tackling the Down Side: Social Capital, Women's Empowerment and Micro-

Finance in Cameroon. Development and Change 32(2001):435-464.

Mbodj, Mohamed

1991 The Politics of Independence: 1960-1986. In Structural Adjustment in Senegal.

Christopher L. Delgado and Sidi Jammeh, eds. Pp 119-126. New York: Praeger

Publishers.

Neff, Gina

1996. Microcredit, Microresults. Left Business Observer (74).

O'Laughlin, Bridget

2007 A Bigger Piece of a Very Small Pie: Intrahousehold Resource Allocation and

Poverty Reduction in Africa. Development and Change 38(1):21-44. 
Perry, Donna L.

2005 Wolof Women, Economic Liberalization, and the Crisis of Masculinity in Rural Senegal. Ethnology 44(3):207-226.

Pitamber, Sunita

2003 Factors Impeding the Poverty Reduction Capacity of Micro-credit: Some Field Observations from Malawi and Ethiopia. Sustainable Development through Entrepreneurship (74).

Rankin, Katharine N.

2002 Social Capital, Microfinance, and the Politics of Development. Feminist

Economics 8(1):1-24.

Rakodi, Carole

1991 Women's Work or Household Strategies? Environment and Urbanization 3(2):39-45.

Ross, Eric S.

2008 Culture and Customs of Senegal. Connecticut: Greenwood Press.

Roy, Ananya

2010 Poverty Capital: Microfinance and the Making of Development. New York: Routledge.

Roy, Marc-André, and David Wheeler 2006 A Survey of Micro-Enterprise in Urban West Africa: Drivers Shaping the Sector. Oxfam GB 16(5):452-464.

Smets, Peer, and Erik Bahre

2004 When Coercion Takes Over: The Limits of Social Capital in Microfinance Schemes. In Livelihood and Microfinance: Anthropological and Sociological Perspectives on Savings and Debt. Hotze Lont and Otto Hospes, eds. Pp 215-236. Amsterdam: Eburon Academic Publishers.

Sanogo, Diouratié with Saumya RamaRao, Heidi Jones, Penda N'diaye, Bineta M'bow and Cheikh Bamba Diop

2003 Women's Heallth and Action Research Centre (WHARC). African Journal of

Reproductive Health 7(2):57-73.

Sarr, Ndèye Fatou

2005 Réseau PAMECAS: Impacts Socio-Economiques des Crédits Alloués aux Membres. M.A. thesis, University Cheikh Anta Diop, Dakar, Senegal. 
Takahashi, Kuni

2010 India’s Microcredit Industry Faces Meltdown. New York Times, November 18:A5.

Tata, J., and S. Prasad

2010 Micro-Credit Programs, Social Capital, and Micro-Business Performance.

International Journal of Business and Globalisation 5(1):31-45.

Thorsen, Dorte

2002 'We Help Our Husbands!' Negotiating the Household Budget in Rural Burkina

Faso. Development and Change 33(1):129-146.

Tshibaka, Tshikala B.

2003 Economic Policy Reforms, External Factors, and Domestic Agricultural Terms

of Trade in Selected West African Countries. In African Voices on Structural Adjustment.

Thandika Mkandawire and Charles C. Soludo, eds. Pp 275-3-4. Dakar: CODESRIA.

Versluysen, Eugene

1999 Defying the Odds: Banking for the Poor. Kumarian Press, Inc.

Van de Walle, Etienne ed.

2006. African Households: Censuses and Surveys. New York: M.E. Sharp.

Woolcock, Michael and Deepa Narayan

1999 Social Capital: Implications for Development Theory, Research, and Politics.

World Bank Research Observer 15(2):1-49.

Yunus, Mohamed and A. Jolis

1998 Banker to the Poor. London: Aurum Press.

Agence Nationale de le Statistique et de la Démographie

2004 Situation Economique et Sociale de la Région de Dakar. http://www.ansd.sn

Agence Nationale de le Statistique et de la Démographie

2005 Situation Economique et Sociale de la Région de Dakar. http://www.ansd.sn

Agence Nationale de le Statistique et de la Démographie

2007 Situation Economique et Sociale de la Région de Dakar. http://www.ansd.sn

Agence Nationale de le Statistique et de la Démographie

2008 Situation Economique et Sociale de la Région de Dakar. http://www.ansd.sn

Agence Nationale de le Statistique et de la Démographie

2009 Situation Economique et Sociale de la Région de Dakar. http://www.ansd.sn 
United Nations Development Programme

Senegal Human Development Report 2005. http://www.undp.org

United Nations Development Programme

Senegal Human Development Report 2008. http://www.undp.org

United Nations Development Programme

Senegal Human Development Report 2009. http://www.undp.org

United States Agency for International Development

Success Story: Keeping Loan Payments on Track. http://senegal.usaid.gov

http://www.worldbank.org

http://www.bceao.int

http://who.int/en 
APPENDIX 


\section{TABLES}

- Marital Status of Total Sample of 166 Participants (in percent)

\begin{tabular}{|l|l|}
\hline Married & $69 \%$ \\
\hline Divorced & $11 \%$ \\
\hline Widowed & $11 \%$ \\
\hline Single & $9 \%$ \\
\hline
\end{tabular}

- Where Participants Invest their Credit or Revenues from it (in percent)

\begin{tabular}{|l|c|}
\hline $\begin{array}{l}\text { Credit/Revenues invested in the Household } \\
\text { (nutrition/education/health) }\end{array}$ & $81 \%$ \\
\hline $\begin{array}{l}\text { Credit/Revenues invested in other areas than } \\
\text { the Household (savings/business) }\end{array}$ & $82 \%$ \\
\hline $\begin{array}{l}\text { Credit/Revenues not invested in the } \\
\text { Household }\end{array}$ & $19 \%$ \\
\hline
\end{tabular}

- Business Activity of Participants (in percent)

\begin{tabular}{|l|c|}
\hline $\begin{array}{l}\text { Sales of Eatable Products } \\
\text { (cereals/vegetables/fish/juices/water etc...) }\end{array}$ & $23 \%$ \\
\hline $\begin{array}{l}\text { Sales of other Products } \\
\text { (fabric/cosmetics/accessories etc...) }\end{array}$ & $61 \%$ \\
\hline $\begin{array}{l}\text { Sales of Meals/Restaurateurs } \\
\text { (breakfast/lunch/sandwiches) }\end{array}$ & $4 \%$ \\
\hline Sewing/Tailoring/Dressmaking & $9 \%$ \\
\hline
\end{tabular}

- Level of Education of Participants (in percent)

\begin{tabular}{|l|l|}
\hline Illiterate (no formal education) & $35 \%$ \\
\hline Primary School Education & $36 \%$ \\
\hline $\begin{array}{l}\text { Secondary School Education } \\
\text { (Junior and/or senior high school) }\end{array}$ & $26 \%$ \\
\hline High School Degree & $3 \%$ \\
\hline Acquired Training & $14 \%$ \\
\hline Attended Arabic School & $4 \%$ \\
\hline
\end{tabular}




\section{Research Questionnaire}

\section{Identification:}

- Name (optional)

- Ethnicity

- Marital status

- Number or children

- Age

\section{Financial Agency}

- What areas in the household do you spend money?

- Who handles/manages the money in your household?

- Do you have an account besides that of the microcredit institution?

- Do you belong to a tontine or other association as well?

\section{Household Structure and Leadership}

- $\quad$ Are you renting this place?

- What household members do you live with?

- Who is the head of household?

- Do you have any co-wife?

- If yes, do you live together?

- Do you do the cooking?

- Do you do the cleaning?

- Do you wash clothes?

- Do you take care of your children personally? 


\section{Situation Pre-microcredit}

- What business activities were you conducting?

-Were making profit from it?

- Where did you reinvest those profits?

- Did you get credit from other sources?

\section{Current Microcredit Situation}

- Where are you getting microcredit from?

- How long have you been getting these loans?

- What activity are you conducting?

- Do you have a savings account or saving your money otherwise?

- Is this credit enough to sustain your activities?

- How are you repaying this credit?

a. easily

b. with difficulty

c. on time

d. late

- Where are you reinvesting this credit or the revenues from it?

- What downsides have you experienced with microcredit?

- Which household members, besides yourself, do benefit from this credit?

- What do you suggest to improve the credit system?

\section{Education}

- Are you formally educated?

- If yes, what is your level of education? 
- Did you get any training?

- Are your children currently enrolled in school?

- Are you paying for their schooling?

- If not, who does?

- If yes, are you able to afford their schooling?

- Are your children getting good results at school?

\section{Nutrition}

- Are you making enough food to eat at meals?

- How many meals do you eat per day?

- Is that enough?

- How many meals did you eat yesterday?

- What did you eat yesterday?

- Do your children complain that they are hungry?

\section{Health}

- Do you have access to health facilities?

a. for general care?

b. for prenatal care?

c. to give birth?

- Is that access easy or difficult?

- Do your children have access to health facilities?

- Is that access easy or difficult?

- How do you get to the hospital?

- Have all your children been vaccinated? 
- Are all your children healthy?

- Are you and your children currently taking any medication?

- Do you have access to affordable health facilities in your area?

- Do you have clean water at home? 


\section{VITA}

\section{SAFIETOU KANE}

1995

1997-1999

2001

$2003-2005$

2005

2007

2008

2006-2009
Baccalaureate in letters Notre Dame High School Dakar, Senegal,

French Tutor, U D C, Washington Dc. Duties: tutoring Students in French.

B.A. Sociology/Anthropology University of the District of Columbia Washington D.C.

Out-of-Sate tuition exemption scholarship from Florida West Africa Linkage Institute (FLAWI).

Teaching assistantship funding from African New World Studies, Florida International University, Miami, FL.

Duties: grading papers, keeping attendance records, administering exams.

Co-editing Department's newsletter

Editorial assistant - Encyclopedia of the African Diaspora Co-Organizer of Encyclopedia of the African Diaspora Symposium.

M.A. African Studies and Transnational Policy Analysis

Florida International University

Miami, Fl

Volunteering/interning in the summer 2007 with The Women's Global Education Project (WGEP), a non-profit based in Chicago and working on sending girls to school in Senegal.

M.A. Comparative Sociology

Florida International University

Miami, F1

Graduate teaching assistant, Department of Sociology and Anthropology

Florida International University, Miami Fl

Duties: grading papers, proctoring quizzes and exams, some lecturing. 
RESEARCH AND PROFESSIONAL INTERESTS

. International/African development

. Microfinance

. Gender and development

. Health, education and economic opportunities in Africa and Senegal.

PUBLICATIONS AND PRESENTATIONS

. African Studies Association Conference - Nov 2010, San Francisco

Paper presented: "Women and Development in Senegal: Microcredit and Household Well Being."

. Society for Applied Anthropology Conference - March 2010, Mexico.

Paper presented: "Women and Development in Senegal: Microcredit and Household Well Being."

. Florida International University Scholarly Forum - March 2010, Miami.

Presentation: "Senegalese Women and Microcredit."

. African Studies Association Conference - Nov 2008, Chicago.

Paper presented: "African Women and Microcredit: Lessons from Senegal."

. African Studies Association Conference - Oct 2007, New York.

.Entry on "African Development" and "Wolof" in Encyclopedia of the African Diaspora, ABC/CLIO, Oxford, England. 2006.

. African Studies Association Conference - Nov 2004, New Orleans.

. African Studies Association Conference - Nov 2003, Boston.

PROFESSIONIAL MEMBERSHIPS

. Advisory Board member of the Women's Global Education Project (WGEP)

. Member of African Studies Association

LANGUAGES

. English (fluent)

. French (fluent)

. Wolof (fluent)

. Spanish (good) 